\title{
A STUDY OF LEPTOSPIROSIS IN SOUTH AFRICAN HORSES AND ASSOCIATED RISK FACTORS
}

\author{
BY \\ VINCENT SIMBIZI
}

SUBMITTED IN PARTIAL FULFILMENT OF THE REQUIREMENTS FOR THE DEGREE OF MAGISTER SCIENTIAE (VETERINARY SCIENCE)

Date submitted: December 2015 


\section{ACKNOWLEDGMENTS}

I wish to acknowledge and express my sincere gratitude and appreciation to my Principal Supervisor Professor Bruce Gummow, epidemiologist and lecturer from the Discipline of Veterinary Sciences, James Cook University (JCU) for his valuable guidance, advice, supervision and moral support throughout the study. He was very patient in reading this manuscript repeatedly, providing relevant comments and editing it. He managed to secure funds for the project and his different visits to South Africa during the course of this project were very encouraging. Without his commitment, patience and support, this study would not have been successfully completed.

I would like also to thank the co-supervisor of this project, Professor Montague N. Saulez, equine specialist from Winelands Equine Vet for his support and valuable comments when I was writing this manuscript. Without him, the collection and the shipping of samples from Gauteng and Western Cape Provinces would not have been possible.

My sincere thanks also go to Dr Andy Potts, from the Bacterial Serology Laboratory, ARCOnderstepoort Veterinary Institute for his patience in supervising the laboratory analysis of the samples. He was always making sure that the reported results from analysis were correct. My sincere gratitude also goes to Christine Lötter, the veterinarian technologist from the same laboratory for providing all the necessary tools before analysing the samples. Her patience and guidance were a strong support.

I would also like to thank the veterinary staff from Drakensberg Veterinary Clinic and Baker \& McVeigh Equine Hospital for collecting, processing and shipping the samples.

I would also like to express my sincere gratitude to Professor Peter Thompson, epidemiologist from the Department of Production Animal Studies, University of Pretoria, for his advice in the statistical analysis of this project.

My special thanks also go to the Directorate of Veterinary Services of the Department of Rural Development and Agrarian Reform for having allowed me to pursue this investigation while I was working. Without its support, this project would not have been completed.

Lastly, I thank my family members: my son Brad Simbizi, my brothers Marc and Dario Simbizi and my sister Sylvie Simbizi. I thank my mom and dad for being supportive throughout my life. 


\section{SUMMARY}

Most leptospiral infections in horses are asymptomatic; however, acute disease manifestations as well as reproductive failure and recurrent uveitis have been reported. In South Africa, the epidemiology of the disease in horses is not well documented.

A serosurvey to determine what serovars were present in horses from Gauteng, KwaZuluNatal and Western Cape Provinces and to get an estimate of the seroprevalence of leptospirosis was carried out from January 2013 until April 2014 with the assistance of four large equine hospitals: Baker \& McVeigh Equine Hospital (2 branches), the Equine Clinic of the Onderstepoort Veterinary Academic Hospital, Faculty of Veterinary Science, University of Pretoria and the Drakenstein Veterinary Clinic. Furthermore, associations between potential risk factors and both seropositive horses to the predominant serovar Bratislava and to Leptospira spp were statistically evaluated using univariable analysis and multivariable logistic regression models.

Adult horses admitted to each equine hospital and horses seen on ambulatory service for various purposes were included in the study. Severely-ill, chronically infected, and horses with underlying immunosuppressive conditions were excluded from sampling, to control for potential bias.

A total of 663 horse sera were collected and tested against a panel of 24 leptospiral serovars using the microscopic agglutination test. The most predominant serovars in Gauteng were Bratislava [32\%, 95\% CI: 29-35\%]; Djasiman [10.4\%, 95\% CI: 8-12\%] and Arborea [8.9\%, 95\% CI: 7-11\%], in the Western Cape Province, Bratislava [27.35\%, 95\% CI: 23-32]; Djasiman [15.4\%, 95\% CI: 12-19\%] and Arborea [14.5\%, 95\% CI: $11-18 \%]$ and in KwaZulu-Natal, Bratislava [39.4\%, 95\% CI: 34-44\%]; Arborea [9.6\%, 95\% CI: 7-13\%]; and Tarassovi [7.7\%, 95\% CI: 5-10\%] respectively. Twenty one serovars representing 17 serogroups were detected in South African horses with serovar Bratislava being the most serodominant.

The apparent prevalence to one or more serovars of Leptospira spp at a serum dilution of 1:100 in Gauteng, KwaZulu-Natal and Western Cape Provinces was 49\%; 37\% and 32\% respectively. The true prevalence was calculated for each province taking into account the clustering effect during the sampling and was found to be between 24-74\% in Gauteng; 26$39 \%$ in the Western Cape and 20-54\% in KwaZulu-Natal. 
Nooitgedacht (South African horse breed) horses were found to be at greater risk of being seropositive to both serovar Bratislava $(\mathrm{OR}=5.08)$ and Leptospira spp (OR=6.3). Similarly, horses residing on properties with forestry in the vicinity were found to be at greater risk of being seropositive to both serovar Bratislava $(\mathrm{OR}=9.3)$ and Leptospira spp $(\mathrm{OR}=5.2)$. This study has shown that a high proportion of horses in South Africa are exposed to a wide range of serovars, inferring a complex epidemiology. It also describes for the first time new serovars of Leptospira in South African horses that have not previously been reported. 


\section{TABLE OF CONTENTS}

ACKNOWLEDGMENTS

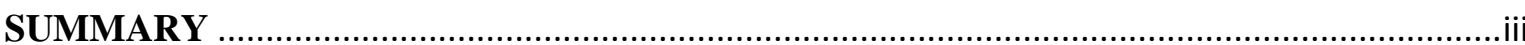

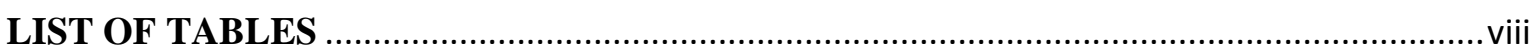

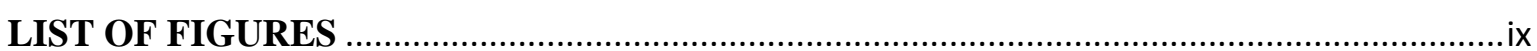

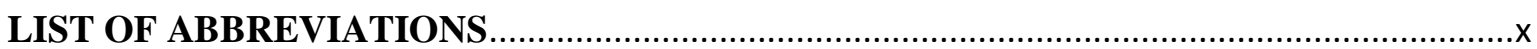

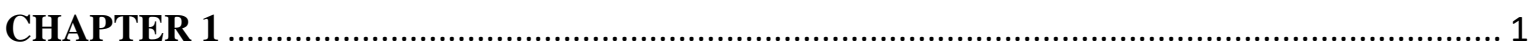

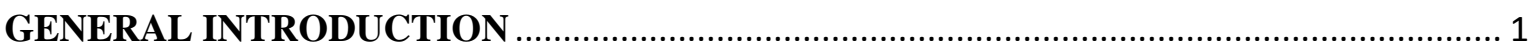

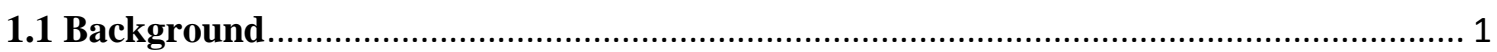

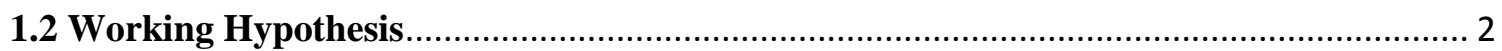

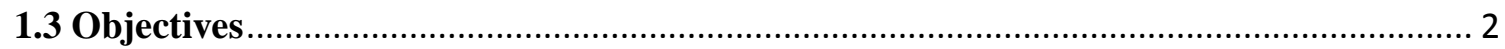

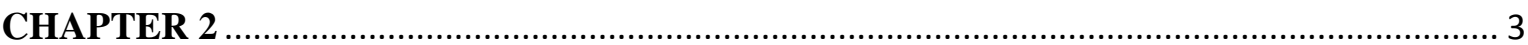

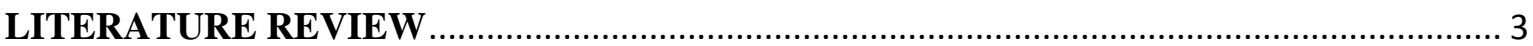

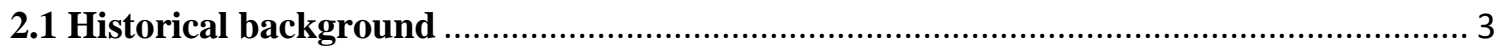

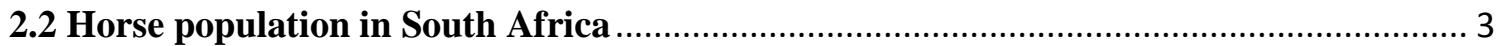

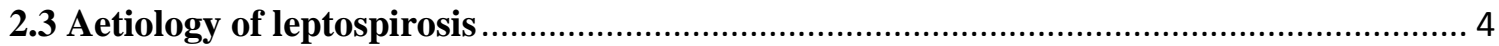

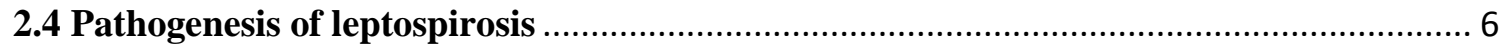

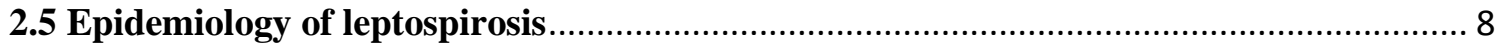

2.6 Common serovars affecting horses and their geographical location ............................ 10

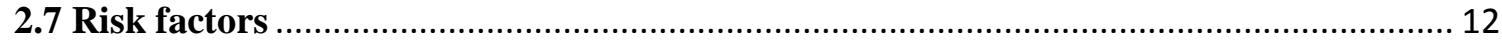

2.8 Leptospirosis in other species of animals in South Africa ........................................... 14

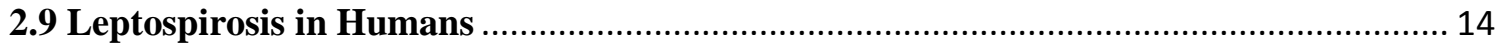

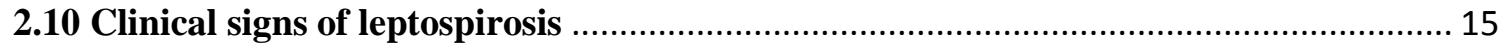

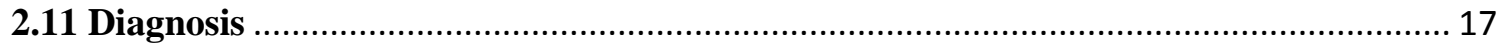

2.11.1 Identification of the agent ................................................................................... 17

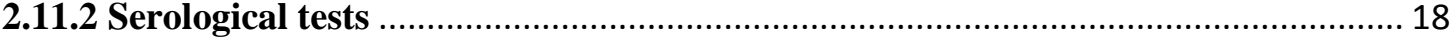

2.12. Prevention and therapy of equine leptospirosis...................................................... 19

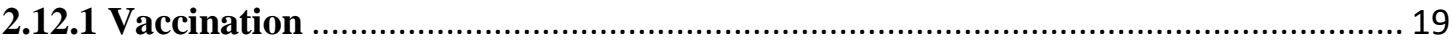

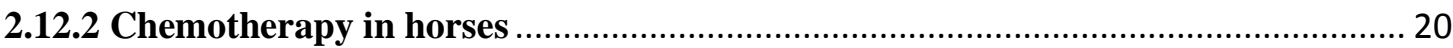

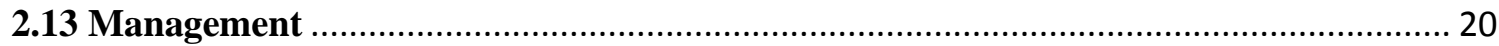

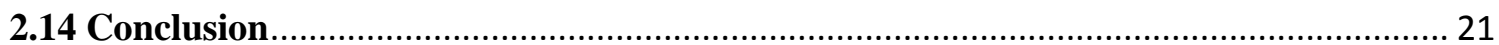

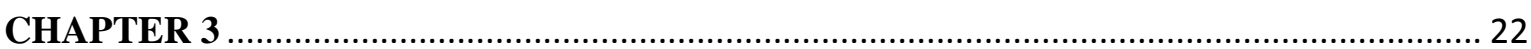

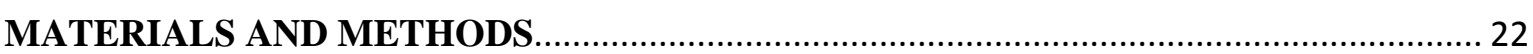

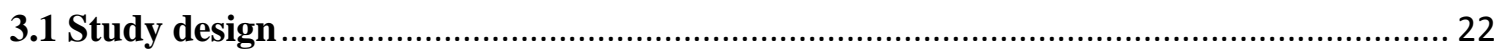

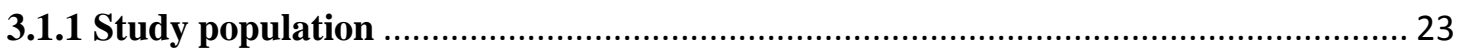

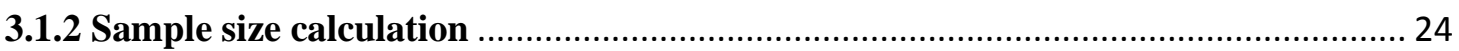

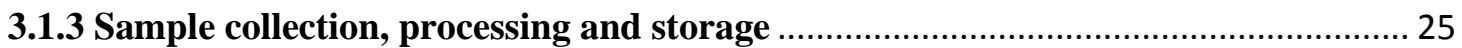




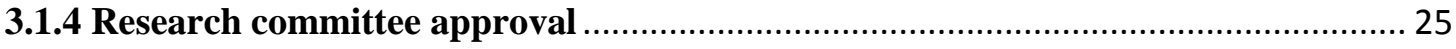

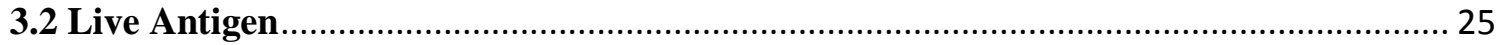

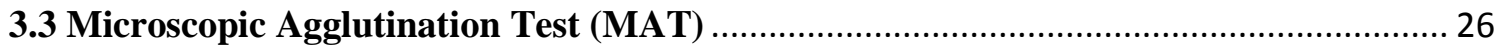

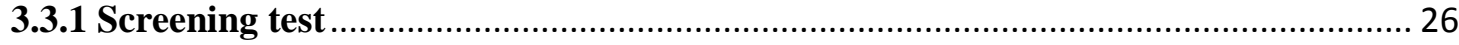

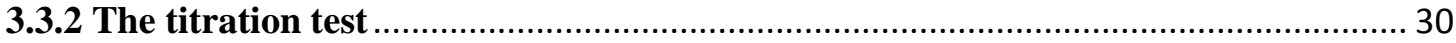

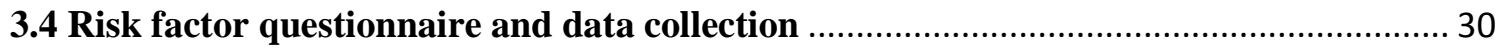

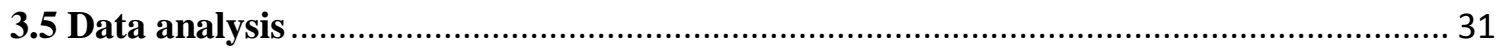

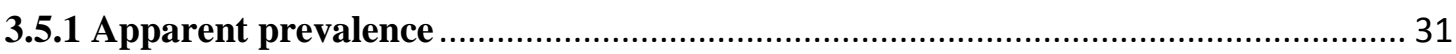

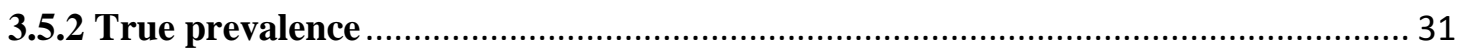

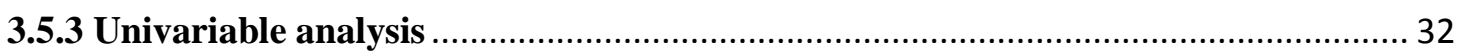

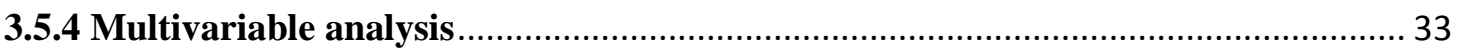

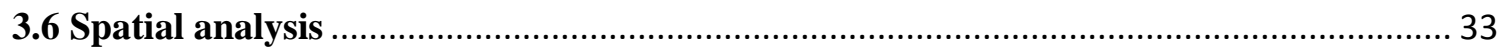

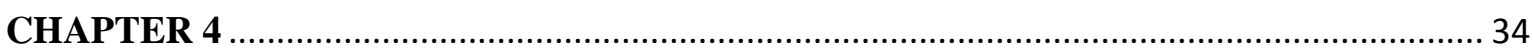

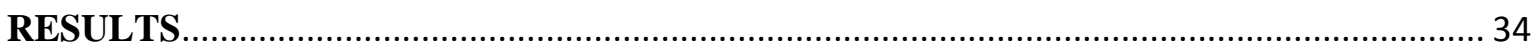

4.1. Apparent prevalence of Leptospira spp in Gauteng Province ......................................... 34

4.2. Apparent prevalence of Leptospira spp in the Western Cape Province ........................ 36

4.3. Apparent prevalence of Leptospira spp in KwaZulu-Natal Province ............................ 38

4.4 Univariable analysis of risk factors for association with serovar Bratislava .................. 39

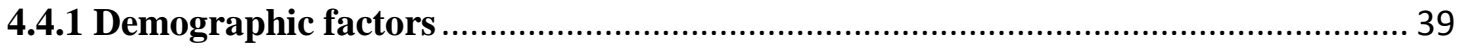

4.4.2 Geographic and environmental factors ................................................................. 41

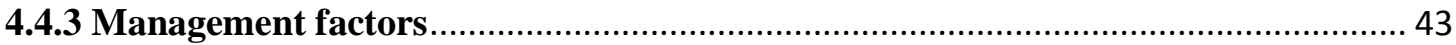

4.4.4. Disease history and association with serovar Bratislava. .................................... 44

4. 5. Significant Risk Factors to serovar Bratislava and Multivariable Logistic Regression

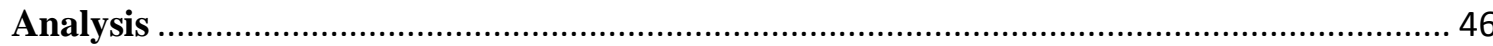

4.6 Univariable analysis of risk factors for association with seropositivity of horses to

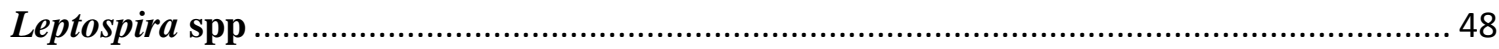

4.7 Significant Risk Factors to Leptospira spp and Multivariable Logistic Regression

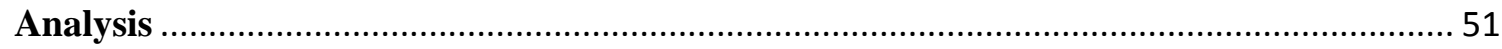

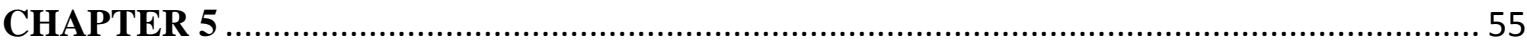

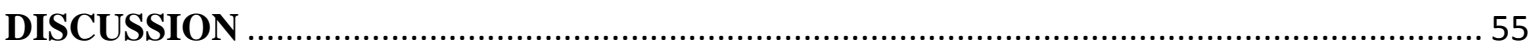

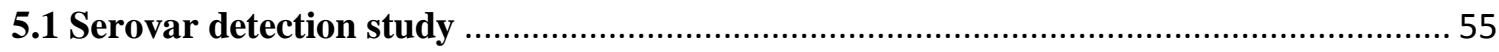

5.2 Apparent prevalence of Leptospira serovars in three provinces ..................................... 56

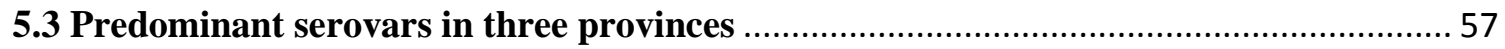

5.4 Risk factors and their association with serovar Bratislava and Leptospira spp. ............ 59

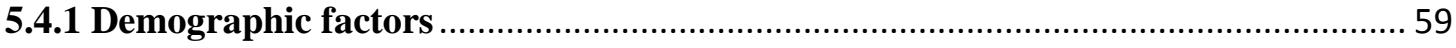

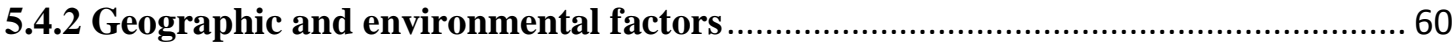

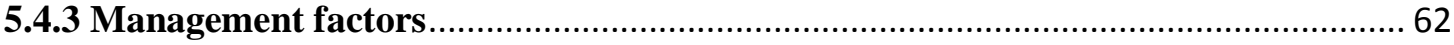


5.5 Disease history and its association with antibodies to both serovar Bratislava and Leptospira spp.

5.6 Limitations 64

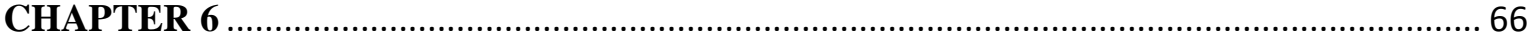

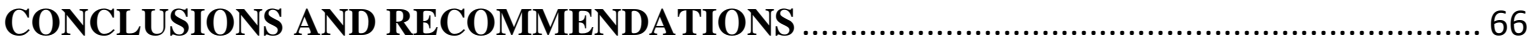

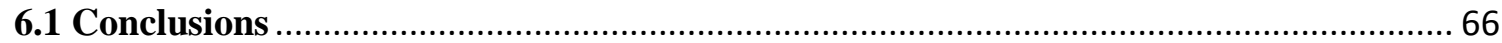

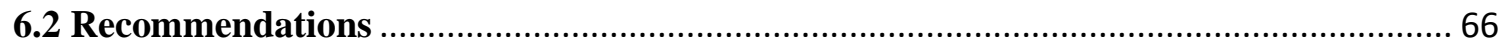

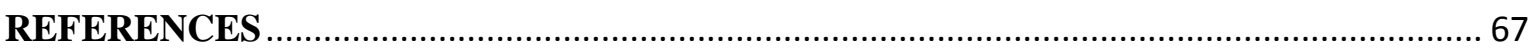

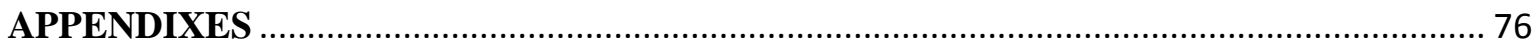




\section{LIST OF TABLES}

TABLES

PAGE

NO.

2.1 Common serovars isolated from horses and their geographical location.

3.1 Reference serovars and strains of 19 serogroups of Leptospira interrogans species used as antigens for the MAT.

4.1 Apparent prevalence of Leptospira spp in Gauteng Province.

4.2 Apparent prevalence of specific serovars of Leptospira in Gauteng Province.

4.3 Apparent prevalence of Leptospira spp in the Western Cape Province.

4.4 Apparent prevalence of specific serovars in the Western Cape Province.

4.5 Apparent prevalence of Leptospira spp in Kwazulu Natal Province.

4.6 Apparent prevalence of specific serovars of Leptospira in Kwazulu Natal Province.

4.7 Seroprevalence of serovar Bratislava by horse demographic factors and use of 663 horses in three provinces and univariable results.

4.8 Seroprevalence of serovar Bratislava by geographic and environmental factors in three provinces and univariable results.

4.9 Seroprevalence of serovar Bratislava by management factors in three provinces and results of univariable analysis.

4.10 Seroprevalence of serovar Bratislava by clinical signs horses exhibited in recent past in three provinces and univariable results.

4.11 Results of multivariable logistic regression analysis of the final model.

4.12 Seroprevalence of Leptospira spp by horse demographic factors and use of 663 horses in three provinces and univariable results.

4.13 Seroprevalence of Leptospira spp by geographic and environmental factors in three provinces and univariable results.

4.14 Seroprevalence of Leptospira spp by management factors in three provinces and univariable results.

4.15 Seroprevalence of Leptospira spp by clinical signs horses exhibited in recent past in three provinces.

4.16 Results of multivariable logistic regression analysis of the final model. 


\section{LIST OF FIGURES}

Figure 1 Ultrastructure of pathogenic leptospires. (From Greene CE, editor: Infectious diseases of the dog and cat, ed 3, St Louis, 2006, Saunders; courtesy University of Georgia, Athens.)...............4

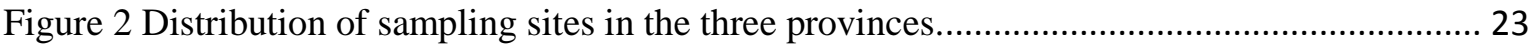

Figure 3 U-bottom plate used to dilute the test sera for the first batch. ......................................... 28

Figure 4 Flat bottom plate (P1 or 1 ) in which five test sera were tested against 8 serovars. .......... 28

Figure 5 Distribution of sampled horses and proportion of positive horses in Gauteng ................... 53

Figure 6 Distribution of sampled horses and proportions of positive horses in KZN..................... 54

Figure 7 Distribution of sampled horses and proportions of positive horses in the Western Cape

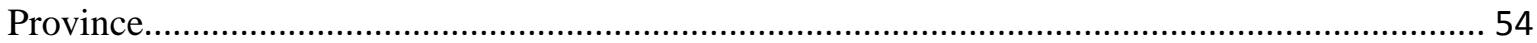




\section{LIST OF ABBREVIATIONS}

KZN

ARC

OVI

OIE

OR

MAT

CI

OVAH

ERU

PCR

AP

JCU

WC

$\mu l$
KwaZulu-Natal

Agricultural Research Council

Onderstepoort Veterinary Institute

Office International des Epizooties

Odds Ratio

Microscopic Agglutination Test

Confidence Interval

Onderstepoort Veterinary Academic Hospital

Equine Recurrent Uveitis

Polymerase Chain Reaction

Apparent Prevalence

James Cook University

Western Cape

Microliter 


\section{CHAPTER 1}

\section{GENERAL INTRODUCTION}

\subsection{Background}

Leptospirosis is a widespread zoonotic disease caused by infection with spirochetes belonging to the genus Leptospira (Levett. 2001). Leptospirosis, in addition to being the most common bacterial zoonosis worldwide (Lau et al. 2010), is also classified as an emerging infectious disease (Bolin. 1996, Leon et al. 2006). The infection usually results from direct transmission via contaminated urine, placental fluids, and tissues of affected animals or indirectly from a contaminated environment (Baverud et al. 2009). Leptospires can also penetrate the accidental host through mucous membranes or skin abrasions (Thiermann. 1984). The disease in animals may present in various forms, depending on host species, environmental conditions and the infecting serovar (Pinna et al. 2014). Incidental serovars usually cause acute clinical syndromes including haematuria, fever, jaundice, anorexia and respiratory distress (Yan et al. 2010) but host adapted serovars cause chronic or subclinical infections in reservoir hosts, becoming an important source of infection for humans or other animals (Suepaul et al. 2011).

Although most leptospiral infections in horses are asymptomatic (Hathaway et al. 1981, Hajikolaei et al. 2005, Verma et al. 2013), the most frequently recognized clinical manifestations of leptospirosis in horses are recurrent uveitis and periodic ophthalmia (Levett. 2001, Verma and Stevenson. 2012). The disease has been associated with reproductive tract infection (Divers and Chang. 2009) in pregnant mares which can result in placentitis, abortion or stillbirths (Bernard et al. 1993, Timoney et al. 2011), renal disease in young horses (Quinn et al. 2011) and hepatic dysfunction (Hathaway et al. 1981).

Serologic surveys performed in several countries indicate that leptospiral infections are common in horses. These studies confirm that there is widespread exposure to Leptospira 
worldwide and that exposure is significantly more common than clinical disease (Frellstedt. 2009). Titers to a wide variety of serovars have been reported in horses, and in general, the most common tend to be titers to Leptospira interrogans serovars Icterohaemorrhagiae, Bratislava, Pomona, Ballum, and Grippotyphosa (Hines. 2014).

A paucity of information exists regarding the leptospiral serovars in the equine population of South Africa. The reported predominant serovar was found to be Pomona in horses that were tested in South Africa (Anon. 1986-1987) but the epidemiology of this disease in South Africa has not yet been fully investigated.

\subsection{Working Hypothesis}

Based on the published reports on leptospirosis in South Africa, we hypothesised the following:

1. Leptospirosis is a worldwide bacterial disease with serological evidence being common in horses, therefore different leptospiral serovars will be detected in horses being investigated under this study in South Africa.

2. Horse demographic factors, geographic and environmental factors, and management factors will be associated with seropositivity of leptospires in horses.

\subsection{Objectives}

The objectives of this study were:

1. To identify the common leptospiral serovars existing in horses that were serviced by four large equine hospitals in South Africa.

2. To carry out an epidemiological study to examine risk factors associated with equine leptospirosis in South Africa. 


\section{CHAPTER 2}

\section{LITERATURE REVIEW}

\subsection{Historical background}

Although the horse was in regular use in North and West Africa from 600 AD, there were none in the southern tip of Africa prior to European colonisation (Swart. 2007). Horses were the first domestic stock imported by the settlers and horses became integral to their identity as Europeans (Swart. 2007). The differentiation of equine breeds was progressive: the original "South East Asia Ponies," introduced in the Cape from Java in 1653 made way for English Thoroughbreds imported for the racing industry in the late eighteenth century. The original imported horses became the founders of the "Cape Horse" which was a fusion of the Southeast Asian pony, imported Persians, South American stock, North American stock, English Thoroughbred and Spanish Barbs with a particularly significant Arabian genetic influence (Swart. 2007). From 1836 to 1899, other breeds such as the Flemish Stallions from the Netherlands, as well as Hackeys, Norfolk Trotters and Cleveland Bays were imported and bred into what eventually become known as the Boerperd ${ }^{1}$. Today, the South African Thoroughbred industry is a multi-million rand enterprise and of major economic importance.

\subsection{Horse population in South Africa}

According to the report from the Department of Agriculture, Forestry \& Fisheries in 2004, South Africa had 318722 horses that were kept on commercial and communal farms. The distribution of horses within 9 provinces of South Africa was the following: The Eastern Cape Province with 103710 horses (32.5\%); Free State with 50389 horses (15.8\%); Northern Cape with 37006 horses (11.6\%); North West with 34269 horses (10.7\%); Gauteng with 32714 horses (10.2\%); KwaZulu-Natal with 22569 horses (7\%); Western

\footnotetext{
${ }^{1}$ www.saboerperd.com/p2/history/sa-boerperd-breed-history.html
} 
Cape with 18576 horses (5.8\%); Mpumalanga with 15194 horses (4.7\%) and Limpopo with 4295 horses (1.3\%) (Department of Agriculture, Forestry \& Fisheries. 2004). However, information on the demographics of the horse population in South Africa as well as information on the South African horse industry is scant.

\subsection{Aetiology of leptospirosis}

Leptospirosis was first recognised and reported in man by Adolf Weil in 1886 (Weil. 1886). Later, the etiology of leptospirosis was demonstrated independently in 1915 in Japan and Germany (Everard. 1996). Leptospira spp are flexible, motile, helicoidal, usually hooked each end (Quinn et al. 2011) and showing characteristics of both Gram negative and Gram positive bacteria (Levett. 2001). They have two axial flagella, each attaching at opposing ends of the organism by platelike insertion discs.

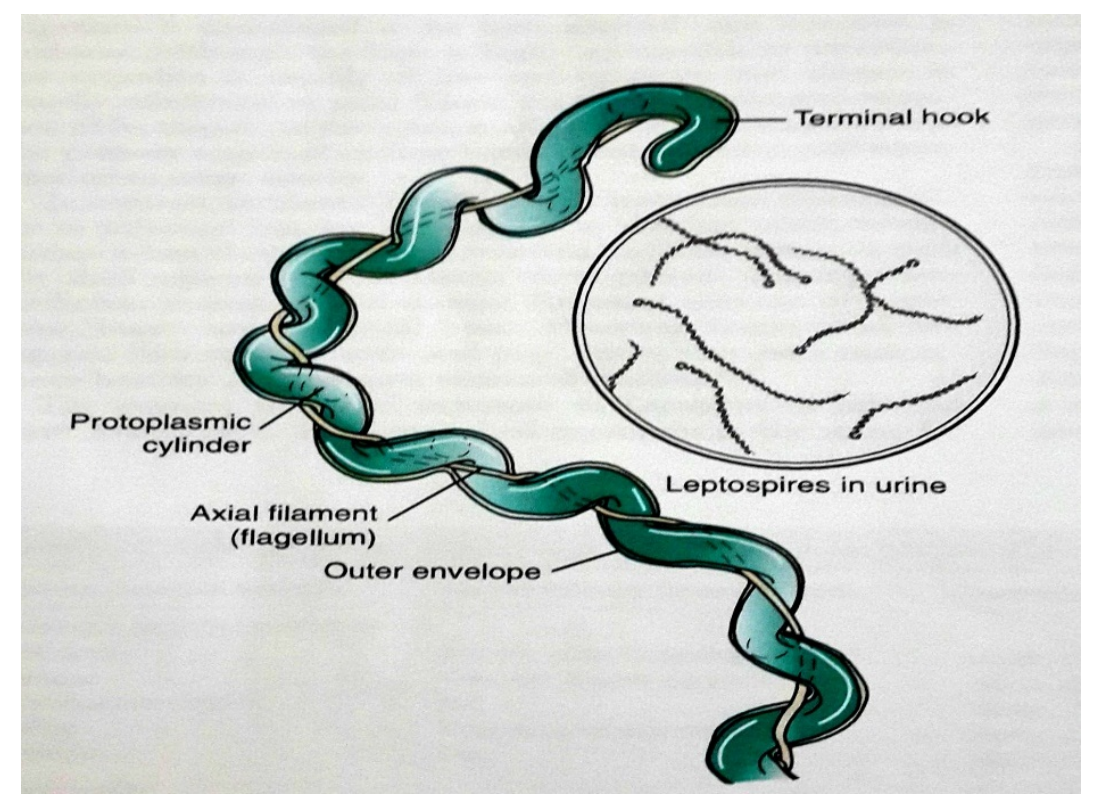

Figure 1 Ultrastructure of pathogenic leptospires. (From Greene CE, editor: Infectious diseases of the dog and cat, ed 3, St Louis, 2006, Saunders; courtesy University of Georgia, Athens.) 
The distal end of each flagellum is not attached and extends toward the center of the cell, sometimes overlapping the flagellum from the opposite end (Hines. 2014). The FlaA and FlaB proteins constitute the flagellar sheath and core respectively. The role played by these flagella is to facilitate motility (Adler and de la Pena Moctezuma. 2010). Leptospires are obligate aerobes with an optimum growth temperature of $28^{\circ} \mathrm{C}$ to $30^{\circ} \mathrm{C}$. They grow slowly and require a media enriched with vitamins B1 and B12, long-chain fatty acids and ammonium salts. Currently, the most widely used medium is based on the oleic acid, bovine serum albumin and polysorbate (Tween) medium EMJH (Adler and de la Pena Moctezuma. 2010). Although leptospires have Gram negative characteristics, they don't stain well with conventional bacteriological dyes. Therefore, other techniques, such as darkfield microscopy, silver impregnation and immunologic staining have been used to identify leptospires (Adler and Faine. 2006, Quinn et al. 2011). Leptospires have a typical double membrane structure in which the cytoplasmic membrane and peptidoglycan cell wall are closely associated and are overlaid by an outer membrane (Levett. 2001). This outer membrane is rich in lipopolysaccharide (LPS) which constitutes the main antigen for Leptospira. In addition to LPS, structural and functional proteins form part of the outer membrane. A large proportion of such proteins are lipoproteins (Adler and de la Pena Moctezuma. 2010). The porin OmpL1 and LipL41 are proteins located in the outer membrane and have been shown to be antigenic (Adler and Faine. 2006).

Classification of organisms within the genus Leptospira is complex. Currently, two separate systems of classification are used: The traditional phenotypic classification system based on serotyping in which leptospires are grouped into two species, the pathogenic species Leptospira interrogans and the non-pathogenic, saprophytic species Leptospira biflexa (Levett. 2001, Quinn et al. 2011). 
Within each species, the serovars are organized into serogroups based on shared antigenicity. In this system, it was shown that $L$. interrogans contains at least 218 serovars organized into 23 serogroups, and L. biflexa with at least 60 serovars organized into 28 serogroups (Hines. 2014). The genotypic classification system is the second system and is based on deoxyribonucleic acid homology. With this classification, within each species various serovars are recognized on the basis of serological reactions (Ellis. 1995). Currently, 17 genomospecies of Leptospira have been defined (Hines. 2014) with L. borgpetersenii, L. fainei, L. inadai, L. interrogans sensu stricto, L. kirschneri, L. meyeri, L. noguchii, L. santarosai and L. weilii being recognized as pathogenic species (Quinn et al. 2011). The name $L$. interrogans is used to identify species in both the phenotypic and the genotypic classification systems, causing some confusion. Therefore, L. interrogans sensu stricto is sometimes used to denote the specific genomospecies, whereas L. interrogans sensu lato (in the broad sense) is used when referring to the more general phenotypic species (Hines. 2014). Serovars that have the same antigens belong to the same serogroup. Serologically similar leptospires may belong to different species (Levett. 2001).

\subsection{Pathogenesis of leptospirosis}

In order to penetrate the body, leptospires need a portal of entry. This can be achieved when animals consume surface water contaminated with urine shed by a maintenance host species. Leptospires can also enter the body when the skin is abraded (Thiermann. 1984) or softened by prolonged immersion in water (Hunter. 2004, Quinn et al. 2011). Following infection, organisms enter the blood stream and localize in the liver where primary replication takes place, and from the liver, the organisms are released into the blood, resulting in a leptospiraemia (Hines. 2014). The leptospiraemic phase which persists for about a week, is characterised by high fever 7-9 days after the initial exposure (Frellstedt. 2009). The primary lesion during this phase is damage to the endothelia of small blood vessels, resulting in 
localized ischemia in organs leading to renal tubular necrosis, hepatocellular and pulmonary damage, meningitis, myositis and placentitis (Adler and de la Pena Moctezuma. 2010). It seems that Leptospira do not have specific tissue tropism as they replicate in many tissues, including lungs, brain, kidney, eyes, liver, spleen, mammary gland or pregnant uterus (Hines. 2014). Clinical signs are dependent on the site of localization. Some factors are thought to play a role in the virulence of different isolates of leptospires. These include several outer membrane proteins like lipopolysaccharide (LPS) which is responsible for the serovar specificity of leptospires (Adler and de la Pena Moctezuma. 2010, Hines. 2014), some haemolysins (Miller et al. 2007; Quinn et al. 2011), protein and glycolipoprotein cytotoxins (Levett. 2001). One cytotoxic sphingomyelinase produced by leptospires is thought to be responsible for hepatocellular damage and haemorrhages in the lungs, mucous membranes and kidneys (Hunter. 2004). Localization in the proximal tubules of the kidneys in maintenance hosts causes a mild, chronic, interstitial nephritis and long-term leptospiruria (Hines. 2014). Foetal infection as a result of leptospires crossing the placenta varies in outcome, depending on the age of the foetus. Abortion may result or the foetus may survive by producing antibodies, or it may be born weak and be latently infected (Bernard et al. 1993).

The humoral immune response seems to play an important role in control of infection and immunity to leptospires. Antibodies are generally produced within a few days of infection and immunity is specific to the causative serovar and closely related serovars. In a maintenance host, when there is infection by a host-adapted serovar, concentrations of antibody may remain low, allowing organisms to persist, primarily in the kidney (Hines. 2014). 
The pathogenesis of leptospiral-induced inflammation in equine recurrent uveitis is still unknown, but there is evidence that both persistent infection and autoimmune mechanisms may play a role (Pearce et al. 2007).

\subsection{Epidemiology of leptospirosis}

Subclinically infected hosts, also known as reservoir hosts or definitive hosts, have the ability to maintain the disease and hence are also referred to as maintenance hosts (Levett. 2001). These maintenance hosts, which include numerous wild and domestic animal species, serve as a source of infection for incidental or accidental hosts (Hathaway et al. 1981). They can easily become infected but they develop mild or no clinical signs. In particular maintenance host species, some specific serovars of leptospira are generally found and epidemiologic studies suggest that these host preferences may vary both with geographic regions and over time (Hines. 2014). These maintenance hosts are considered to be the primary source of environmental contamination and transmission to other species because of their continuous excretion of leptospires in the urine (Quinn et al. 2011). In a study by Bernard et al. (1993), naturally infected broodmares shed the organism in the urine for 52105 days after leptospiral abortions.

In contrast, incidental hosts typically have a low susceptibility to infection, but they are more likely to develop acute, severe disease when they do become infected. The shedding of organisms for these hosts is generally short, making them inefficient transmitters of disease (Hines. 2014). For most serovars of Leptospira, horses are incidental hosts. However there is some evidence suggesting that horses may be maintenance hosts for $L$. interrogans serovar Bratislava (Ellis et al. 1983a, Ellis et al. 1983b, Rocha et al. 2004). Some other serovars that have been confirmed to be maintained in some domestic and wild animals are Hardjo with cattle, and Pomona with pigs, cattle and rodents, whereas serovars Bataviae, Icterohaemorrhagiae, Copenhageni, Autumnalis, Arborea, Australis and Zanoni are known 
to be maintained in rats and a wide range of small rodents (Adler and Faine. 2006). Wildlife plays an important role in transmission of this disease to other species including humans because some wild species, markedly small mammals, act as reservoir of some serovars (Millan et al. 2009), and thus can be important in the maintenance of Leptospira spp in the environment.

Horses become infected directly when in contact with infected urine which is considered the primary source of exposure to Leptospira (Levett. 2001). Urine becomes infected as the result of chronic infection of the renal tubules (Thiermann. 1984). Leptospira can also spread through placental tissues, aborted foetuses, uterine discharges and milk (Hines. 2014). The most effective way of transmission of the disease is from the urine of carrier animals to susceptible hosts by water-borne wastes like slurry or run-off water from infected animal houses (Gummow et al. 1999, Hesterberg et al. 2009). In order to survive, organisms shed in the urine require favourable conditions such as adequate moisture and a neutral or slightly alkaline pH. Stagnant water can be contaminated by live leptospira for prolonged periods (Hines. 2014).

Chances of survival for leptospires are reduced by some factors like run-off caused by heavy rainfall, salinity and high levels of other species of bacteria. Drying and $\mathrm{pH}$ values below six or exceeding eight are detrimental to their survival outside hosts. Ambient temperatures of $10^{\circ} \mathrm{C}$ to $25^{\circ} \mathrm{C}$ favour survival, and temperatures lower than $7^{\circ} \mathrm{C}$ to $10^{\circ} \mathrm{C}$ or higher than $34^{\circ} \mathrm{C}$ to $36^{\circ} \mathrm{C}$ are detrimental (Hines. 2014).

Other routes of transmission of the disease have been reported. Those include veneral, transplacental (Thiermann. 1984, Levett. 2001), cutaneous, oral, respiratory or conjunctival routes. Currently there are no reports of leptospiral transmission through semen or embryo transfer in horses even though leptospires have been isolated from bull semen (Thiermann. 1984). Foetal infection has been documented in foals after localization in the pregnant uterus, 
resulting in abortion (Ellis et al. 1983b, Bernard et al. 1993), stillbirth (Donahue et al. 1995) and premature foals (Vemulapalli et al. 2005).

Little information is available about experimental induction of leptospirosis in horses. In a study where horses were challenged with an equine isolate of $L$. interrogans serovar Kennewicki, it has been shown that clinical disease in experimentally infected horses can be mild or inapparent and in order to recognise the infecting serovar, repeated serologic testing was necessary (Yan et al. 2010).

\subsection{Common serovars affecting horses and their geographical location}

In horses, seroprevalence has been shown to vary depending on the geographic location and the serovars assessed (Lees and Gale. 1994). The occurrence of specific serovars depends on the presence and prevalence of the specific host species that act as infection reservoirs in different geographical areas (Turk et al. 2013). Favourable environmental conditions such as warm temperatures, moisture, neutral soil pH (Dickeson and Love. 1993) and standing surface water support the survival of pathogenic leptospires in the environment for a long period, hence increasing infection opportunities. Table 2.1 shows different serovars isolated from horses and their geographical location. 
Table 2.1: Common serovars isolated from horses and their geographical location

\begin{tabular}{|c|c|c|}
\hline Serovar & Geographical location & Reference \\
\hline $\begin{array}{l}\text { Pomona group (including } \\
\text { serovar Kennewicki) }\end{array}$ & North and South America & $\begin{array}{l}\text { (Sillerud et al. 1987); } \\
\text { (Frazer. 1999); (Faber et al. } \\
\text { 2000); (Donahue and } \\
\text { Williams. 2000) }\end{array}$ \\
\hline $\begin{array}{l}\text { Grippotyphosa, } \\
\text { Icterohaemorrhagiae }\end{array}$ & Europe & $\begin{array}{l}\text { (Donahue et al. 1995); } \\
\text { (Dwyer et al. 1995); } \\
\text { (Wollanke et al. 2001) }\end{array}$ \\
\hline $\begin{array}{l}\text { Bratislava, } \\
\text { Icterohaemorrhagiae, Sejroe }\end{array}$ & Sweden & (Baverud et al. 2009) \\
\hline Bratislava & Mongolia & (Odontsetseg et al. 2005) \\
\hline $\begin{array}{l}\text { Icterohaemorrhagiae, } \\
\text { Copenhageni, Bratislava }\end{array}$ & Brazil & $\begin{array}{l}\text { (Hashimoto et al. 2007); } \\
\text { (Braga et al. 2011); (Coiro } \\
\text { et al. 2012); (Hamond et al. } \\
\text { 2012); (Pinna et al. 2012); } \\
\text { (Hamond et al. 2013); } \\
\text { (Pinna et al. 2014) }\end{array}$ \\
\hline $\begin{array}{l}\text { Icterohaemorrhagiae, } \\
\text { Bratislava, Pomona }\end{array}$ & Italy & (Ebani et al. 2012) \\
\hline Sejroe, Bratislava & Korea & (Jung et al. 2010) \\
\hline Copenhageni, Bratislava & Netherlands & (Houwers et al. 2011) \\
\hline $\begin{array}{l}\text { Bratislava, Pomona } \\
\text { Icterohaemorrhagiae }\end{array}$ & Croatia & (Turk et al. 2013) \\
\hline Grippotyphosa, Sejroe & Nothern Poland & $\begin{array}{l}\text { (Arent and Kedzierska- } \\
\text { Mieszkowska. 2013) }\end{array}$ \\
\hline Copenhageni & South-eastern Australia & (Dickeson and Love. 1993) \\
\hline Ballum & Southern New South Wales & (Swart et al. 1982) \\
\hline Arborea & $\begin{array}{l}\text { Northern Queensland } \\
\text { (Australia) }\end{array}$ & (Wangdi et al. 2013) \\
\hline
\end{tabular}




\subsection{Risk factors}

Different studies have assessed risk factors for exposure to leptospirosis in horses. The disease appears to be endemic in certain geographical areas due to favourable environmental conditions, which include a mild climate and high precipitation (tropical climate). High periods of precipitation increase the exposure to leptospires by releasing the leptospires from the soil and bringing them to the surface in standing water or even floods (Barwick et al. 1997). A strong association between periods of high rainfall and the incidence of leptospirosis has been reported (Ward. 2002). In Australia, seropositivity of horses to serovar Arborea was significantly associated with the average annual rainfall (Wangdi et al. 2013). Seasonal variations also play a role in leptospiral infections: In a study conducted in Sweden, seasonal variations in leptospiral titres associated with management factors for two serovars Icterohaemorrhagiae and Bratislava have been demonstrated; for serovar Icterohaemorrhagiae, an increased infection incidence was found in late summer and autumn, whereas for serovar Bratislava, the highest seroprevalence was found in spring and summer (Baverud et al. 2009). Another study in Korea has shown this seasonal variation where more antibodies against Leptospira serovars were detected in summer and autumn compared to spring and winter (Jung et al. 2010).

A study has demonstrated how age in horses was significantly associated with the presence of titers, with the chance of being seropositive increasing by approximately $10 \%$ with each year of life (Lees and Gale. 1994). Other authors have also reported the same increase of seroprevalence of leptospirosis with the age of the horse (Park et al. 1992, Lees and Gale. 1994, Williams et al. 1994, Barwick et al. 1997) despite the fact that in Australia, no significant association was observed between seropositivity and age groups (Wangdi et al. 2013). 
The breed difference in seroprevalence has been indicated in one study in Sweden where ponies and coldbloods had a lower odd ratio of seropositivity to serovar Icterohaemorrhagiae (Baverud et al. 2009).

Gender also seems to be considered as a risk factor since in Australia, it was demonstrated that geldings were more at risk of being seropositive to serovar Arborea (Wangdi et al. 2013).

Sugarcane cultivation in Australia is thought to contribute to an increase in the number of rodent population hence facilitating the spread of leptospires (Slack et al. 2006, Miller et al. 2007). In Australia, the detection of serovar Arborea-seropositive horses was strongly associated with the presence of surgacane fields in the vicinity (Wangdi et al. 2013).

Management factors also constitute a major risk factor to leptospiral infections: In a study by Lees and Gale. (1994), it was shown that track horses that were managed individually had lower odds ratios than rodeo horses that were managed in groups for all investigated serovars including serovar Bratislava and Icterohaemorrhagiae. Another study has determined and quantified risk factors associated with exposure of horses to the serovars Pomona, Autumalis and Bratislava. The study found that risk of seropositivity varies according to some factors including management practices and population density (Barwick et al. 1997). Other established risk factors include an increased rodent activity and an increased exposure to wildlife (Barwick et al. 1997, Levett. 2001, Frellstedt. 2009).

Slurry from a piggery used to manure pasture and existence of pigs in the vicinity of horseproperties have been identified as one important source of serovar Pomona infection to animals grazing on pastures (Gummow et al. 1999, Hesterberg et al. 2009). In Australia, it was demonstrated that the proportion of properties seropositive to serovar Arborea was significantly higher for those that ran horses together with pigs (including those visited by feral pigs) and those with pigs in the neighbourhood compared with properties without pigs 
in the vicinity (Wangdi et al. 2013). Similarly, cattle sharing pasture space with horses have been an important source of serovar Hardjo infection in horses (Ellis et al. 1983b).

\subsection{Leptospirosis in other species of animals in South Africa}

In South Africa, limited reports on leptospirosis have been published and pigs, cattle and dogs were the main animals studied. In pigs serovar Pomona has been incriminated as the cause of severe economic losses in South African pig farms (Delange et al. 1987, Hunter et al. 1987, Gummow et al. 1999). Antibodies to serovars Icterohaemorrhagiae, Hardjo and Bratislava were also shown to be much more prevalent by another serological survey of slaughter pigs in South Africa (Potts et al. 1995). In cattle, a study conducted in communal cattle of KZN identified serovar Pomona as the most common serovar although other serovars like Tarassovi, Bratislava, Canicola, Hardjo, Icterohaemorrhagiae, Szwajizak and Grippotyphosa were also detected (Hesterberg et al. 2009).

In dogs, a serological survey done in South African dogs has revealed that the most frequent serovars represented were Canicola and Pyrogenes (Roach et al. 2010).

\subsection{Leptospirosis in Humans}

Leptospirosis is the most widespread zoonosis globally. Its clinical manifestation in humans is very wide, ranging from subclinical infection to a severe syndrome of multiorgan infection with high mortality (Levett. 2001). Humans acquire infection through contact with water, food, or soil contaminated with urine of infected animals, especially rodents (Waitkins. 1986). A similar picture of the disease was seen in the past with sewer workers. The use of personal protective equipment has changed the epidemiology of the disease but farmers and people involved in water sports activities are still affected (Waitkins. 1986).

The first South African case of leptospirosis was diagnosed in 1952 in a Cape Town fish hawker who died of typical Weil's disease due to $L$. interrogans serovar 
Icterohaemorrhagiae. In the 1960s and 1970s further cases of leptospirosis were published from Cape Town, and one from Kwazulu Natal Province. A recent case of human leptospirosis in a 34 year old resident of Gauteng who presented with an acute febrile illness with significant splenomegaly and multisystem pathology was also published (NICD. 2015).

In South Africa, a rodent-related zoonosis study was conducted from 2003 until 2006 in three provinces (Limpopo, KwaZulu-Natal and the Eastern Cape) and the seroprevalance of leptospirosis in humans was $19.8 \%$ in Cato Crest (Durban, KwaZulu Natal Province) (Saif et al. 2012). Clinical samples from all over the country were also sent to the Special Bacterial Pathogens Reference Unit in Johannesburg in 2009, 2010 and 2011 and IgM was detected in all the samples. The study has found that the apparent incidence of leptospirosis in the South African human population is moderately high based on the detected positives in suspected cases. The study also found that the communities in informal settlements in urban areas are at risk as infected rodent populations are a continuous source of transmission (Saif et al. 2012). However this study could not establish which serovars were present.

\subsection{Clinical signs of leptospirosis}

Most leptospiral infections of horses are subclinical. Leptospirosis can cause clinical signs in horses, which may include fever, jaundice, anorexia, and lethargy (Levett. 2001). After experimental infection in one study, some horses were presented with oedema of both hindlimbs during the pyremic period (Yan et al. 2010). Leptospiral organisms have been shown to be associated with equine uveitis (Sillerud et al. 1987). Uveitis has been described after naturally acquired infection as well as experimental infection with leptospires (Faber et al. 2000, Yan et al. 2010). It is thought to occur after the decline of the febrile phase and latent phases that can in some cases lasts several months or as long as 1-2 years after the clinical diagnosis (Bryans. 1955, Wollanke et al. 2001). It is recurrent, may be uni-or bilateral and characterized clinically by miosis, congestion of the sclera, photophobia, severe 
lacrimation and sometimes blindness (Davidson et al. 1987). Other syndromes caused by leptospirosis include renal dysfunction and hepatic dysfunction (Quinn et al. 2011).

Leptospiremia is the cause of infection of the reproductive organs, and in pregnant animals, foetal resorption, abortion, stillbirth, premature or weak neonates may follow (Hodgin et al. 1989, Donahue et al. 1991, Bernard et al. 1993, Vemulapalli et al. 2005, Timoney et al. 2011). Abortion has also been associated with mixed Leptospira and equine herpesvirus type 1 infection (Donahue et al. 1995). The most common serovar involved in equine abortions was found to be Pomona (Donahue et al. 1995, Szeredi and Haake. 2006).

In dogs, four syndromes associated with leptospirosis have been identified namely icteric, haemorrhagic, uraemic (Stuttgart disease) and reproductive (abortion and premature or weak puppies) (Adler and de la Pena Moctezuma. 2010). Typical leptospirosis in dogs may present with fever, jaundice, vomiting, diarrhoea, intravascular disseminated coagulation, uremia caused by renal failure, haemorrhages and death (Bolin. 1996).

In pigs, as in cattle, leptospirosis causes abortions, stillbirths, reproductive failure (Ellis et al. 1986, Christianson. 1992), foetal mummification, weak piglets or calves and agalactia (Adler and de la Pena Moctezuma. 2010). Other syndromes associated with leptospirosis include haemolytic crisis, chronic interstitial nephritis and mastitis (Hunter. 2004).

In humans the majority of the recognized cases present with a fever of sudden onset. Other symptoms include chills, headache, myalgia, abdominal pain (Levett. 2001), a mild, influenza-like illness to a severe infection with renal and hepatic failure, pulmonary distress and death (Adler and de la Pena Moctezuma. 2010). 


\subsection{Diagnosis}

Even though a history suggestive of exposure to contaminated urine and clinical signs in affected animals may indicate leptospirosis, the diagnosis should be confirmed by laboratory tests. The following diagnostic techniques are currently being used for diagnosis.

\subsubsection{Identification of the agent}

The demonstration of leptospires in blood and milk of animals showing clinical signs suggestive of acute leptospirosis is considered to be diagnostic. However, isolation from blood is not often successful because bacteraemia is transient and not always accompanied by clinical signs. Antibiotic treatments in animals prior to blood collection also decrease the likelihood of identifying the agent in blood. Failure to demonstrate leptospires in the urine does not eliminate the possibility that the animal is a chronic renal carrier. It can indicate that the animal was not excreting detectable numbers of leptospires at the time of testing (OIE. 2008).

\subsubsection{Culture of leptospires}

Culture is one of the most specific methods of demonstrating the presence of leptospires. Leptospires are obligate aerobes with an optimum growth temperature of $28^{\circ} \mathrm{C}-30^{\circ} \mathrm{C}$. They grow in media enriched with vitamins B1 and B 12, long-chain fatty acids (used as the sole carbon source) and ammonium salts (Adler and de la Pena Moctezuma. 2010). Currently, the most widely used medium is based on oleic acid, bovine serum albumin and polysorbate (Tween) medium EMJH (Ellis. 1986, Adler and de la Pena Moctezuma. 2010). Contamination can be controlled by addition of a variety of selective agents like 5fluorouracil and nalidixic acid (OIE. 2008).

Cultures should be incubated at $29 \pm 1^{\circ} \mathrm{C}$ for at least 16 weeks, and preferably for 26 weeks (Ellis. 1986). The time required for detection of a positive culture varies with the leptospiral 
serovar and the numbers of organisms present in the sample. Cultures should be examined by dark-field microscopy every 1-2 weeks (OIE. 2008).

\subsubsection{Immunochemical staining techniques}

Immunofluorescence (IF) was found to be very useful in the demonstration of leptospires in tissue samples (Ellis et al. 1983, Poonacha et al. 1993). Immunohistochemistry (IHC) can demonstrate the distribution and localization of antigen in tissue sections (Szeredi and Haake. 2006). Silver impregnation techniques can also be used for demonstration of leptospires in tissues (Quinn et al. 2011).

\subsubsection{Molecular diagnosis}

Polymerase chain reaction (PCR) has been applied to the identification of leptospires in tissues and body fluids (Gerritsen et al. 1991, Merien et al. 1992, Vemulapalli et al. 2005) due to its sensitivity and capacity to give an early diagnosis. It seems to be more reliable and give positive results when urine samples contain few leptospires (Vaneys et al. 1989). PCR has also been used to make a definitive diagnosis of horses with Equine recurrent uveitis (ERU), and it was found more reliable than culture for detecting the presence of leptospires in the aqueous humor (Faber et al. 2000). However in one study, PCR could not detect leptospiral DNA in fixed equine ocular tissues affected with end-stage ERU (Pearce et al. 2007). PCR does not identify the infecting serovar, although some primer sets may permit further identification to the species or strain level when the PCR amplicons are sequenced (OIE. 2008). Real-time PCR is faster than regular PCR and the risk of contamination is minimised (Picardeau. 2013).

\subsubsection{Serological tests}

Serological tests used to diagnose the presence of leptospiral infection include the microscopic agglutination test (MAT) and the enzyme-linked immunoassay (ELISA). 
The most common test used for serologic diagnosis of leptospirosis is the MAT. In this test, sera react with live antigen suspensions of various leptospiral serovars. It detects both immunoglobulin M (IgM) and immunoglobulin G (IgG) antibodies (Terpstra. 2003). Darkfield microscopy is then used to read the results with the end point being the highest dilution of serum at which $50 \%$ of the leptospires are agglutinated. As an individual animal test, the MAT is very useful in diagnosing acute infection; the demonstration of a four-fold change in antibody titers in paired acute and convalescent serum samples is diagnostic. The MAT is a serogroup-specific assay, although cross-reaction may occur between some serogroups especially in acute-phase samples (Levett. 2001). Hickey (2010) reported the sensitivity and specificity of MAT as high as $92 \%$ and $95 \%$ respectively. The sensitivity can be improved by including serovars representative of all serogroups and, preferably, all locally common serovars (OIE. 2008). A high single MAT titer of $\geq 400$ in the presence of clinical signs together with history of contact of infected animals or a four-fold rise in titer in paired serum samples indicate a current Leptospira infection (Adler and de la Pena Moctezuma. 2010). It is important to consider the vaccination history of the animals under test because animals that have been vaccinated may have antibodies against the serovars present in the vaccine used (OIE. 2008). Some studies have demonstrated a negative correlation between ERU and serum antibody concentrations (Matthews et al. 1987, Faber et al. 2000).

\subsection{Prevention and therapy of equine leptospirosis}

\subsubsection{Vaccination}

Leptospiral vaccines for veterinary use are suspensions of one or more strains of Leptospira inactivated in such a manner that immunogenic activity is retained (OIE. 2008). The immunity against leptospirosis is largely humoral and relatively serovar specific (Levett. 2001). A successful vaccination programme requires epidemiological studies to assess the 
prevalence of different Leptospira serovars in a given population (Adler and de la Pena Moctezuma. 2010).

Commercial vaccines are available globally for cattle, pigs and dogs (OIE. 2008). In South Africa, multivalent, inactivated leptospiral vaccine are produced by different companies: Pfizer Animal Health Group and Intervet supply respectively Vanguard ${ }^{\circledR} 5 \mathrm{~L}$ and Nobivac ${ }^{\circledR}$ Lepto for dogs which contain the serovars Icterohaemorrhagiae and Canicola. Virbac Animal Health produces Titanium ${ }^{\mathrm{TM}} 5$ FP + L5 for cattle, a modified live virus vaccine with a liquid bacterin containing serovars Icterohaemorrhagiae, Pomona, Hardjo, Grippotyphosa and Canicola. Currently there is no approved vaccine against leptospirosis for use in horses in South Africa. However, a vaccine is now available in North America. Zoetis has introduced the Lepto EQ Innovator ${ }^{\circledR}$ vaccine, which is the first USDA approved equine specific vaccine labeled to prevent leptospirosis due to L. Pomona (Zoetis. 2015).

\subsubsection{Chemotherapy in horses}

Some recommended antibiotics for the treatment of leptospirosis include penicillin, oxytetracycline, streptomycin, dihydrostreptomycin, and erythromycin (Prescott. 1991, Bernard et al. 1993). Treatment for ERU consists of a combination of anti-inflammatory agents and mydriatics. One study suggested the use of an intravitreal sustained-release cyclosporine delivery device for the treatment of ERU (Gilger et al. 2001). Vitrectomy and replacement of vitreous with a saline solution of gentamicin has also been recommended (Gerhards et al. 1999).

\subsection{Management}

Control should be based on limiting exposure to stagnant water and to potential carriers (Bernard et al. 1993). The irrigation of pasture using slurry from piggeries and mixing 
different animals on the same pasture must be avoided to prevent the spread of infection (Gummow et al. 1999, Hesterberg et al. 2009).

Infected animals should be isolated and contaminated areas cleaned and disinfected. In order to protect the susceptible animals in high-risk environments, doxycycline was shown to be effective for short-term prophylaxis (Sehgal et al. 2000).

\subsection{Conclusion}

Leptospirosis is one of the most widespread zoonotic diseases and some studies have established the existence of leptospiral antibodies in animals in South Africa. To date there are no studies available on leptospirosis in South African horses and few studies have been done that look at the risk factors associated with the disease in any species in South Africa. The objectives of this study were therefore to determine what serovars occur in horses in South Africa and to identify risk factors that may be associated with the disease in horses in South Africa. This would provide important information for future control of the disease in horses. 


\section{CHAPTER 3}

\section{MATERIALS AND METHODS}

\subsection{Study design}

A survey to determine what serovars were present in the horse population of South Africa and to get an estimate of the seroprevalence of leptospirosis was carried out from January 2013 until April 2014 in three provinces of South Africa with the assistance of four large equine hospitals: Baker \& McVeigh Equine Hospital (2 branches), the Equine Clinic of the Onderstepoort Veterinary Academic Hospital, Faculty of Veterinary Science, University of Pretoria and the Drakenstein Veterinary Clinic. Baker and McVeigh is both hospital and ambulatory based and have branches in Summerveld (Kwazulu-Natal) and in Milnerton (Cape Town). This hospital offers in-house facilities as well as an extensive ambulatory service to racehorses, sport horses, polo ponies and the pleasure horse community in Cape Town and the Western Cape. The Drakenstein Veterinary Clinic is a purpose-built facility situated in the Western Cape Province which offers in-house as well as ambulatory services for companion animals including small animals and horses. The hospital is equipped with state-of-the-art diagnostic equipment and a full diagnostic laboratory. The Equine Clinic of the Onderstepoort Veterinary Academic Hospital is situated in Gauteng Province and provides state-of-the-art facilities for the clinical departments and is the focus of the Faculty's clinical service-rendering activities to the surrounding community, as well as for the provision of a national referral service. A non-probability sampling was carried out on horses admitted to each equine hospital as well as horses seen on ambulatory visits. The blood samples collected in the survey were tested against 24 serovars of Leptospira. Owners of horses bled were asked to complete a questionnaire to obtain demographic data and information on potential risk factors that may be associated with lepto-seropositive horses. Figure 2 shows the distribution of sampling sites in the three provinces. 


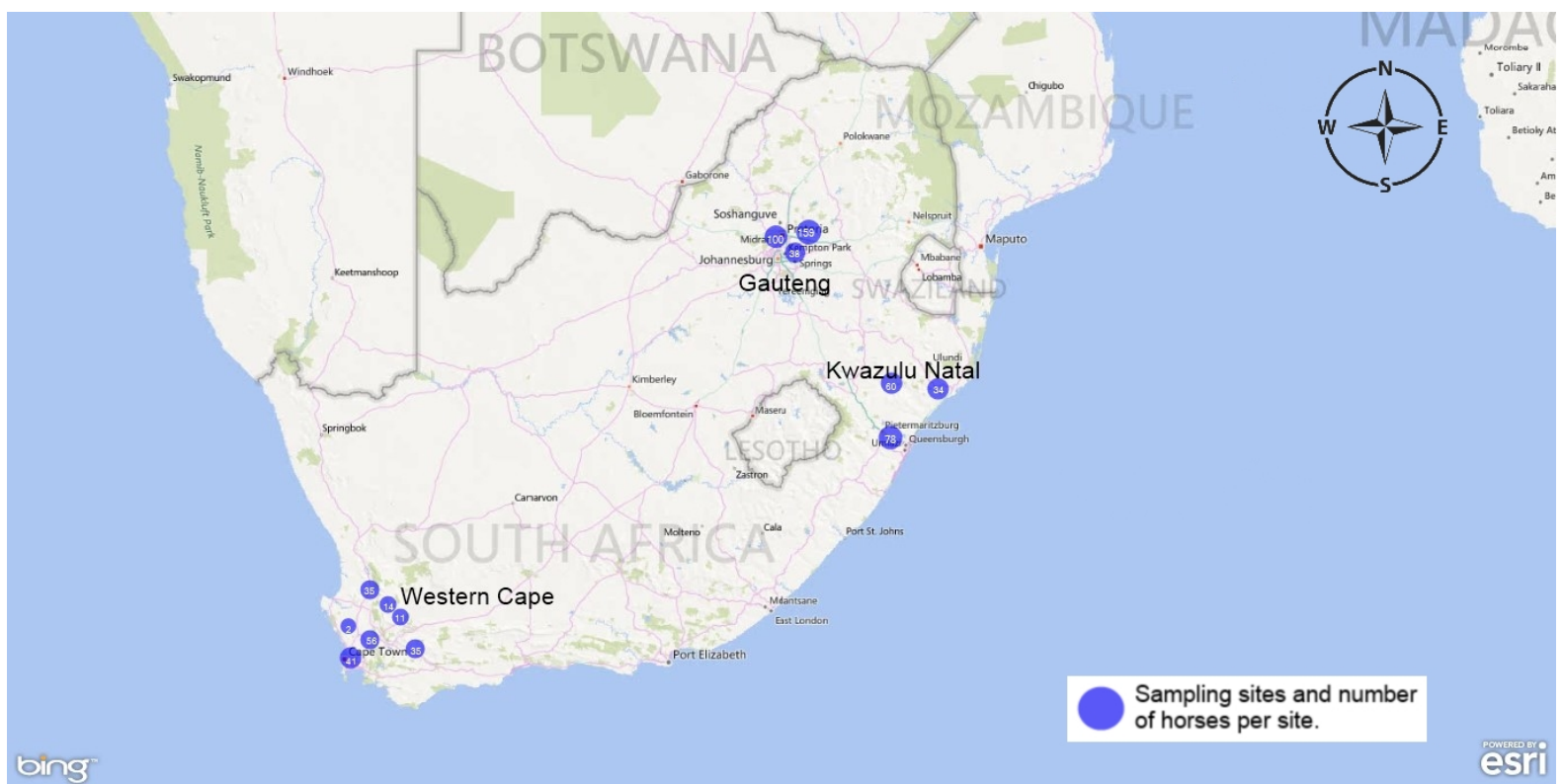

Figure 2 Distribution of sampling sites in the three provinces.

\subsubsection{Study population}

Adult horses ( $>2$ years) admitted in each equine hospital and horses seen on ambulatory service for various purposes (routine examination, castration, vaccination and other common veterinary procedures) were included in the study. To control for potential bias, severely-ill, chronically infected, and horses with underlying immunosuppressive conditions were excluded from sampling. Horses that had not been on the farm for at least 12 months prior to the time of blood collection were also excluded from sampling.

Horses were then stratified according to the activity they perform as follows:

- $\quad$ Breeding horses: brood mares and stallions used as sires.

- General pleasure horses: retired and young horses not used for a specific activity.

- Equestrian event horses: involved in show jumping, endurance riding, team sports (polo and polocrosse) and competition riding.

- Work horses: involved in riding schools.

- $\quad$ Racehorses: which were mainly used for racing.

- $\quad$ Other: other than the above-mentioned categories. 


\subsubsection{Sample size calculation}

The calculated simple size was found to be 315 horses in each province where the hospitals are located (Gauteng, Kwazulu-Natal and Western Cape Provinces). Each province was assumed to be an independent population of horses. The sample size was calculated using the following formula adopted from (Thrusfield. 2005).

$n=\left[Z_{\alpha}^{2} P_{\exp }\left(1-P_{\exp }\right)\right] / d^{2}$

Where: $\quad n=$ required sample size

$$
\begin{aligned}
& P_{\exp }=\text { expected prevalence } \\
& d \quad=\text { desired absolute precision } \\
& \mathrm{Z}^{2}=1.96^{2}
\end{aligned}
$$

The expected prevalence of $27 \%$ with a desired absolute precision of $\pm 5 \%$ was used in this calculation since Anon. (1986-1987) reported 27\% as the seroprevalence of leptospirosis in horses that were sampled in South Africa.

Assuming the survey estimate to be within 5\% of the true level $95 \%$ of the time, the sample size required was $n=(4 \times 0.27 \times 0.73) / 0.0025=315$ horses in each Province. This sample size was still powerful enough to detect leptospiral serovars in horses at a prevalence of $1 \%$ or below. The total number of horses required for the survey in the three provinces was therefore 945.

The equine demographic profile in South Africa is scant as well as the information on the number of registered properties with horses and number of horses per property. Three different horse populations were considered in this survey, each one residing in a different part of the country with a different ecosystem: The Western Cape Province is climatologically diverse, with many distinct micro- and macroclimates created by the varied topography and the influence the surrounding ocean currents (Tyson and Preston-Whyte. 2000). Most of the Province is considered to have a Mediterranean climate with cool, wet winters and warm, dry summers. Both the Great Karoo and Little Karoo, in the interior, have an arid to semi-arid climate with cold, frosty winters and hot summers with occasional thunderstorms. The Garden Route and the Overberg on the south coast have a maritime climate with cool, moist winters and mild, moist summers.

Kwazulu-Natal Province enjoys sunshine year-round with a temperate, sub-tropical climate. Despite its varied topography from the 3,000-metre peaks of the Drakensberg in the west to the sub-tropical wetlands of the Elephant Coast in the north-east, the province enjoys hot 
and humid summers (October -April) and mild winters (May - September). In general, the coast is subtropical with sea temperatures around the low $20^{\circ} \mathrm{C}$ and seldom dropping below $19^{\circ} \mathrm{C}$. The inland regions become progressively cooler further west particularly at night. Both Midlands and Zululand regions have a mild climate with relatively high summer rainfall and dry winters but while the weather is generally predictable, it's possible to experience all four seasons in a day at any time of year.

Gauteng Province is situated on the interior plateau of South Africa and receives most of its rainfall in summer. The annual average rainfall in Gauteng varies between just over $700 \mathrm{~mm}$ on the Witwatersrand and just over $600 \mathrm{~mm}$ north of the Magaliesberg (SAWS. 1998). Most of Gauteng falls into the climate region: Moist Highveld Grassland, and is relatively cool with average annual maximum temperatures of about $22^{\circ} \mathrm{C}$ in the south but increasing to $25^{\circ} \mathrm{C}$ in the north (Kruger. 2004). The extreme northern parts of Gauteng fall into the Central Bushveld climate region. The maximum rainfall over Gauteng occurs during the December and January months (Kruger. 2004).

\subsubsection{Sample collection, processing and storage}

Horses were bled via jugular venipuncture and blood was collected into $10 \mathrm{ml}$ vacutainer tubes $^{2}$ with clot activator. After centrifugation, the serum was transferred into two cryotubes ${ }^{3}$ and stored at $-20^{\circ} \mathrm{C}$. A unique code was given to each of two duplicate cryotubes for identification of the horse bled. The sera were then stored in each hospital before shipping frozen on dry ice to the Ondersterpoort Veterinary Institute (OVI). Pertinent data was captured and maintained in Microsoft Excel 2013 for analysis.

\subsubsection{Research committee approval}

The study was approved by the research committee of the University of Pretoria (V040-12) (See Appendix ii). This approval includes ethics.

\subsection{Live Antigen}

A panel of 24 serovars and strains representative of 19 serogroups used as antigen for the MAT is given in Table 3.1. These serovars are the most commonly isolated in the tropics

\footnotetext{
${ }^{2}$ The Scientific Group, China.

${ }^{3}$ Greiner Bio-One GmbH, Frickenhausen, Germany
} 
and the most commonly reported in different surveys across the globe. Live cultures with densities of approximately $2 \times 10^{8}$ leptospires per ml were used as the antigens ${ }^{4}$.

\subsection{Microscopic Agglutination Test (MAT)}

The MAT was carried out at the Ondersterport Veterinary Institute (OVI) in Pretoria which consists of two tests in succession namely a screening test to determine if the sera react to the antigen followed by titrations of the reacting sera to determine if they are positive at a serum dilution of 1:50.

\subsubsection{Screening test}

The following steps were followed:

A laboratory number, animal number and a total number of samples to be tested were written out on the screening test form, to keep a record of the test.

The U-bottom microtitre plates were numbered with care, according to the screening test form. Each row on the U-bottom microtitre plate was tested in a flat bottom plate (Figure 3 and Figure 4).

The test serum $(20 \mu \mathrm{l})$ was transferred into the U-bottom microtitre plate using a pipette (according to the test form), with a new tip for each serum sample, leaving the last well of the first row of the U-bottom plate open for negative antigen controls. The positive control serum was never dispensed in the U-bottom plate (the positive control serum was added to a flat bottom plate according to the screening test form, and each flat bottom plate was used to test against eight serovars).

The next step was to dispense $140 \mu \mathrm{l}$ of Sorensen's buffer using an 8 channel electronic pipette into the wells of the U-bottom microtitre plates containing test sera. This produced a 1/8 dilution of test sera.

The flat bottom plates were marked afterwards according to the screening test form and on each plate seven test sera were tested except the first flat bottom plate of each batch which was used to test five test sera (Figure 4).

\footnotetext{
${ }^{4}$ Leptospirosis Reference Centre, KIT Biomedical Research, Amsterdam, The Netherlands.
} 
Using the 8 channel electronic pipette, $25 \mu$ l Sorensen's buffer were dispensed in all the wells of columns 3-10 and rows A-H of a flat bottom microtitre plate numbered according to the test form.

The diluted test sera $(50 \mu \mathrm{l})$ were then picked up from the U-bottom plate (new tips for each new row of test sera) using the $50 \mu l 8$ channel electronic pipette on stepper mode. Each row of diluted test serum on the U-bottom plate was tested in one flat bottom test plate. Row 9 A-H of the plate in which the positive sera must be added (first flat bottom plate for each batch) had only buffer. Five $\mu$ l of positive sera (control) corresponding to the relevant antigen were then dispensed into row 9 A-H of each first flat bottom plate per batch, by changing the new tip for each serovar.

Afterwards $25 \mu$ l of antigen were dispensed in wells 3-10 of each flat bottom plate, using a different row for each serovar and new tips for each serovar.

After shaking each plate gently for \pm 10 seconds, the plates were stacked on top of each other, and covered with a clean plate and incubated in the dark at $29^{\circ} \mathrm{C}$ for 2 hours. The final serum dilution was 1/88 and positive and negative controls were included in one plate each day.

Using a dry condenser dark-field microscope, wells on the flat bottom plate were examined for reaction starting with well A10 (negative control of row A) and read from right to left.

An agglutination of $80-100 \%$ was taken as a reaction and reacting sera was correlated to the corresponding serovar. 


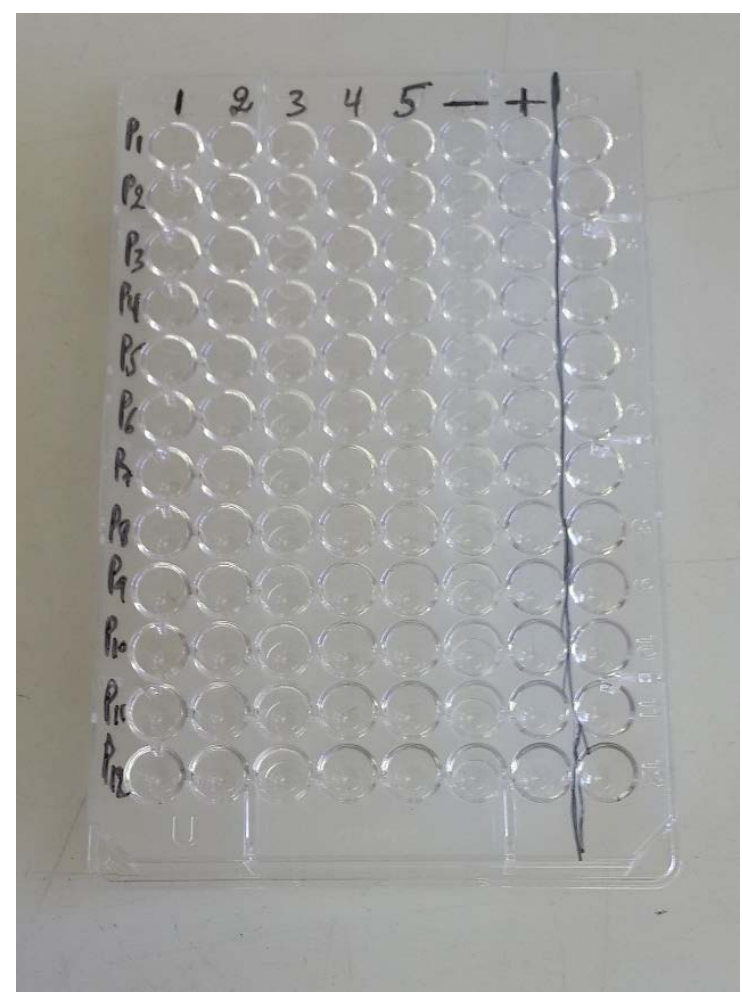

Figure 3 U-bottom plate used to dilute the test sera for the first batch.

Diluted samples 1, 2, 3, 4, 5 were tested in one flat bottom plate which was labelled as P1 (or 1). Twelve flat bottom plates were needed per batch for the screening test. P2 (or 2) until P12 had seven test sera each to be tested. The total number of samples to be diluted and tested was 82, representing one batch.

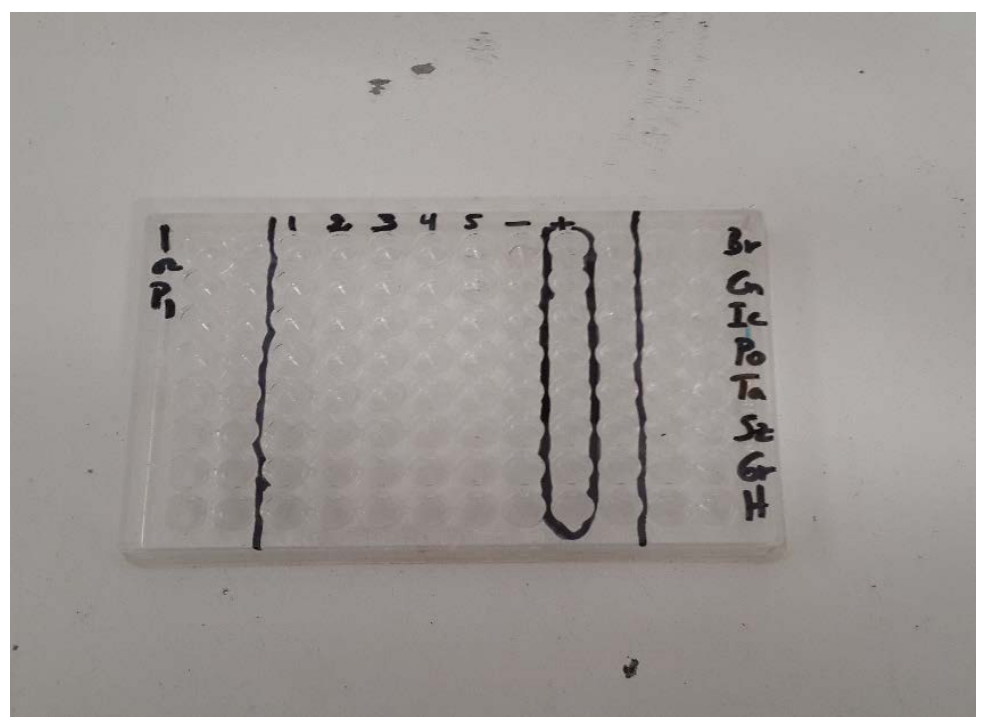

Figure 4 Flat bottom plate (P1 or 1) in which five test sera were tested against 8 serovars.

This plate had positive and negative controls included. The encircled wells represent row 9 A-H where positive controls will be added. 
Table 3.1 Reference serovars and strains of 19 serogroups of Leptospira interrogans species used as antigens for the Microscopic Agglutination Test

\begin{tabular}{lll}
\hline Serovar & Strain & Serogroup \\
\hline Pomona & Pomona & Pomona \\
Tarassovi & Perepelitsin & Tarassovi \\
Topaz & $94-79940 / 3$ & Tarassovi \\
Hardjo & Hardjoprajitno & Sejroe \\
Medanensis & Hond HC & Sejroe \\
Kremastos & Kremastos & Hebdomadis \\
Canicola & Hond Utrecht IV & Canicola \\
Copenhageni & M20 & Icterohaemorrhagiae \\
Zanoni & Zanoni & Pyrogenes \\
Robinson & Robinson & Pyrogenes \\
Arborea & Arborea & Ballum \\
Grippotyphosa & Moskva V & Grippotyphosa \\
Australis & Ballico & Australis \\
Szwajizak & Szwajizak & Mini \\
Bulgarica & Nikolaevo & Autumnalis \\
Bataviae & Swart & Bataviae \\
Celledoni & Celledoni & Celledoni \\
Cynopteri & 3522C & Cynopteri \\
Djasiman & Djasiman & Djasiman \\
Javanica & Veldrat Bataviae 46 & Javanica \\
Panama & CZ 214 & Panama \\
Shermani & 1342 K & Shermani \\
Bratislava & Jez Bratislava & Australis \\
Hebdomadis & Hebdomadis & Hebdomadis \\
\hline
\end{tabular}




\subsubsection{The titration test}

Serum samples with titers of $\geq 100$ were retested to determine an endpoint using doubling dilutions of sera beginning at 1/100 through to 1/3200 using the following procedure:

The titration test form was completed to keep a record of the test and each serovar had its own number of samples to be tested and differed from serovar to serovar.

A positive and negative control sera were included for each serovar and each flat bottom microtitre plate was marked according to the test form.

The next step was to pipette $10 \mu \mathrm{l}$ test sera into the wells of column $2 \mathrm{~A}-\mathrm{H}$ of the flat microtitre plate according to the titration test result form and to pipette $115 \mu$ S Sorensen's buffer into the wells of column $2 \mathrm{~A}-\mathrm{H}$ containing the $10 \mu \mathrm{l}$ test sera.

Twenty five $\mu \mathrm{l}$ buffer were dispensed into wells 3 to 10 of rows $\mathrm{A}$ to $\mathrm{H}$ using the electronic $300 \mu l$ 8-channel pipette and $25 \mu$ l diluted serum (1/12.5) were picked up from column 2 A$\mathrm{H}$, and diluted up to column 9. Twenty five $\mu \mathrm{l}$ were then picked up from column $9 \mathrm{~A}-\mathrm{H}$ and discarded.

Twenty five $\mu \mathrm{l}$ antigen were afterwards dispensed into wells 3 to 10 of each row, using the serovars according to the titration test form. For each serovar new tips were used.

After shaking each plate gently for \pm 10 seconds, the plates were stacked on top of each other, and covered with a clean plate and incubated in the dark at $29^{\circ} \mathrm{C}$ for 2 hours.

The plates were examined by dark-field microscopy. The endpoint was defined as the dilution of serum that shows 50\% agglutination, leaving 50\% free cells compared with a control culture diluted $1 / 2$ in phosphate buffered saline (OIE. 2008). The result of the test was reported as a titre that is the reciprocal of the endpoint serum dilution.

\subsection{Risk factor questionnaire and data collection}

A questionnaire (see Appendix i) was made available for the owners of horses under the study in order to identify risk factors related to seropositive horses. All owners of horses bled were informed and invited to participate. The questionnaire followed a classic epidemiological approach taking into account population (e.g. age, sex, breed), spatial (e.g. where the horses were kept) and temporal (e.g. clinical signs in the last twelve months) 
variables as well as management factors that could be related to leptospirosis in horses. Owner details were also recorded.

Other environmental information regarding the annual average temperature and rainfall which correspond to each horse-property was obtained from the South African Weather Service (http://www.weathersa.co.za). This information was used to determine a possible association between those two factors (annual average temperature and rainfall) and the leptospiral positive properties.

\subsection{Data analysis}

\subsubsection{Apparent prevalence}

MAT titers for each serovar in each province were summarized in tables. The apparent prevalence for each of the 24 serovars of leptospires per province was calculated based on the frequency of positive titers to that specific serovar. The predominant serovar was the one with the greatest frequency of titres.

\subsubsection{True prevalence}

A sensitivity of $92 \%$ and the specificity of $95 \%$ for the MAT was used to calculate the true prevalence (Hickey. 2010) using the following formulae adopted from Cameron. (1999).

$$
\operatorname{Var}(\mathrm{AP})=\frac{\mathrm{AP}(1-\mathrm{AP})}{\mathrm{n}(\mathrm{Se}+\mathrm{Sp})^{2}} \quad(\text { Equation } 1)
$$

Where: $\quad \operatorname{Var}(\mathrm{AP}) \quad=$ estimate of variance for the apparent prevalence,

$$
\begin{aligned}
& \text { AP = apparent prevalence, } \\
& \text { Se = sensitivity of the MAT (92\%) } \\
& \text { Sp = specificity of the MAT (95\%) }
\end{aligned}
$$

Equation 1 was used to calculate 95\% Confidence Interval (CI) for the true prevalence (Cameron. 1999), using the following equation:

$$
\mathrm{AP}-\left(\mathrm{Z}_{\alpha / 2} \mathrm{x} \sqrt{\operatorname{Var}(\mathrm{AP})}\right) ; \mathrm{AP}+\left(\mathrm{Z}_{\alpha / 2} \mathrm{x} \sqrt{\operatorname{Var}(\mathrm{AP})}\right) \quad \text { (Equation 2) }
$$

Where, $\mathrm{Z}_{\alpha / 2}$ at a $95 \%$ confidence level is 1.96 . 
The overall seroprevalence of leptospirosis in each province was calculated taking into account clustering within the data using Equation 3 and Equation 4 (Thrusfield. 2005). A seropositive horse to one or more serovars was considered seropositive to Leptospira.

$\hat{P}-1.96\left\{\frac{C}{T} \sqrt{\frac{V}{C(C-1)}}\right\}, \hat{P}+1.96\left\{\frac{C}{T} \sqrt{\frac{V}{C(C-1)}}\right\}, \quad$ (Equation 3)

Where:

$\mathrm{C}=$ number of clusters in the sample

$\mathrm{T}=$ total number of animals in the sample

and:

$\mathrm{V}=\hat{P}^{2}\left(\sum n^{2}\right)-2 \hat{P}\left(\sum n m\right)+\left(\sum m^{2}\right)$

(Equation 4)

Where:

$\mathrm{n}=$ number of animals sampled in each cluster

$\mathrm{m}=$ number of diseased animals sampled in each cluster

\subsubsection{Univariable analysis}

Data from the questionnaire interviews were captured and transferred to a spreadsheet (Microsoft Excel 2013) and analysed with NCSS $9^{5}$ statistical software. In the initial univariable analysis, all the variables from the three provinces were combined and tested individually for their unconditional association with the outcome variables using the Chisquare test ( $\mathrm{P}$-value $<0.15)$. The outcome variable was considered as a positive horse to the most predominant serovar. Proportions of seropositive horses to the predominant serovar in different categories of variables were calculated. A parallel univariable analysis using the Chi-square test was also done with the same variables. The outcome variable was considered as a positive horse to Leptospira spp. Similarly, proportions of seropositive horses to Leptospira spp in different categories of variables were also calculated. 


\subsubsection{Multivariable analysis}

The variables (factors) that were found to be associated with each of the two outcomes on univariable analysis with P-value $<0.15$ (Katz. 1999), were considered for inclusion in the multivariate logistic regression models to analyse the amount of effect on the outcome when such variables (factors) were present. Before the model was run, a reference value was specified for each categorical variable (Hintze. 2013). The logistic models were reduced by backward elimination, removing each independent variable with $\mathrm{P}_{\text {Wald }}>0.15$ until all the remaining variables were significant $\left(\mathrm{P}_{\text {wald }}<0.15\right)$. The results were reported as odds ratios with 95\% confidence intervals and P-values.

\subsection{Spatial analysis}

Epi info $7^{6}$ was used to plot the distribution of horses bled as well as the proportions of horses that came up positives after the MAT.

${ }^{6}$ wwwn.cdc.gov/epiinfo/7/ 


\section{CHAPTER 4}

\section{RESULTS}

\subsection{Apparent prevalence of Leptospira spp in Gauteng Province}

The total number of surveyed horses in Gauteng Province was 297 representing 20 clusters. A cluster was considered as a group of horses coming from one property or a stable with several owners. The apparent prevalence of one or more serovars of Leptospira spp at a serum dilution of 1:100 was $49 \%$ (Table 4.1). The true prevalence was calculated taking into account the clustering effect during the sampling (See Appendix iii) and was between 24\% and $74 \%$. Of the 20 clusters that were used in the survey in this province, 16 were positive to one or more serovars of Leptospira (80\%). The apparent prevalence of specific serovars of Leptospira in Gauteng Province is given in Table 4.2.

Table 4.1 Apparent prevalence of Leptospira spp in Gauteng Province

\begin{tabular}{|c|c|c|c|c|}
\hline No & Cluster & $\begin{array}{c}\text { No of } \\
\text { horses } \\
\text { sampled }\end{array}$ & $\begin{array}{c}\text { No of } \\
\text { positive } \\
\text { horses }\end{array}$ & $\begin{array}{c}\text { Apparent } \\
\text { prevalence }\end{array}$ \\
\hline 1 & Cluster 1 & 22 & 17 & 77.27 \\
\hline 2 & Cluster 2 & 54 & 48 & 88.89 \\
\hline 3 & Cluster 3 & 2 & 0 & 0.00 \\
\hline 4 & Cluster 4 & 38 & 27 & 71.05 \\
\hline 5 & Cluster 5 & 59 & 17 & 28.81 \\
\hline 6 & Cluster 6 & 100 & 24 & 24.00 \\
\hline 7 & Cluster 7 & 1 & 1 & 100.00 \\
\hline 8 & Cluster 8 & 1 & 1 & 100.00 \\
\hline 9 & Cluster 9 & 1 & 1 & 100.00 \\
\hline 10 & Cluster 10 & 1 & 1 & 100.00 \\
\hline 11 & Cluster 11 & 1 & 1 & 100.00 \\
\hline 12 & Cluster 12 & 1 & 1 & 100.00 \\
\hline 13 & Cluster 13 & 1 & 1 & 100.00 \\
\hline 14 & Cluster 14 & 1 & 0 & 0.00 \\
\hline 15 & Cluster 15 & 1 & 0 & 0.00 \\
\hline 16 & Cluster 16 & 1 & 0 & 0.00 \\
\hline 17 & Cluster 17 & 1 & 1 & 100.00 \\
\hline 18 & Cluster 18 & 1 & 1 & 100.00 \\
\hline 19 & Cluster 19 & 1 & 1 & 100.00 \\
\hline \multirow[t]{3}{*}{20} & Cluster 20 & 9 & 2 & 22.22 \\
\hline & TOTAL & 297 & 145 & 49 \\
\hline & $\begin{array}{l}\mathbf{A}_{1} \\
\mathbf{9 5}\end{array}$ & $\begin{array}{l}\text { preva } \\
\text { r the }\end{array}$ & $\begin{array}{l}49 \% \\
\text { reval }\end{array}$ & $24-74 \% *$ \\
\hline
\end{tabular}

*See Appendix iii 
Table 4.2: Apparent prevalence of specific serovars of Leptospira in Gauteng Province

\begin{tabular}{|c|c|c|c|c|c|c|c|c|c|}
\hline \multirow[b]{2}{*}{ Serovar } & \multicolumn{6}{|c|}{ No of sera with indicated MAT titres } & \\
\hline & 100 & 200 & 400 & 800 & 1600 & 3200 & Tot[AP] & $\begin{array}{l}\text { AP 95 } \\
\text { LCL }\end{array}$ & $\begin{array}{l}\% \mathrm{CI} \\
\text { UCL }\end{array}$ \\
\hline Bratislava & 35 & 33 & 17 & 1 & 0 & 0 & $86[32]$ & 0.29 & 0.35 \\
\hline Djasiman & 7 & 10 & 10 & 1 & 0 & 0 & $28[10.4]$ & 0.08 & 0.12 \\
\hline Arborea & 3 & 7 & 7 & 6 & 1 & 0 & 24 [8.9] & 0.07 & 0.11 \\
\hline Topaz & 2 & 9 & 7 & 4 & 1 & 0 & 23 [8.5] & 0.07 & 0.10 \\
\hline Canicola & 9 & 1 & 2 & 1 & 0 & 1 & 14 [5.2] & 0.04 & 0.07 \\
\hline Icterohaemorrhagiae & 7 & 6 & 1 & 0 & 0 & 0 & 14 [5.2] & 0.04 & 0.07 \\
\hline Zanoni & 3 & 6 & 4 & 0 & 0 & 0 & 13 [4.8] & 0.03 & 0.06 \\
\hline Robinsoni & 3 & 5 & 5 & 0 & 0 & 0 & 13 [4.8] & 0.03 & 0.06 \\
\hline Ballico & 7 & 2 & 0 & 0 & 0 & 0 & 9 [3.3] & 0.02 & 0.04 \\
\hline Javanica & 3 & 1 & 2 & 2 & 0 & 0 & 8 [2.97] & 0.02 & 0.04 \\
\hline Cynopteri & 3 & 3 & 1 & 1 & 0 & 0 & 8 [2.97] & 0.02 & 0.04 \\
\hline Tarassovi & 3 & 4 & 0 & 0 & 0 & 0 & $7[2.6]$ & 0.02 & 0.04 \\
\hline Bataviae & 5 & 0 & 0 & 1 & 0 & 0 & $6[2.2]$ & 0.01 & 0.03 \\
\hline Mednensis & 1 & 0 & 3 & 1 & 0 & 0 & 5 [1.86] & 0.01 & 0.03 \\
\hline Pomona & 0 & 2 & 0 & 1 & 0 & 0 & 3 [1.1] & 0.00 & 0.02 \\
\hline Swazijak & 2 & 0 & 1 & 0 & 0 & 0 & 3 [1.1] & 0.00 & 0.02 \\
\hline Bulgarica & 3 & 0 & 0 & 0 & 0 & 0 & 3 [1.1] & 0.00 & 0.02 \\
\hline Hardjo & 0 & 0 & 1 & 0 & 0 & 0 & $1[0.4]$ & 0.00 & 0.01 \\
\hline Shermani & 1 & 0 & 0 & 0 & 0 & 0 & $1[0.4]$ & 0.00 & 0.01 \\
\hline Grippotyphosa & 0 & 0 & 0 & 0 & 0 & 0 & $0[0]$ & 0.00 & 0.00 \\
\hline Panama & 0 & 0 & 0 & 0 & 0 & 0 & $0[0]$ & 0.00 & 0.00 \\
\hline Celledoni & 0 & 0 & 0 & 0 & 0 & 0 & $0[0]$ & 0.00 & 0.00 \\
\hline Kremastos & 0 & 0 & 0 & 0 & 0 & 0 & $0[0]$ & 0.00 & 0.00 \\
\hline Hebdomadis & 0 & 0 & 0 & 0 & 0 & 0 & $0[0]$ & 0.00 & 0.00 \\
\hline Total & 97 & 89 & 61 & 19 & 2 & 1 & 269 & & \\
\hline
\end{tabular}

Serovar Bratislava had the highest apparent prevalence compared to the rest of the serovars used in the MAT. The apparent prevalence of Bratislava serovar was 32\% [95\% CI: 29, 35], followed by serovars Djasiman 10.4\% [95\% CI: 8, 12] and Arborea 8.9\% [95\% CI: 7, 11]. 


\subsection{Apparent prevalence of Leptospira spp in the Western Cape Province}

The total number of surveyed horses in the Western Cape Province was 194 representing 8 clusters. The apparent prevalence of one or more serovars of Leptospira spp at a serum dilution of 1:100 was 32\% (Table 4.3). The true prevalence was calculated taking into account the clustering effect during the sampling (See Appendix iv) and was between 26\% and 39\%. Each cluster had at least one positive horse to one or more serovars. The apparent prevalence of specific serovars of Leptospira in the Western Cape Province is given in Table 4.4.

Table 4.3 Apparent prevalence of Leptospira spp in the Western Cape Province

\begin{tabular}{|c|c|c|c|c|}
\hline No & Cluster & $\begin{array}{c}\text { No of } \\
\text { horses } \\
\text { sampled }\end{array}$ & $\begin{array}{c}\text { No of } \\
\text { positive } \\
\text { horse }\end{array}$ & $\begin{array}{c}\text { Apparent } \\
\text { prevalence }\end{array}$ \\
\hline 1 & Cluster 1 & 41 & 13 & 31.71 \\
\hline 2 & Cluster 2 & 2 & 1 & 50.00 \\
\hline 3 & Cluster 3 & 35 & 13 & 37.14 \\
\hline 4 & Cluster 4 & 16 & 6 & 37.50 \\
\hline 5 & Cluster 5 & 11 & 2 & 18.18 \\
\hline 6 & Cluster 6 & 35 & 7 & 20.00 \\
\hline 7 & Cluster 7 & 14 & 4 & 28.57 \\
\hline 8 & Cluster 8 & 40 & 17 & 42.50 \\
\hline & TOTAL & 194 & 63 & 32 \\
\hline \multicolumn{5}{|c|}{$\begin{array}{l}\text { Apparent prevalence: } 32 \% \\
\text { 95\% CI for true prevalence: } 26-39 \% *\end{array}$} \\
\hline
\end{tabular}

*See Appendix iv 
Table 4.4: Apparent prevalence of specific serovars of Leptospira in the Western Cape Province

\begin{tabular}{|c|c|c|c|c|c|c|c|c|}
\hline \multirow[b]{2}{*}{ Serovar } & \multicolumn{6}{|c|}{ No of sera with indicated MAT titres } & \multirow{2}{*}{\multicolumn{2}{|c|}{$\begin{array}{r}\text { Tot[AP] AP 95\% Cl } \\
\text { LCL UCL }\end{array}$}} \\
\hline & 100 & 200 & 400 & 800 & 1600 & 3200 & & \\
\hline Bratislava & 21 & 8 & 3 & 0 & 0 & 0 & $32[27.35]$ & 0.230 .32 \\
\hline Djasiman & 2 & 2 & 9 & 3 & 2 & 0 & 18 [15.4] & 0.120 .19 \\
\hline Arborea & 6 & 5 & 4 & 2 & 0 & 0 & 17 [14.5] & 0.110 .18 \\
\hline Javanica & 4 & 2 & 4 & 0 & 1 & 0 & 11 [9.4] & 0.070 .12 \\
\hline Canicola & 8 & 0 & 1 & 0 & 0 & 0 & 9 [7.7] & 0.050 .10 \\
\hline Tarassovi & 5 & 3 & 0 & 0 & 0 & 0 & 8 [6.8] & 0.040 .09 \\
\hline Topaz & 1 & 2 & 2 & 1 & 0 & 0 & $6[5.1]$ & 0.030 .07 \\
\hline Bulgarica & 0 & 1 & 4 & 0 & 0 & 0 & $5[4.3]$ & 0.020 .06 \\
\hline Pomona & 1 & 1 & 1 & 0 & 0 & 0 & $3[2.56]$ & 0.010 .04 \\
\hline Cynopteri & 2 & 0 & 0 & 0 & 0 & 0 & 2 [1.7] & 0.000 .03 \\
\hline Grippotyphosa & 1 & 0 & 1 & 0 & 0 & 0 & 2 [1.7] & 0.000 .03 \\
\hline Robinsoni & 0 & 2 & 0 & 0 & 0 & 0 & 2 [1.7] & 0.000 .03 \\
\hline Icterohaemorrhagiae & 1 & 0 & 0 & 0 & 0 & 0 & $1[0.85]$ & 0.000 .02 \\
\hline Celledoni & 0 & 0 & 0 & 0 & 1 & 0 & 1 [0.85] & 0.000 .02 \\
\hline Hardjo & 0 & 0 & 0 & 0 & 0 & 0 & $0[0]$ & 0.000 .00 \\
\hline Zanoni & 0 & 0 & 0 & 0 & 0 & 0 & $0[0]$ & 0.000 .00 \\
\hline Panama & 0 & 0 & 0 & 0 & 0 & 0 & $0[0]$ & 0.000 .00 \\
\hline Swajizak & 0 & 0 & 0 & 0 & 0 & 0 & $0[0]$ & 0.000 .00 \\
\hline Ballico & 0 & 0 & 0 & 0 & 0 & 0 & $0[0]$ & 0.000 .00 \\
\hline Bataviae & 0 & 0 & 0 & 0 & 0 & 0 & $0[0]$ & 0.000 .00 \\
\hline Shermani & 0 & 0 & 0 & 0 & 0 & 0 & $0[0]$ & 0.000 .00 \\
\hline Hebdomadis & 0 & 0 & 0 & 0 & 0 & 0 & $0[0]$ & 0.000 .00 \\
\hline Kremastos & 0 & 0 & 0 & 0 & 0 & 0 & $0[0]$ & 0.000 .00 \\
\hline Mednensis & 0 & 0 & 0 & 0 & 0 & 0 & $0[0]$ & 0.000 .00 \\
\hline Total & 52 & 26 & 29 & 6 & 4 & $\mathbf{0}$ & 117 & \\
\hline
\end{tabular}

Serovar Bratislava had the highest apparent prevalence compared to the rest of the serovars used in the MAT. The apparent prevalence of Bratislava serovar was 27.35\% [95\% CI: 23, 32]. The next most prevalent serovars were Djasiman 15.4\% [95\% CI: 12, 19] and Arborea $14.5 \%$ [95\% CI: 11,18$]$. 


\subsection{Apparent prevalence of Leptospira spp in KwaZulu-Natal Province.}

The total number of surveyed horses in the KwaZulu-Natal Province was 172 representing 8 clusters. The apparent prevalence of one or more serovars of Leptospira at a serum dilution of $1: 100$ was $37 \%$ (Table 4.5 ). The true prevalence was calculated taking into account the clustering effect during the sampling (See Appendix v) and was between 20\% and 54\%. Each cluster had at least one positive horse to one or more serovars. The apparent prevalence of specific serovars of Leptospira in KwaZulu-Natal Province is given in Table 4.6

Table 4.5 Apparent prevalence of Leptospira spp in KwaZulu-Natal Province

\begin{tabular}{|c|c|c|c|c|}
\hline No & Cluster & $\begin{array}{c}\text { No of } \\
\text { horses } \\
\text { sampled }\end{array}$ & $\begin{array}{c}\text { No of } \\
\text { positive } \\
\text { horse }\end{array}$ & $\begin{array}{c}\text { Apparent } \\
\text { prevalence }\end{array}$ \\
\hline 1 & Cluster 1 & 78 & 21 & 26.92 \\
\hline 2 & Cluster 2 & 6 & 4 & 66.67 \\
\hline 3 & Cluster 3 & 9 & 5 & 55.56 \\
\hline 4 & Cluster 4 & 25 & 20 & 80.00 \\
\hline 5 & Cluster 5 & 20 & 4 & 20.00 \\
\hline 6 & Cluster 6 & 8 & 2 & 25.00 \\
\hline 7 & Cluster 7 & 11 & 2 & 18.18 \\
\hline 8 & Cluster 8 & 15 & 5 & 33.33 \\
\hline & TOTAL & 172 & 63 & 37 \\
\hline
\end{tabular}

*See Appendix v 
Table 4.6: Apparent prevalence of specific serovars of Leptospira in KwaZulu-Natal Province

\begin{tabular}{|c|c|c|c|c|c|c|c|c|}
\hline \multirow[b]{2}{*}{ Serovar } & \multicolumn{6}{|c|}{ No of sera with indicated MAT titres } & \multirow{2}{*}{\multicolumn{2}{|c|}{$\begin{array}{r}\text { Tot[AP]AP 95\%CI } \\
\text { LCL UCL }\end{array}$}} \\
\hline & 100 & 200 & 400 & 800 & 1600 & 3200 & & \\
\hline Bratislava & 10 & 8 & 10 & 7 & 5 & 1 & $41[39.4]$ & $0.34 \quad 0.44$ \\
\hline Arborea & 2 & 3 & 4 & 1 & 0 & 0 & $10[9.6]$ & $0.07 \quad 0.13$ \\
\hline Tarassovi & 4 & 2 & 2 & 0 & 0 & 0 & 8 [7.7] & $0.05 \quad 0.10$ \\
\hline Djasiman & 3 & 2 & 2 & 0 & 0 & 0 & 7 [6.7] & $0.04 \quad 0.09$ \\
\hline Pomona & 2 & 2 & 2 & 0 & 0 & 0 & $6[5.8]$ & 0.030 .08 \\
\hline Topaz & 1 & 1 & 3 & 0 & 1 & 0 & $6[5.8]$ & 0.030 .08 \\
\hline Canicola & 0 & 1 & 2 & 1 & 1 & 0 & $5[4.8]$ & 0.030 .07 \\
\hline Javanica & 3 & 1 & 1 & 0 & 0 & 0 & $5[4.8]$ & $0.03 \quad 0.07$ \\
\hline Robinsoni & 2 & 2 & 0 & 0 & 0 & 0 & $4[3.8]$ & 0.020 .06 \\
\hline Cynopteri & 2 & 2 & 0 & 0 & 0 & 0 & $4[3.8]$ & 0.020 .06 \\
\hline Grippotyphosa & 1 & 0 & 0 & 1 & 0 & 0 & 2 [1.9] & 0.010 .03 \\
\hline Ballico & 1 & 1 & 0 & 0 & 0 & 0 & 2 [1.9] & 0.010 .03 \\
\hline Icterohaemorrhagiae & 0 & 1 & 1 & 0 & 0 & 0 & 2 [1.9] & 0.010 .03 \\
\hline Bulgarica & 0 & 0 & 0 & 1 & 0 & 0 & 1 [0.96] & $\begin{array}{lll}0.00 & 0.02\end{array}$ \\
\hline Celledoni & 0 & 1 & 0 & 0 & 0 & 0 & 1 [0.96] & $\begin{array}{lll}0.00 & 0.02\end{array}$ \\
\hline Hardjo & 0 & 0 & 0 & 0 & 0 & 0 & $0[0]$ & $0.00 \quad 0.00$ \\
\hline Zanoni & 0 & 0 & 0 & 0 & 0 & 0 & $0[0]$ & $0.00 \quad 0.00$ \\
\hline Panama & 0 & 0 & 0 & 0 & 0 & 0 & $0[0]$ & $0.00 \quad 0.00$ \\
\hline Swajizak & 0 & 0 & 0 & 0 & 0 & 0 & $0[0]$ & $0.00 \quad 0.00$ \\
\hline Bataviae & 0 & 0 & 0 & 0 & 0 & 0 & $0[0]$ & $0.00 \quad 0.00$ \\
\hline Kremastos & 0 & 0 & 0 & 0 & 0 & 0 & $0[0]$ & $0.00 \quad 0.00$ \\
\hline Shermani & 0 & 0 & 0 & 0 & 0 & 0 & $0[0]$ & $\begin{array}{lll}0.00 & 0.00\end{array}$ \\
\hline Hebdomadis & 0 & 0 & 0 & 0 & 0 & 0 & $0[0]$ & $\begin{array}{lll}0.00 & 0.00\end{array}$ \\
\hline Mednensis & 0 & 0 & 0 & 0 & 0 & 0 & $0[0]$ & $\begin{array}{lll}0.00 & 0.00\end{array}$ \\
\hline Total & 31 & 27 & 27 & 11 & 7 & 1 & 104 & \\
\hline
\end{tabular}

Serovar Bratislava had the highest apparent prevalence compared to the rest of the serovars. The apparent prevalence of Bratislava serovar was 39.4\% [95\% CI: 34, 44], followed by serovars Arborea 9.6\% [95\% CI: 7, 13] and Tarassovi 7.7\% [95\% CI: 5, 10].

\subsection{Univariable analysis of risk factors for association with serovar Bratislava}

\subsubsection{Demographic factors}

Information on horse demographic factors like breed, gender, age and the type of activity each horse performed was collected using a questionnaire. Those factors were then analysed in order to find out if there was any association between these postulated risk factors and a seropositive horse to the predominant serovar Bratislava.

Horses were grouped into six categories of breeds: Thoroughbred, Arabian, Pony, Warmblood, Nooitgedacht and Others. Horses that were crossbreeds and the breeds which were underrepresented were grouped under an Others category. Seroprevalence of the 
serovar Bratislava within each category was calculated (Table 4.7) and analysed for association using the Chi-square test. Breed was significantly associated with this serovar $\left(\chi^{2}=72.33, \mathrm{df}=5, \mathrm{P}<0.001\right)$.

Mare, stallion and gelding formed three different categories under the variable gender. This variable was also analysed for a possible association with serovar Bratislava. However stallions were underrepresented (Table 4.7). Mares had a seroprevalence of $27.75 \%$ for serovar Bratislava, while stallions and geldings had a prevalence of $50 \%$ and $17.84 \%$ respectively. The difference between genders was significant $\left(\chi^{2}=11.43, \mathrm{df}=2, \mathrm{P}<0.001\right)$. Therefore, the variable gender was associated significantly with seropositivity to serovar Bratislava.

Age of sampled horses ranged from 1 to 30 years old with a median of 11 years old. Horses were then classified into three age groups (1-6, 7-15, 16+) and the seroprevalence to serovar Bratislava was calculated for each age group and analysed to assess if age was associated with this serovar. Although the results showed that seroprevalence increases with the increase of age, there was no statistically significant difference among the three age groups $\left(\chi^{2}=2.60, \mathrm{df}=2, \mathrm{P}=0.27\right)$. The highest seroprevalence $(28.57 \%)$ to this serovar was found among the last age group (16+) (Table 4.7).

The variable "use" was also used to accommodate six different categories of horses based on the activity they performed: breeding, racing, work horse, general pleasure, equestrian events or other activities. This variable was also analysed for a possible association with the seropositivity to Bratislava serovar for each category using the Chi-square test. The highest seroprevalence (65.38\%) was found among the "Others" category. There was a statistically significant difference with respect to activity of horses $\left(\chi^{2}=57.33\right.$, $\left.\mathrm{df}=5, \mathrm{P}<0.001\right)$. Therefore, variable "use" was significantly associated with seropositivity to serovar Bratislava. 
Table 4.7 Seroprevalence of serovar Bratislava by horse demographic factors and use of 663 horses in three provinces and univariable results.

\begin{tabular}{|c|c|c|c|c|c|c|}
\hline & & $\begin{array}{l}\text { No. of } \\
\text { positive } \\
\text { horses }\end{array}$ & & & & \\
\hline Variables & $\begin{array}{l}\text { No. of } \\
\text { horse } \\
\text { tested }\end{array}$ & $\geq 1: 100$ & AP (\%) & $\chi^{2}$ & df & $\begin{array}{l}\text { P- } \\
\text { value }\end{array}$ \\
\hline Gender $^{a}$ & & & & 11.43 & 2 & $<0.001$ \\
\hline Females & 364 & 101 & 27.75 & & & \\
\hline Stallions & 10 & 5 & 50 & & & \\
\hline Gelding & 241 & 43 & 17.84 & & & \\
\hline Breed $^{\mathrm{b}}$ & & & & 72.33 & 5 & $<0.001$ \\
\hline Arabian & 32 & 5 & 15.62 & & & \\
\hline Nooitgedacht & 63 & 42 & 66.67 & & & \\
\hline Pony & 57 & 11 & 19.3 & & & \\
\hline Thoroughbred & 332 & 65 & 19.58 & & & \\
\hline Warmblood & 47 & 5 & 10.64 & & & \\
\hline Others & 84 & 22 & 26.19 & & & \\
\hline Age $^{c}$ & & & & 2.60 & 2 & 0.27 \\
\hline Group 1 (1-6 years) & 103 & 28 & 27.18 & & & \\
\hline $\begin{array}{l}\text { Group } 2 \text { (7-15 } \\
\text { years) }\end{array}$ & 359 & 80 & 22.28 & & & \\
\hline Group $3(16+$ years $)$ & 140 & 40 & 28.57 & & & \\
\hline Use $^{d}$ & & & & 57.33 & 5 & $<0.001$ \\
\hline Breeding & 171 & 35 & 20.47 & & & \\
\hline Work horse & 60 & 11 & 18.33 & & & \\
\hline Equestrian events & 208 & 51 & 24.52 & & & \\
\hline General pleasure & 101 & 16 & 15.84 & & & \\
\hline Others & 52 & 34 & 65.38 & & & \\
\hline Racing & 23 & 2 & 8.69 & & & \\
\hline
\end{tabular}

\subsubsection{Geographic and environmental factors}

Annual average temperature and annual average rainfall that the properties received were used as variables. Annual average temperature of the properties in the three provinces ranged from $21.5^{\circ} \mathrm{C}$ to $26.7^{\circ} \mathrm{C}$ with a median of $26^{\circ} \mathrm{C}$. Horses were grouped into three categories based on the annual average temperature their properties received. The group with annual average temperature ranging from 21.5 to $23.9^{\circ} \mathrm{C}$ was considered as a low temperature group whereas the groups with annual average temperature ranging from $24-25.9$ and $\geq 26^{\circ} \mathrm{C}$ were considered as medium and high temperature groups, respectively (Table 4.8). The proportion of seropositive horses to serovar Bratislava was calculated for those categories. There was 
no significant difference between the three categories of temperature $\left(\chi^{2}=0.18\right.$, $\mathrm{df}=2$, $\mathrm{P}=0.91)$.

Similarly, horses were grouped into three categories based on the average annual precipitation their properties received. Average annual rainfall received by the properties in the three provinces ranged from $395.6 \mathrm{~mm}$ to $1050.6 \mathrm{~mm}$ with a median of $625.6 \mathrm{~mm}$. The three categories were classified as low average annual rainfall $(0-600 \mathrm{~mm})$, medium average annual rainfall (600-1000 $\mathrm{mm})$ and high average annual rainfall $(>1000 \mathrm{~mm})$ (Table 4.8). The seroprevalence to serovar Bratislava was calculated for these three groups and analysed using the Chi-square test. Rainfall was associated with horses that had antibodies to serovar Bratislava (Yates' $\chi^{2}=28.14$, df $=2, \mathrm{P}<0.001$ ).

Agricultural activities in the vicinity of horse-properties were considered as another variable. The different categories that formed part of this variable were: Forestry, fruit trees, sugarcane and other. This variable "agricultural activities" was found to be significantly associated with horses seropositive to serovar Bratislava after analysis using the Chi-square test (Yates' $\left.\chi^{2}=50.09, \mathrm{df}=3, \mathrm{P}<0.001\right)$.

Province was also considered as a variable with three categories, each one representing the name of the province. Proportion of seropositive horses to serovar Bratislava was calculated for those categories (Table 4.8). The variable "Province" was significantly associated with seropositivity of horses to serovar Bratislava after analysis using the Chi-square test $\left(\chi^{2}=\right.$ 10.27, $\mathrm{df}=2, \mathrm{P}=0.006)$. 
Table 4.8 Seroprevalence of serovar Bratislava by geographic and environmental factors in three provinces and univariable results.

\begin{tabular}{|c|c|c|c|c|c|c|}
\hline & & $\begin{array}{l}\text { No. of } \\
\text { positive } \\
\text { horses }\end{array}$ & & & & \\
\hline Variables & $\begin{array}{l}\text { No. of } \\
\text { horses } \\
\text { tested }\end{array}$ & $\geq 1: 100$ & AP (\%) & $\chi^{2}$ & df & $\begin{array}{l}\text { P- } \\
\text { value }\end{array}$ \\
\hline Temperature $^{a}$ & & & & 0.18 & 2 & 0.91 \\
\hline Low & 179 & 43 & 24.02 & & & \\
\hline Medium & 82 & 21 & 25.6 & & & \\
\hline High & 311 & 80 & 25.72 & & & \\
\hline Avg annual rainfall b & & & & 28.14 & 2 & $<0.001$ \\
\hline Low & 162 & 62 & 38.27 & & & \\
\hline Medium & 431 & 86 & 19.95 & & & \\
\hline High & 34 & 2 & 5.88 & & & \\
\hline \multicolumn{7}{|c|}{ Agricultural activity ${ }^{c}$} \\
\hline Forestry & 25 & 20 & 80 & 50.09 & 3 & $<0.001$ \\
\hline Fruit trees & 100 & 22 & 22 & & & \\
\hline Sugarcane & 104 & 13 & 12.5 & & & \\
\hline Other & 363 & 90 & 24.79 & & & \\
\hline Province $^{d}$ & & & & 10.27 & 2 & 0.006 \\
\hline Kwazulu Natal & 172 & 41 & 23.84 & & & \\
\hline Gauteng & 295 & 86 & 29.15 & & & \\
\hline Western Cape & 194 & 32 & 16.49 & & & \\
\hline
\end{tabular}

${ }^{\mathrm{a}}$ For ninety one horses, information on average annual temperature was missing. ${ }^{\mathrm{b}}$ For thirty six horses, information on average annual rainfall was missing. ${ }^{c}$ For seventy one horses, information on agricultural activity was missing. ${ }^{\mathrm{d}}$ For two horses, information on the province was missing

\subsubsection{Management factors}

Presence of other animals (cattle, small ruminants, pigs, dogs, wild animals or other species) in the vicinity of the horse-property had a significant influence on the status of the property being seropositive to serovar Bratislava. Many horse-properties had more than one of these species either sharing the pasture or present in the neighbourhood. The presence of other species of animals in the vicinity was analysed individually using the Yates' corrected Chisquare test. Of these species, presence of cattle (Yates' $\chi^{2}=2.45$, $\mathrm{df}=1, \mathrm{P}=0.12$ ), small ruminants (Yates' $\chi^{2}=8.45$, $\mathrm{df}=1, \mathrm{P}=0.003$ ), dogs (Yates' $\chi^{2}=4.55, \mathrm{df}=1, \mathrm{P}=0.03$ ) and pigs (Yates' $\chi^{2}=21.24$, $\mathrm{df}=1, \mathrm{P}<0.001$ ) were significantly associated with seropositivity to serovar Bratislava in horses. The highest seroprevalence (45.69\%) was found in horses with pigs in the neighbourhood (Table 4.9).

Bore hole water, dam water, municipal water and river were the main four sources of water for the horses used in this survey. Some horses had more than one source of water. The 
proportion of seropositive horses using bore hole water was higher compared to those that used other sources (Table 4.9). The variable source of water had no significant association with seropositivity of horses to serovar Bratislava when analysed using the Yate's corrected Chi-square test (Yates' $\chi^{2}=3.70, \mathrm{df}=4, \mathrm{P}=0.45$ ). Similarly, difference in the proportion of seropositive horses whose owners claimed to have rodents on the property was not significant compared to horses without rodents on the property (Yates' $\chi^{2}=0.43$, df $=1$, $\mathrm{P}=0.51)$.

Table 4.9 Seroprevalence of serovar Bratislava by management factors and use of 663 horses in three provinces and results of univariable analysis.

\begin{tabular}{|c|c|c|c|c|c|c|}
\hline & & $\begin{array}{l}\text { No. of } \\
\text { positive } \\
\text { horses }\end{array}$ & & & & \\
\hline Variables & $\begin{array}{l}\text { No. of } \\
\text { horses } \\
\text { tested }\end{array}$ & $\geq 1: 100$ & AP (\%) & $\chi^{2}$ & df & $\begin{array}{l}\text { P- } \\
\text { value }\end{array}$ \\
\hline \multicolumn{7}{|l|}{$\begin{array}{l}\text { Other animals in } \\
\text { the vicinity }\end{array}$} \\
\hline Cattle & 329 & 102 & 31 & 2.45 & 1 & 0.12 \\
\hline Small ruminants & 42 & 4 & 9.52 & 8.45 & 1 & 0.003 \\
\hline Dogs & 17 & 1 & 5.88 & 4.55 & 1 & 0.03 \\
\hline Pigs & 116 & 53 & 45.69 & 21.24 & 1 & $<0.001$ \\
\hline Wild animals & 10 & 2 & 20 & 0.4 & 1 & 0.53 \\
\hline Others & 83 & 22 & 26.5 & 0.28 & 1 & 0.59 \\
\hline Water source ${ }^{b}$ & & & & 3.70 & 4 & 0.45 \\
\hline Bore hole & 314 & 80 & 25.48 & & & \\
\hline Dam + Bore hole & 12 & 3 & 25 & & & \\
\hline Municipal & 88 & 17 & 19.32 & & & \\
\hline River & 201 & 50 & 24.87 & & & \\
\hline Dam water & 14 & 1 & 7.14 & & & \\
\hline Rodent problem ${ }^{c}$ & & & & 0.43 & 1 & 0.51 \\
\hline No & 54 & 11 & 20.37 & & & \\
\hline Yes & 575 & 140 & 24.35 & & & \\
\hline
\end{tabular}

${ }^{a}$ For two hundred and four horses, information on other species of animals around the horseproperties was missing. ${ }^{b}$ For thirty four horses, information on water source was missing. ${ }^{\mathrm{c}}$ For thirty four horses, information on rodent problem was missing.

\subsubsection{Disease history and association with serovar Bratislava.}

During the telephonic interview, the owners were asked if their horses had exhibited some clinical signs like ocular disease, kidney disease, high fever, jaundice and abortion which are the main clinical signs for equine leptospirosis. None of those clinical signs was associated with seropositive horses to serovar Bratislava after analysis and of all the sampled horses, no horse was said to have kidney disease. 
Table 4.10 Seroprevalence of serovar Bratislava by clinical signs horses exhibited in recent past in three provinces and univariable results.

\begin{tabular}{|c|c|c|c|c|c|c|}
\hline \multirow[b]{2}{*}{ Variables } & \multirow[b]{2}{*}{$\begin{array}{l}\text { No. horse } \\
\text { tested }\end{array}$} & \multicolumn{5}{|l|}{$\begin{array}{l}\text { No. of } \\
\text { positive } \\
\text { horses }\end{array}$} \\
\hline & & $\geq 1: 100$ & AP (\%) & $\chi^{2}$ & df & $\begin{array}{l}\text { P- } \\
\text { value }\end{array}$ \\
\hline Ocular & & & & 1.59 & 1 & 0.21 \\
\hline disease $^{a}$ & & & & & & \\
\hline Yes & 41 & 7 & 17.07 & & & \\
\hline No & 414 & 114 & 27.54 & & & \\
\hline High fever ${ }^{b}$ & & & & 0.98 & 2 & 0.61 \\
\hline Yes & 13 & 3 & 23.07 & & & \\
\hline No & 433 & 116 & 28.46 & & & \\
\hline Not known & 18 & 3 & 16.66 & & & \\
\hline Abortion ${ }^{c}$ & & & & 0.04 & 1 & 0.84 \\
\hline Yes & 2 & 0 & 0 & & & \\
\hline No & 258 & 82 & 31.78 & & & \\
\hline Stillbirth $^{d}$ & 121 & 45 & 37.19 & 0.22 & 1 & 0.64 \\
\hline Yes & 1 & 1 & 100 & & & \\
\hline No & 257 & 73 & 28.4 & & & \\
\hline
\end{tabular}




\section{5. Significant Risk Factors to serovar Bratislava and Multivariable Logistic Regression Analysis}

The following risk factors were found to be significantly associated with seropositivity to serovar Bratislava after analysis using the Chi-square test in the three provinces:
i. Province
ii. Gender
iii. Breed
iv. Use
v. Pigs in the vicinity of horse-properties
vi. Dogs in the vicinity of horse-properties
vii. Small ruminants in the vicinity of horse-properties
viii. Amount of rainfall each property received
ix. Agricultural activities around the horse-properties

Factor "dogs in the vicinity of horse-properties" was excluded from the multivariable logistic regression model as it had a lot of missing values. The remaining risk factors were further modelled using multivariable logistic regression to arrive at the set of factors that best predicted the outcome of being seropositive to serovar Bratislava. In the process, other factors (province, gender, use, pigs and small ruminants in the vicinity of horse-properties and amount of rainfall each property received) were removed from the model by backward elimination as they were not significant on the Wald test $\left(\mathrm{P}_{\text {Wald }}>0.15\right)$. As a result, the final model was left with two factors (1) agricultural activities and (2) breed (Table 4.11). In the final model, horse-properties surrounded by "forestry" were at greater risk of having seropositive horses to serovar Bratislava (OR=9.3). Similarly, the odds that the breed "Nooitgedacht” becoming seropositive to serovar Bratislava was 5 times higher compared to other breeds of horses $(\mathrm{OR}=5.08)$. 
Table 4.11: Results of multivariable logistic regression analysis of the final model

\section{Run Summary}

Item

Dependent Variable

Reference Group

Number of Groups

Frequency Variable

Numeric Ind. Variables

Categorical Ind. Variables

Final Log Likelihood

Model R ${ }^{2}$

Actual Convergence

Target Convergence

Model D.F.

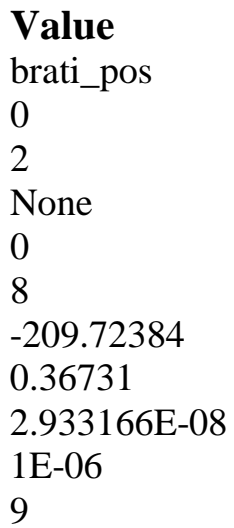

\section{Classification Table}

\section{Estimated}

$\begin{array}{lrrr}\text { Actual } & \mathbf{0} & \mathbf{1} & \text { Total } \\ \mathbf{0} & 221 & 72 & 293 \\ \mathbf{1} & 42 & 83 & 125 \\ \text { Total } & 263 & 155 & 418\end{array}$

Item

Rows Processed 663

Rows Used 418

Rows for Validation $\quad 0$

Rows X's Missing 243

Rows Freq Miss. or $0 \quad 0$

Rows Prediction Only 2

Unique Row Patterns 120

Sum of Frequencies $\quad 418$

Likelihood Iterations 5

Maximum Iterations 20

Completion Status Normal Completion

Percent Correctly classified $=72.7 \%$

\section{Estimated Logistic Regression Model(s)}

Model For brati_pos $=1$

$.77+2.23 *$ (agric_details | Forestry - Other) -.58*(agric_details | Fruitrees - Other) -

$.78 *$ (agric_details | Surgacane - Other) $+.26 *($ breed_details $\mid$ Arabian - Other) +

$1.62 *$ (breed_details | Nooitgedacht - Other) -.21*(breed_details | Pony - Other) -

$.82 *$ (breed_details | Thoroughbred - Other) -1.06*(breed_details | Warmblood - Other)

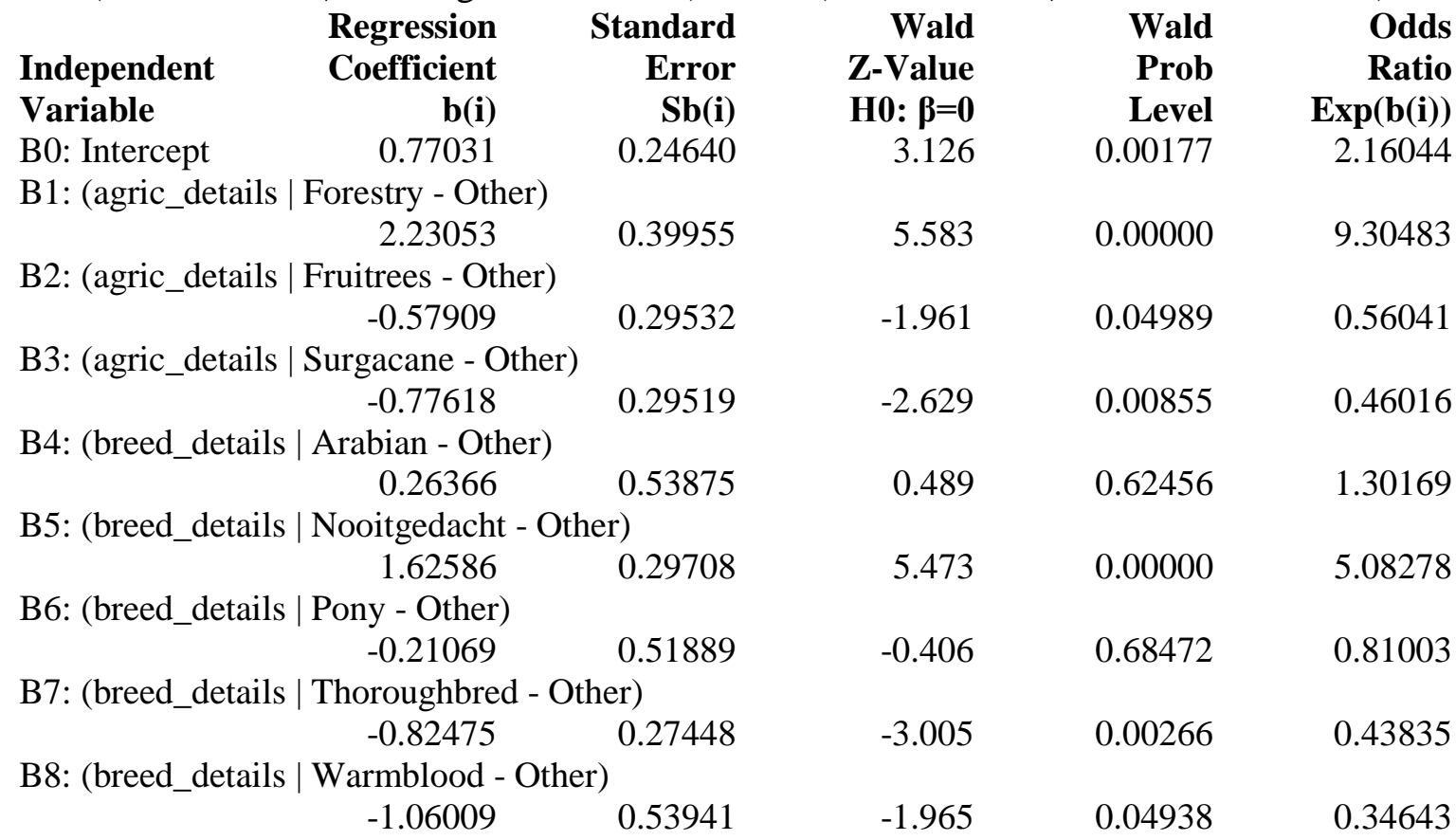

It becomes apparent that only two factors contributed significantly to the outcome of horses being seropositive to the serovar Bratislava. Those two factors were (1) forestry in the vicinity of the horse-properties and (2) Nooitgedacht as a breed of horse. 
4.6 Univariable analysis of risk factors for association with seropositivity of horses to Leptospira spp

A parallel univariable analysis of risk factors that may be associated with seropositivity of horses to Leptospira irrespective of serovar was done using the Chi-square test. These risk factors were categorized the same way as for the initial analysis that looked for association to seropositivity to serovar Bratislava. The following tables summarize the results of this analysis:

Table 4.12 Seroprevalence of Leptospira spp by horse demographic factors and use of 663 horses in three provinces and univariable results.

\begin{tabular}{|c|c|c|c|c|c|c|}
\hline & & $\begin{array}{l}\text { No. of } \\
\text { positive } \\
\text { horses }\end{array}$ & & & & \\
\hline Variables & $\begin{array}{l}\text { No. of } \\
\text { horse } \\
\text { tested }\end{array}$ & $\geq 1: 100$ & AP (\%) & $\chi^{2}$ & df & $\begin{array}{l}\text { P- } \\
\text { value }\end{array}$ \\
\hline Gender $^{a}$ & & & & 13.68 & 2 & 0.001 \\
\hline Females & 365 & 172 & 47.12 & & & \\
\hline Stallions & 10 & 6 & 60 & & & \\
\hline Gelding & 241 & 79 & 32.78 & & & \\
\hline Breed $^{\mathrm{b}}$ & & & & 81.16 & 5 & $<0.001$ \\
\hline Arabian & 32 & 14 & 43.75 & & & \\
\hline Nooitgedacht & 64 & 57 & 89.06 & & & \\
\hline Pony & 57 & 21 & 36.84 & & & \\
\hline Thoroughbred & 332 & 105 & 31.63 & & & \\
\hline Warmblood & 47 & 15 & 31.91 & & & \\
\hline Others & 84 & 46 & 54.76 & & & \\
\hline Age $^{c}$ & & & & 1.26 & 2 & 0.53 \\
\hline Group 1 (1-6 years) & 103 & 41 & 39.80 & & & \\
\hline Group 2 (7-15 & 359 & 148 & 41.22 & & & \\
\hline years) & & & & & & \\
\hline Group 3 (16+ years) & 141 & 65 & 46.09 & & & \\
\hline Use $^{\mathrm{d}}$ & & & & 56.52 & 5 & $<0.001$ \\
\hline Breeding & 172 & 62 & 36.05 & & & \\
\hline Work horse & 60 & 25 & 41.66 & & & \\
\hline Equestrian events & 208 & 77 & 37.02 & & & \\
\hline General pleasure & 101 & 43 & 42.57 & & & \\
\hline Others & 52 & 46 & 88.46 & & & \\
\hline Racing & 23 & 4 & 17.39 & & & \\
\hline
\end{tabular}

${ }^{a}$ For forty seven horses, information on gender was missing. ${ }^{b}$ For forty seven horses, information on breed was missing. ${ }^{\mathrm{c}}$ For sixty horses, information on age was missing. ${ }^{\mathrm{d}}$ For forty seven horses, information on use was missing.

Gender was significantly associated with horses being seropositive to Leptospira $\left(\chi^{2}=13.68\right.$, $\mathrm{df}=2, \mathrm{P}=0.001$ ) after analysis using the Chi-square test (Table 4.12). Stallions had the highest seroprevalence (60\%) but constituted only a small sample of horses. Variables 
"breed" and "use” were also significantly associated with horses being seropositive to Leptospira after analysis using the Chi-square test $\left(\chi^{2}=81.16\right.$, $\mathrm{df}=5, \mathrm{P}<0.001$ and $\chi^{2}=$ 56.52, $\mathrm{df}=5, \mathrm{P}<0.001$ respectively).

Table 4.13 Seroprevalence of Leptospira spp by geographic and environmental factors in three provinces and univariable results.

\begin{tabular}{|c|c|c|c|c|c|c|}
\hline & & $\begin{array}{l}\text { No. of } \\
\text { positive } \\
\text { horses }\end{array}$ & & & & \\
\hline Variables & $\begin{array}{l}\text { No. of } \\
\text { horses } \\
\text { tested }\end{array}$ & $\geq 1: 100$ & AP (\%) & $\chi^{2}$ & df & $\begin{array}{l}\mathbf{P}- \\
\text { value }\end{array}$ \\
\hline Temperature $^{\mathrm{a}}$ & & & & 4.35 & 2 & 0.18 \\
\hline Low & 179 & 67 & 37.43 & & & \\
\hline Medium & 82 & 33 & 40.24 & & & \\
\hline High & 312 & 146 & 46.79 & & & \\
\hline Avg annual rainfall b & & & & 22.74 & 2 & $<0.001$ \\
\hline Low & 163 & 92 & 56.44 & & & \\
\hline Medium & 431 & 157 & 36.43 & & & \\
\hline High & 34 & 9 & 26.47 & & & \\
\hline \multicolumn{7}{|c|}{ Agricultural activity c } \\
\hline Forestry & 25 & 20 & 80 & 25.57 & 3 & $<0.001$ \\
\hline Fruit trees & 100 & 36 & 36 & & & \\
\hline Sugarcane & 104 & 29 & 27.88 & & & \\
\hline Other & 364 & 161 & 44.23 & & & \\
\hline \multicolumn{7}{|l|}{ Province ${ }^{d}$} \\
\hline Gauteng & 296 & 145 & 48.99 & 14.99 & 2 & $<0.001$ \\
\hline Kwazulu Natal & 172 & 63 & 36.63 & & & \\
\hline Western Cape & 194 & 63 & 32.47 & & & \\
\hline
\end{tabular}

${ }^{a}$ For ninety horses, information on average annual temperature was missing. ${ }^{b}$ For thirty five horses, information on average annual rainfall was missing. ${ }^{c}$ For seventy horses, information on agricultural activity was missing. ${ }^{d}$ For one horse, information on province was missing.

Although a high seroprevalence (46.79\%) was found in the group of horses whose properties received a high average annual temperature (Table 4.13), there was no statistical difference between the three groups of temperature $\left(\chi^{2}=4.35, \mathrm{df}=2, \mathrm{P}=0.18\right)$. The variable "average annual rainfall” was significantly associated with horses being seropositive to Leptospira $\left(\chi^{2}\right.$ $=22.74, \mathrm{df}=2, \mathrm{P}<0.001)$. The number of horses that came from properties that received a high average annual rainfall was however small, compared to other groups (Table 4.13). Agriculture activity around the horse-properties was also significantly associated with horses being seropositive to Leptospira spp $\left(\chi^{2}=25.57, \mathrm{df}=3, \mathrm{P}<0.001\right)$. Horses neighbouring "forestry" as the main agricultural activity had the highest seroprevalence (80\%). Similarly, the variable "Province" was also significantly associated with seropositivity of horses to Leptospira $\left(\chi^{2}=14.99, \mathrm{df}=2, \mathrm{P}<0.001\right)$. Gauteng Province had the highest seroprevalence (48.99\%) compared to other Provinces (Table 4.13). 
Table 4.14 Seroprevalence of Leptospira spp by management factors in three provinces and results of univariable analysis.

\begin{tabular}{|c|c|c|c|c|c|c|}
\hline \multirow[b]{2}{*}{ Variables } & \multirow[b]{2}{*}{$\begin{array}{l}\text { No. of } \\
\text { horses } \\
\text { tested }\end{array}$} & \multicolumn{5}{|l|}{$\begin{array}{l}\text { No. of } \\
\text { positive } \\
\text { horses }\end{array}$} \\
\hline & & $\geq 1: 100$ & AP (\%) & $\chi^{2}$ & df & $\begin{array}{l}\text { P- } \\
\text { value }\end{array}$ \\
\hline \multicolumn{7}{|l|}{$\begin{array}{l}\text { Other animals in } \\
\text { the vicinity }{ }^{a}\end{array}$} \\
\hline Cattle & 329 & 161 & 48.94 & 4.02 & 1 & 0.04 \\
\hline Small ruminants & 42 & 11 & 26.19 & 7.29 & 1 & 0.006 \\
\hline Dogs & 17 & 3 & 17.65 & 5.7 & 1 & 0.02 \\
\hline Pigs & 116 & 82 & 70.69 & 38.08 & 1 & $<0.001$ \\
\hline Wild animals & 10 & 3 & 30 & 1.04 & 1 & 0.3 \\
\hline Other & 84 & 34 & 40.48 & 1.25 & 1 & 0.26 \\
\hline Water source $^{\text {b }}$ & & & & 4.4 & 4 & 0.35 \\
\hline Bore hole & 315 & 138 & 43.8 & & & \\
\hline Dam + Bore hole & 12 & 3 & 25 & & & \\
\hline Municipal & 88 & 31 & 35.23 & & & \\
\hline River & 201 & 83 & 41.29 & & & \\
\hline Dam water & 14 & 4 & 28.57 & & & \\
\hline Rodent problem ${ }^{c}$ & & & & 2.26 & 1 & 0.13 \\
\hline No & 54 & 17 & 31.48 & & & \\
\hline Yes & 576 & 242 & 42.01 & & & \\
\hline
\end{tabular}

${ }^{a}$ For two hundred and three horses, information on other species of animals around the horseproperties was missing. ${ }^{\mathrm{b}}$ For thirty three horses, information on water source was missing. ${ }^{\mathrm{c}}$ For thirty three horses, information on rodent problem was missing.

Cattle $\left(\chi^{2}=4.02, \mathrm{df}=1, \mathrm{P}=0.04\right)$, small ruminants $\left(\chi^{2}=7.29, \mathrm{df}=1, \mathrm{P}=0.006\right)$, dogs $\left(\chi^{2}\right.$ $=5.7, \mathrm{df}=1, \mathrm{P}=0.02)$ and pigs $\left(\chi^{2}=38.08, \mathrm{df}=1, \mathrm{P}<0.001\right)$ were species of animals neighbouring horse-properties and significantly associated with seropositivity to Leptospira in horses when analysing using the Chi-square test (Table 4.14). Properties whose owners claimed to have pigs in the vicinity had the highest seroprevalence (70.69\%).

Although, proportion of seropositive horses in those that used bore hole water was higher (Table 4.14) compared to those that used other sources, when analysed individually in a 2x2 table using the Yates' corrected Chi-square test, none of the sources had a significant association with seropositivity of horses to Leptospira $\left(\chi^{2}=4.4\right.$, $\left.\mathrm{df}=4, \mathrm{P}=0.35\right)$.

Having rodents on the property was also significantly associated with horses being seropositive to Leptospira $\left(\chi^{2}=2.26, \mathrm{df}=1, \mathrm{P}=0.13\right.$ ). The high seroprevalence was found among the horse-properties with rodents compared to horse-properties without rodents (42.01\%) (Table 4.14). 
Table 4.15 Seroprevalence of Leptospira spp by clinical signs horses exhibited in recent past in three provinces and results of univariable analysis.

\begin{tabular}{|c|c|c|c|c|c|c|}
\hline \multirow[b]{2}{*}{ Variables } & \multirow[b]{2}{*}{$\begin{array}{l}\text { No. horse } \\
\text { tested }\end{array}$} & \multicolumn{5}{|l|}{$\begin{array}{l}\text { No. of } \\
\text { positive } \\
\text { horses }\end{array}$} \\
\hline & & $\geq 1: 100$ & AP (\%) & $\chi^{2}$ & df & $\begin{array}{l}\text { P- } \\
\text { value }\end{array}$ \\
\hline $\begin{array}{l}\text { Ocular } \\
\text { disease }^{\text {a }}\end{array}$ & & & & 0.74 & 1 & 0.39 \\
\hline Yes & 41 & 16 & 39.02 & & & \\
\hline No & 415 & 191 & 46.02 & & & \\
\hline High fever $^{b}$ & & & & 0.99 & 2 & 0.61 \\
\hline Yes & 13 & 6 & 46.15 & & & \\
\hline No & 434 & 196 & 45.16 & & & \\
\hline Not known & 18 & 6 & 33.33 & & & \\
\hline Abortion ${ }^{c}$ & & & & 0.65 & 1 & 0.42 \\
\hline Yes & 2 & 0 & 0 & & & \\
\hline No & 259 & 139 & 53.67 & & & \\
\hline Stillbirth $^{\mathbf{d}}$ & & & & 0.98 & 1 & 0.32 \\
\hline Yes & 1 & 1 & 100 & & & \\
\hline No & 258 & 130 & 50.39 & & & \\
\hline
\end{tabular}

a For two hundred and seven horses, information on ocular disease was missing. ${ }^{\mathrm{b}}$ For hundred ninety eight horses, information on high fever was missing. ${ }^{\mathrm{c}, \mathrm{d}}$ There were 365 females entries, and 104 horses lacked information on abortion and still births.

Analysis of clinical signs horses exhibited in the recent past using the Chi-square test did not show any significant association with seropositivity to Leptospira spp (Table 4.15).

\subsection{Significant Risk Factors to Leptospira spp and Multivariable Logistic Regression} Analysis

The following risk factors were found to be significantly associated with seropositivity of horses to Leptospira spp after analysis using the Chi-square test in three provinces:
i. $\quad$ Province
ii. Gender
iii. Breed
iv. Use
v. Average annual rainfall each property received
vi. Cattle in the vicinity of horse-properties
vii. Pigs in the vicinity of horse-properties
viii. Dogs in the vicinity of horse-properties
ix. Small ruminants in the vicinity of horse-properties
x. Agricultural activities around the horse-properties
xi. Presence of rodents on the horse-properties

Factor “dogs in the vicinity of horse-properties” was excluded from the multivariable logistic regression model as it had a lot of missing values. The remaining risk factors were further 
modelled using multivariable logistic regression to arrive at the set of factors that best predicted the outcome of being seropositive to Leptospira spp. In the process, other factors (province, gender, use, pigs, cattle and small ruminants in the vicinity of horse-properties, average annual rainfall each property received) were removed from the model by backward elimination as they were not significant on the Wald test $\left(\mathrm{P}_{\text {Wald }}>0.15\right)$. As a result, the final model was left with two factors (1) agricultural activities and (2) breed (Table 4.16). In the final model, horse-properties surrounded by "forestry” as agricultural activity were at greater risk of being seropositive to Leptospira $(\mathrm{OR}=5.2)$. Similarly, the breed "Nooitgedacht" was at greater risk of becoming seropositive to Leptospira spp compared with other breeds of horses $(\mathrm{OR}=6.3)$.

\section{Table 4.16: Results of multivariable logistic regression analysis of the final model}

\section{Run Summary}

$\begin{array}{llll}\text { Item } & \text { Value } & \text { Item } & \text { Value } \\ \text { Dependent Variable } & \text { lepto_pos } & \text { Rows Processed } & 663 \\ \text { Reference Group } & 0 & \text { Rows Used } & 419 \\ \text { Number of Groups } & 2 & \text { Rows for Validation } & 0 \\ \text { Frequency Variable } & \text { None } & \text { Rows X's Missing } & 243 \\ \text { Numeric Ind. Variables } & 0 & \text { Rows Freq Miss. or 0 } & 0 \\ \text { Categorical Ind. Variables } & 10 & \text { Rows Prediction Only } & 1 \\ \text { Final Log Likelihood } & -241.11990 & \text { Unique Row Patterns } & 130 \\ \text { Model R } & 0.40635 & \text { Sum of Frequencies } & 419 \\ \text { Actual Convergence } & 9.433616 \mathrm{E}-08 & \text { Likelihood Iterations } & 5 \\ \text { Target Convergence } & 1 \mathrm{E}-06 & \text { Maximum Iterations } & 20 \\ \text { Model D.F. } & 9 & \text { Completion Status } & \text { Normal Completion }\end{array}$

\section{Estimated Logistic Regression Model(s)}

Model For lepto_pos $=1$

$1.02+.46 *$ (breed_details | Arabian - Other) $+1.84 *$ (breed_details | Nooitgedacht - Other) -.70*(breed_details | Pony - Other) $-1.24 *$ (breed_details | Thoroughbred - Other) $.48 *$ (breed_details | Warmblood - Other) $+1.65 *$ (agric_details | Forestry - Other) $.28 *$ (agric_details | Fruitrees - Other) -.68*(agric_details | Surgacane - Other)

\section{Classification Table}

\section{Estimated}

$\begin{array}{lrrr}\text { Actual } & \mathbf{0} & \mathbf{1} & \text { Total } \\ \mathbf{0} & 181 & 39 & 220 \\ \mathbf{1} & 82 & 117 & 199 \\ \text { Total } & 263 & 156 & 419\end{array}$

Percent Correctly classified $=71.1 \%$ 


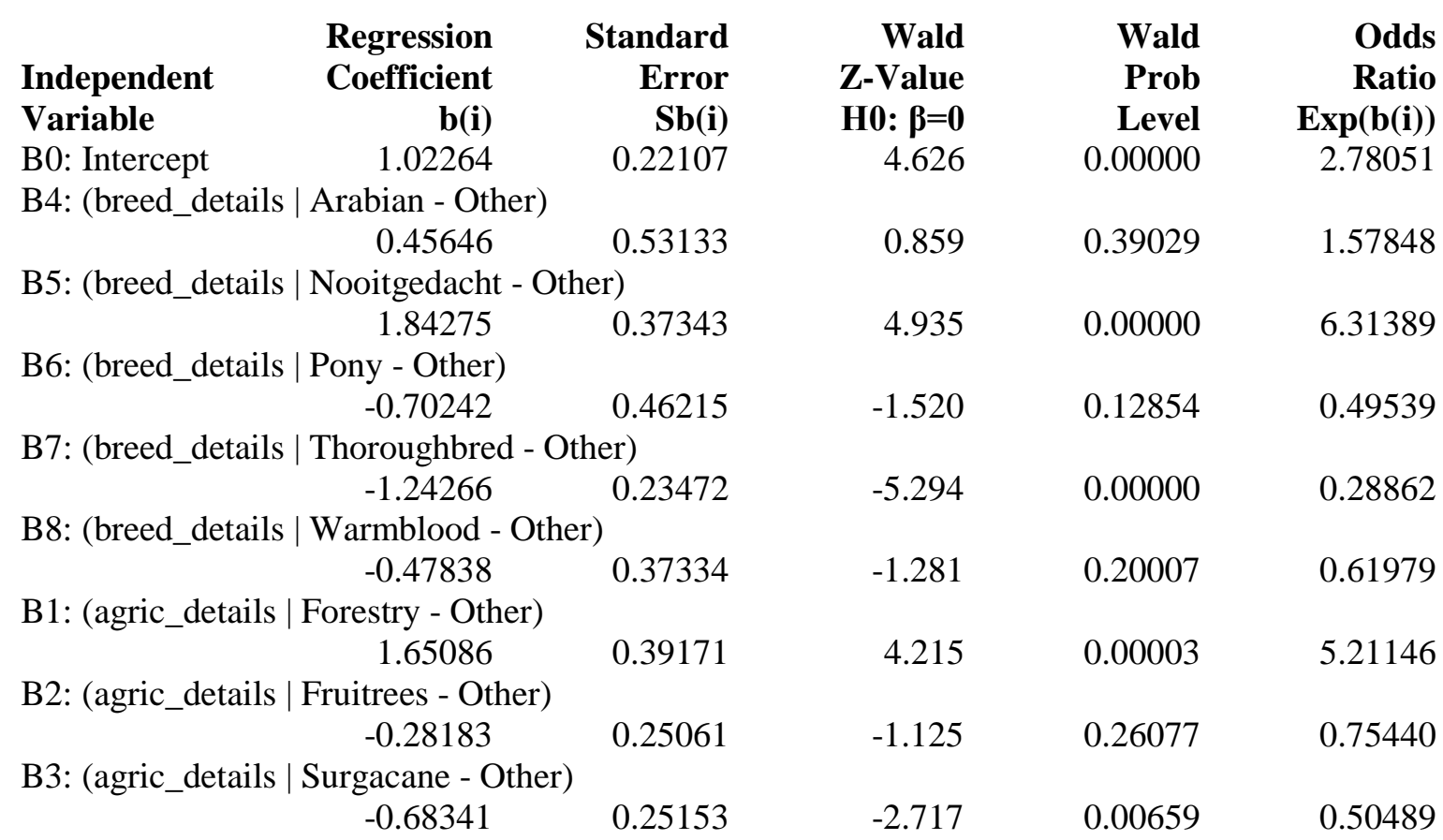

Two factors contributed significantly to the outcome of horses being seropositive to Leptospira spp. Those two factors were (1) "forestry" as agricultural activity in the vicinity of the horse-properties and (2) "Nooitgedacht" as a breed of horse.

Figures 5, 6 and 7 show the proportions of positive horses to Leptospira spp in Gauteng, KZN and Western Cape Provinces, respectively.

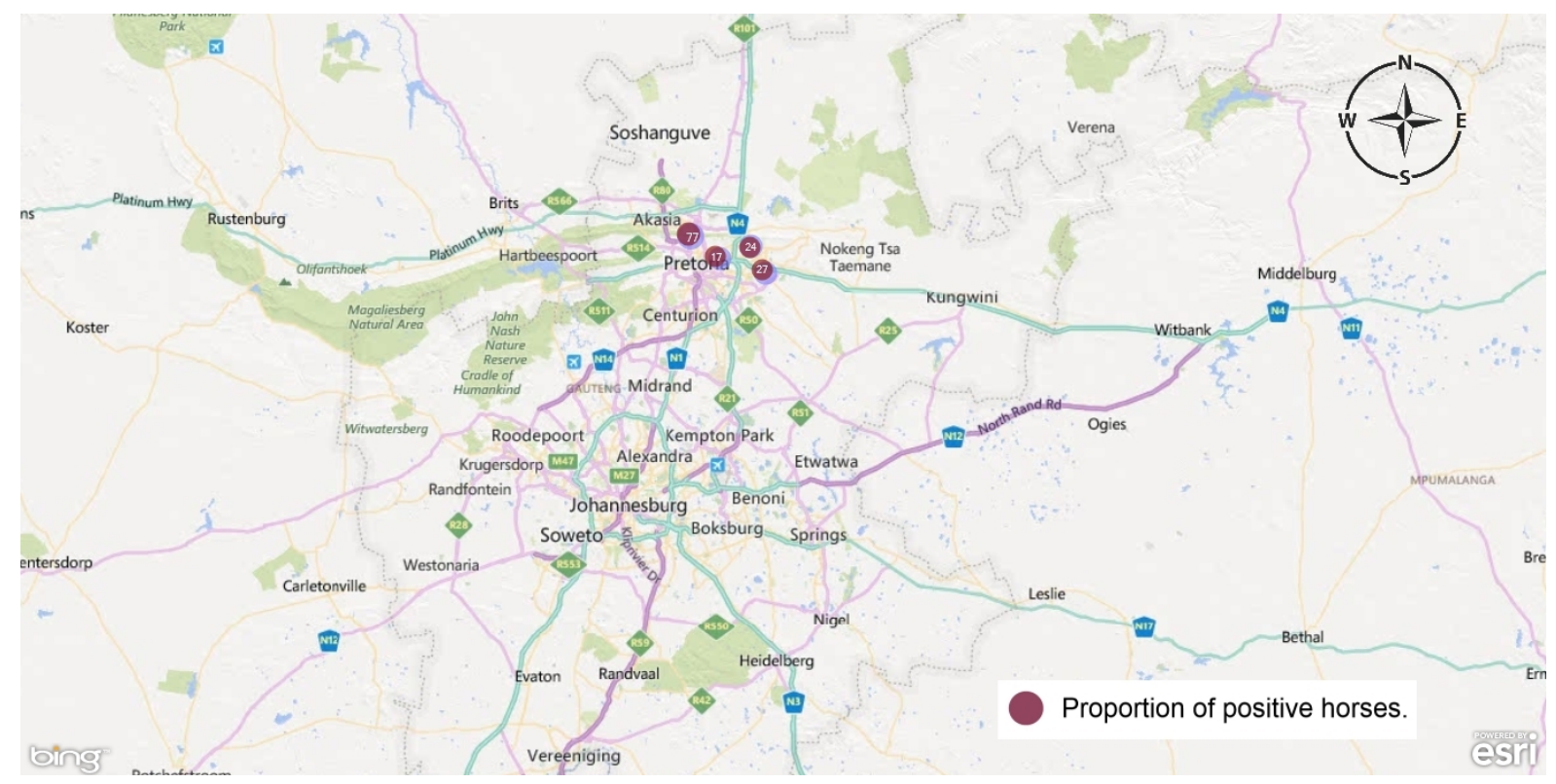

Figure 5 Distribution of sampled horses and proportion of positive horses in Gauteng 


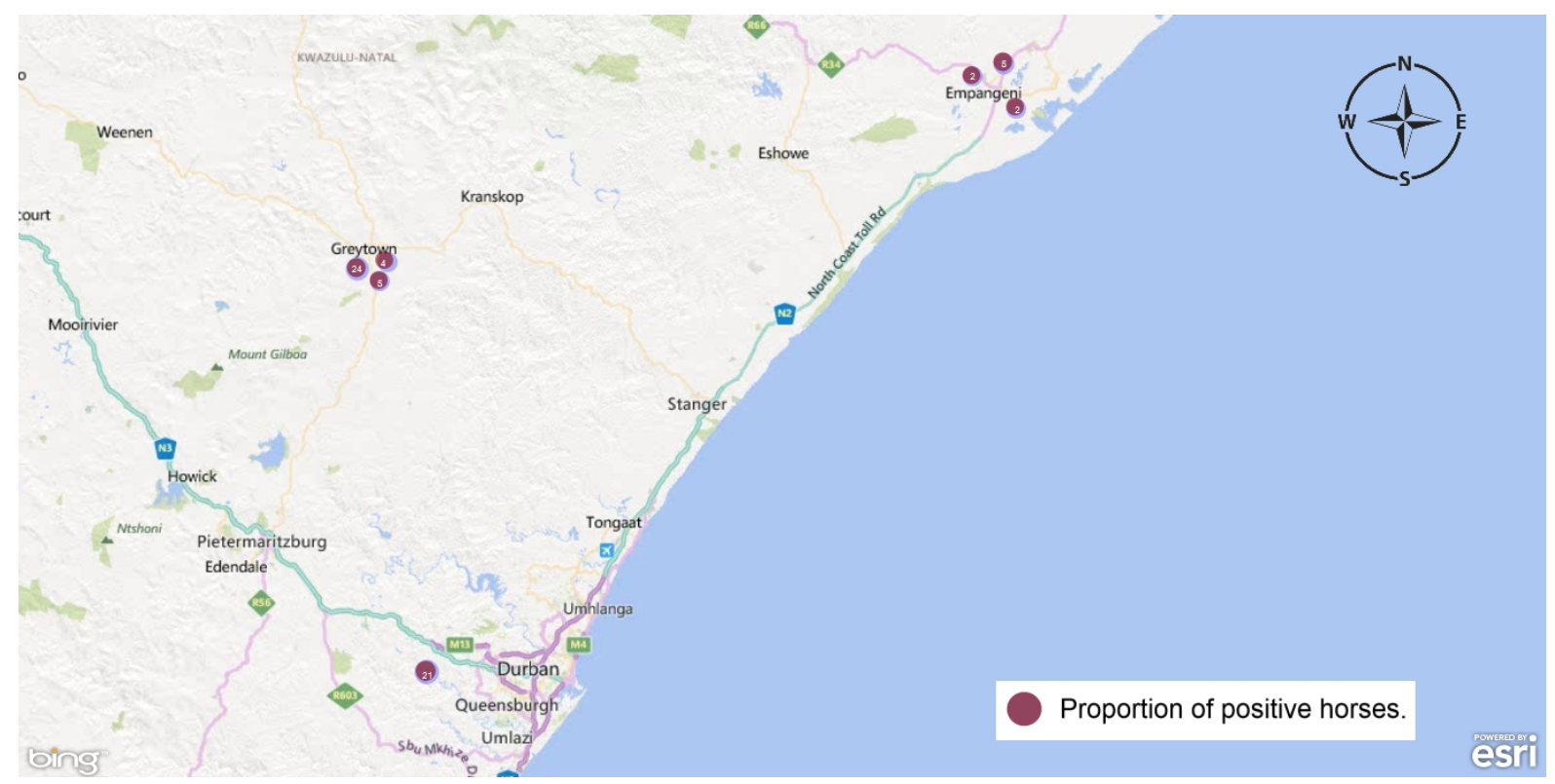

Figure 6 Distribution of sampled horses and proportions of positive horses in KZN

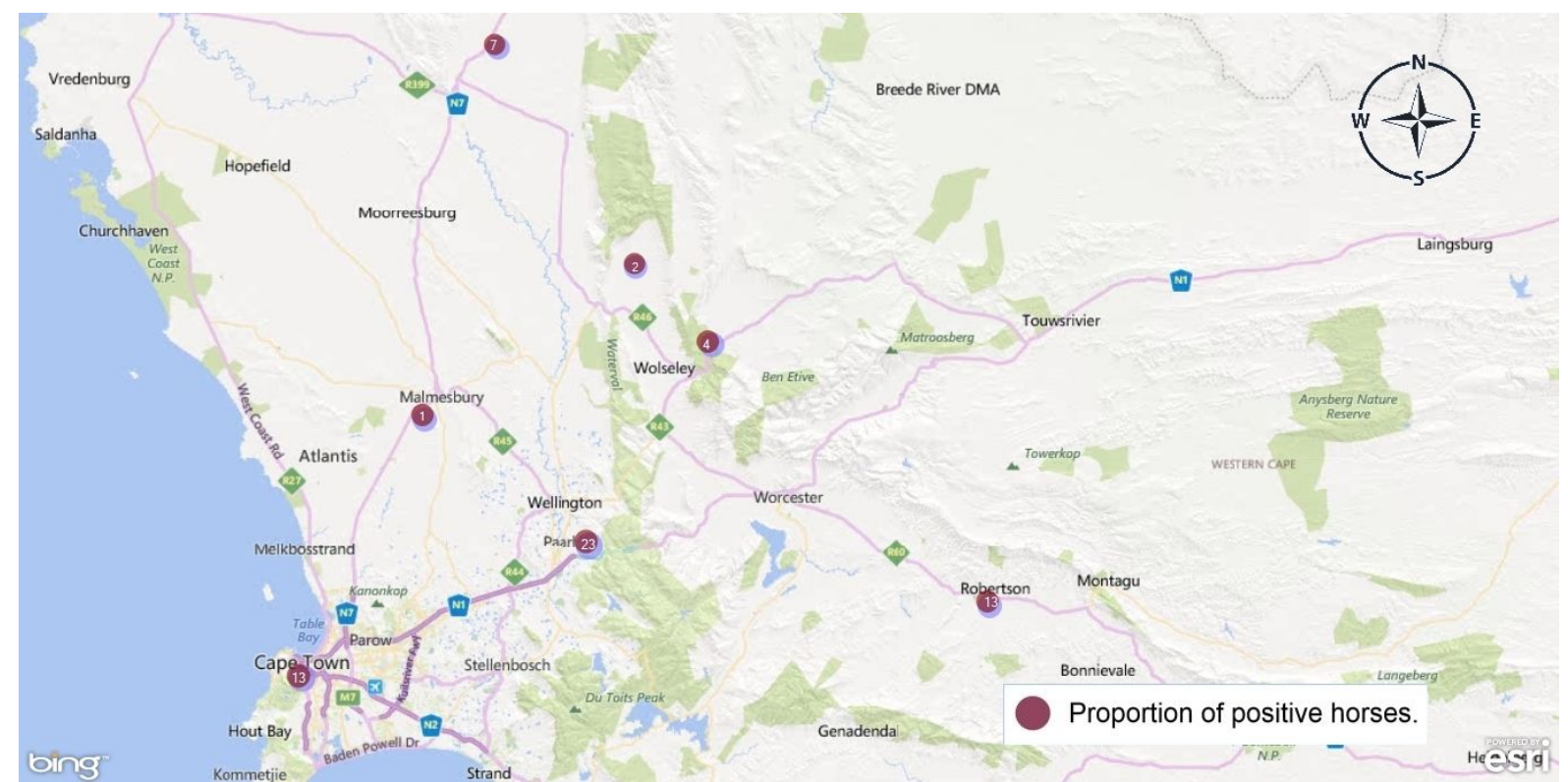

Figure 7 Distribution of sampled horses and proportions of positive horses in the Western Cape Province 


\section{CHAPTER 5}

\section{DISCUSSION}

\subsection{Serovar detection study}

This study detected serovars of Leptospira that were circulating in South African horses with special focus on the horses from Gauteng, Western Cape and KwaZulu-Natal Provinces in the years 2013 and 2014. A random sampling method could not be followed due to the scanty information on the number of properties and the number of horses on each property per province. Furthermore the study design was to consider horses that were admitted to one of the four large equine hospitals or horses seen on ambulatory visit, hence the variations in the number of samples obtained from each province.

Some horses had titers to multiple serovars. This may represent multiple infections or different cross-reactions between serovars from the same serogroups. As an example, serovars Ballum and Arborea both belong to the same serogroup (Ballum) and they react similarly in the MAT (Slack et al. 2006). However, serovar Ballum has never been isolated from any source in South Africa nor was it included in the panel of antigens used. Pending further studies to detect serovar Ballum in South Africa, it was assumed that Arborea seropositive horses were probably only exposed to serovar Arborea. Nine horses (5.7\%) had low titers ranging between 100 and 200 to both serovars Australis (strain Ballico) and Bratislava. The rest of the positive horses had titers to serovar Bratislava only (94.3\%). These two serovars belong to the same serogroup Australis. Although serovar Australis was isolated from dogs in South Africa (Roach et al. 2010), the author believes that the low titers to serovar Ballico were a result of a cross-reaction to serovar Bratislava that may have occurred rather than a multiple infection. Similarly, seven horses (20\%) had titers to both serovars Tarassovi and Topaz which belong to the same serogroup Tarassovi. However, serovar Topaz had higher titers ranging from 200 to 1600 than serovar Tarassovi (100 to 400). Since it is believed that cross-reactivity occurs predominately in lower titers (Barwick et al. 1998), the author believes that this was probably a multiple exposure rather than crossreactivity. Lastly, low titers to serovar Copenhageni were found in the MAT. The author believes that this was probably due to a cross-reaction with serovar Icterohaemorrhagiae as both serovars belong to the same serogroup Icterohaemorrhagiae. The isolation of local strains of Leptospira in South African horses is needed to give better clarification of the serological results. 
It is also important to keep in mind that often the highest detected antibody titre does not represent the infecting serovar. This was described by Levett (2001) as a paradoxical reaction. This particular characteristic of the MAT was also confirmed in a study in Thailand where the MAT was found to be an unreliable predictor of infecting leptospiral serovars (Smythe et al. 2009).

Similarly, a negative serological reaction did not necessarily indicate that horses were free of leptospires. Nevertheless, the MAT results found in this study indicate the level at which horses were exposed to a wide range of leptospiral serovars.

\subsection{Apparent prevalence of Leptospira serovars in three provinces}

The apparent prevalence of Leptospira found in this study appears to be within the same range as other reported findings across the globe. In the present study, the reported apparent prevalence of Leptospira at a serum dilution of 1:100 in Gauteng, KwaZulu-Natal and Western Cape Provinces was 49\%; 37\% and 32\%, respectively. Studies conducted in different parts of the world have reported a prevalence of Leptospira in horses ranging from 12.8\% to 79\% (Park et al. 1992, Barwick et al. 1998, Rocha et al. 2004, Odontsetseg et al. 2005, Jung et al. 2010, Houwers et al. 2011). Within the same region or countries, variations of the prevalence have been also reported like in Brazil (Coiro et al. 2012, de Oliveira Filho et al. 2014), USA (Sillerud et al. 1987, Donahue et al. 1995, Barwick et al. 1998, Donahue and Williams. 2000) and Australia (Swart et al. 1982, Dickeson and Love. 1993, Wangdi et al. 2013). The difference in prevalence between studies may be due to the study area, study population, sampling techniques, environmental conditions, panel of serovars used in the MAT and the interpretation of results in relation to the cut-off used. Although there appears to be a difference in apparent prevalence between the provinces a closer examination of the 95\% confidence interval for true prevalence for each province ( $\mathrm{GP}=24-74$; $\mathrm{WCP}=26-39$; $\mathrm{KZN}=20-54$ ), which accounts for clustering biase, shows a large overlap in true prevalence between the provinces. Indicating that more work needs to be done before one can say whether there is a difference in prevalence between the provinces. In South Africa, the coastal region of KZN would have been expected to have the highest prevalence due to its subtropical climate with high humidity and rainfall. The warm and humid climate along with different other risk factors contribute to the propagation, maintenance and survival of leptospires in the environment. Factors like flooding that occurs from time to time over Gauteng Province (Dyson. 2009, Dyson et al. 2015) and presence of rodents are also associated with higher prevalences, with flooding allowing closer contact between the 
bacteria and the accidental host (Barwick et al. 1997, Levett. 2001, Lau et al. 2010, Bandino et al. 2015). Presence of rodents is discussed further, under management factors.

\subsection{Predominant serovars in three provinces}

Twenty four serovars representing 19 serogroups were used in the MAT. Out of these serovars, 21 serovars from 17 serogroups were detected in this survey. The most predominant serovars in Gauteng were Bratislava; Djasiman and Arborea, in the Western Cape Province, Bratislava; Djasiman and Arborea and in Kwazulu Natal, Bratislava; Arborea and Tarassovi respectively. Serovars Panama, Kremastos and Hebdomadis were not detected in the three provinces. Serovars which were reported for the first time in South African horses in this study were Bratislava, Arborea, Tarassovi, Djasiman, Topaz, Canicola, Javanica, Robinson, Cynopteri, Grippotyphosa, Ballico, Icterohaemorrhagiae, Bulgarica, Celledoni, Hardjo, Zanoni, Swajizak, Bataviae, Mednensis and Shermani. This confirms that horses in South Africa have been exposed to a wide range of previously unknown leptospiral serovars inferring a complex epidemiology.

The three most predominant serovars were almost the same in all three provinces except for KwaZulu-Natal where serovar Tarassovi had the third highest prevalence. The most common serovar in all three provinces was Bratislava. This is not surprising since various studies across the globe have reported the seropredominance of this serovar in their surveys in horses (Odontsetseg et al. 2005, Baverud et al. 2009, Ebani et al. 2012, Turk et al. 2013). However in South Africa, this seems to be the first report in horses. The findings of this study are also in agreement with other studies suspecting that horses may be the maintenance hosts for serovar Bratislava (Ellis et al. 1983, Park et al. 1992, Rocha et al. 2004). The antibody titers of seropositive horses to this serovar ranged from 100 to 800 in general except for Kwazulu Natal where the range was between 100 and 3200. This high range in Kwazulu Natal may indicate more active infection in this Province.

Serovar Arborea was originally described in Italy in 1955 (Kmety and Dikken. 1993). Since then, infection has been reported in humans and animals in different parts of the world including Argentina (Vanasco et al. 2000), New Zealand (Subharat et al. 2011) and Australia (Slack et al. 2006, Slack et al. 2010). Rodents, particularly Mus domesticus and Rattus rattus are believed to be the predominant animal reservoirs for this serovar (Lau et al. 2015). In Australia, it was found to be the most predominant serovar in a recent survey in horses (Wangdi et al. 2013). This serovar was detected in humans in Australia in 1998 and was isolated from rodents from two sites in Queensland (Slack et al. 2006). It was found to be 
significantly associated with pigs and high rainfall in Australia. Since pigs are known to be naturally adapted to serovar Pomona, it was speculated that pigs may have been exposed through mud and flood water due to their poorly developed body heat regulatory mechanisms (Wangdi et al. 2013). It was also reported that this serovar has been emerging in Queensland (Australia) since 2001, with increase in human case numbers as well as expansion of its geographic distribution. Climatic factors (especially flooding) and environmental change were suspected to be the main cause of this emergence (Lau et al. 2015).

Serovar Djasiman was first described in Indonesia and it was believed to be restricted to South-East Asia before. Several cases have been reported in overseas tourists returning from South-East Asia (WHO. 2011). However, a new serovar of serogroup Djasiman isolated from an aborted dog fetus in Argentina has demonstrated that serovars of this serogroup have been distributed to other parts of the world, including South America (Rossetti et al. 2005). The high level of circulating antibodies to this serovar found in this study, ranging from 100 to 1600 indicate that this serovar may not be exotic to South Africa. Further studies regarding the significance of this serovar in South Africa are needed. It may also be useful to raise the awareness of health service practitioners in South Africa with regard to the clinical disease caused by this serovar: a recent case of massive intra-alveolar haemorrhage caused by serovar Djasiman in a 38 years old man returning from Laos is an indication of the severe clinical disease this serovar can cause (Hery et al. 2015).

Serovar Tarassovi which is thought to be maintained by pigs (Alonso-Andicoberry et al. 2001), has been isolated from dogs (Myburgh et al. 1993) and cattle (Hunter. 2004, Hesterberg et al. 2009) in South Africa. However this serovar was not detected in a study of South African pigs (Potts et al. 1995). In Northeastern Mexico, this serovar was found to be the most predominant in cattle (Carvajal-de la Fuente et al. 2012).

Currently, there is no registered vaccine to prevent leptospirosis in horses in South Africa. In the event of equine vaccine development in the future, the four serovars namely Bratislava, Arborea, Djasiman and Tarassovi should be included as the current serological evidence suggest that horses are commonly exposed to these serovars. 


\subsection{Risk factors and their association with serovar Bratislava and Leptospira spp.}

\subsubsection{Demographic factors}

Seroprevalence to serovar Bratislava varied according to breed. Breed was also significantly associated with seropositity of horses to Leptospira spp. In Sweden, ponies and coldbloods had a lower odds ratio of seropositivity to serovar Icterohaemorrhagiae infection compared with other breeds (Baverud et al. 2009). This is also in agreement with the findings from Korea where a low seroprevalence was found in Thoroughbred horses used for racing due to high level of management and care associated with this breed (Jung et al. 2010). In this study, the high seroprevalence of serovar Bratislava was found among Nooitgedacht horses (66.67\%). This breed had also the highest seroprevalence of Leptospira spp compared with other breeds (89.06\%). Interestingly, this breed was also found to be at greater risk of being seropositive to serovar Bratislava $(\mathrm{OR}=5.08)$ and to Leptospira spp $(\mathrm{OR}=6.3)$ in both models. Horses belonging to this breed used in this survey are kept on the premises of the Faculty of Veterinary Science, University of Pretoria. Students use them during practical lessons. Some of these horses serve as blood donors. These horses spend a lot of time outside of their stables. The Onderstepoort Academic Veterinary Hospital is also situated on the same premises. This hospital receives various types of sick animals including exotic birds and wildlife. Some animals (small and large) with severe conditions spend a few days in the hospital before being discharged when they recover. Cattle and small ruminants used for different purposes (practicals, research) are also found on the same premises. Most of Nooitgedacht horses in this study had low titers ranging from 100 to 200 indicating a possible chronic infection. Rodents were also reported to be present on the premises. The environment in which this breed lives seems to be conducive to the propagation and maintenance of Leptospira spp. However the source of infection needs to be established by a proper investigation. It can be assumed that being at greater risk of leptospirosis for this breed may be due to the continuous exposure to leptospiral serovars. It is also not clear if possible "stress" or genetic factors may play a role. However it is important to keep in mind that clustering effect during sampling has contributed to this situation as the high seroprevalence of both Leptospira spp and Bratislava found in this breed doesn't necessarly reflect the reality of the study area particulary in Gauteng where this breed was found.

This study also found a significant association between gender and seropositivity to serovar Bratislava using the Chi-square test. Gender was also significantly associated with seropositivity to Leptospira spp. However, this association must be interpreted with caution 
given the small sample size of stallions. In Australia, the difference between variable gender with regard to seropositivity to serovar Arborea was demonstrated. The odds of geldings being seropositive to this serovar was 3.3 times more than non-gelding in the final model. However in South Africa, the factor gender was not significant in the multivariable logistic regression for both models Bratislava and Leptospira spp.

This current study showed that seropositity to serovar Bratislava increased with the increase in age. The highest prevalence (28.57\%) was found in the oldest age group (16+). Similarly, the oldest age group (16+) had the highest seroprevalence to Leptospira spp (46.09\%). Other authors have also reported the same increase of seroprevalence with increase of age in horses due to the long period of exposure (Park et al. 1992, Lees and Gale. 1994, Williams et al. 1994, Barwick et al. 1997, Baverud et al. 2009). However, the difference in seroprevalence between different age groups was not statistically significant in the Chi-square test for Bratislava and Leptospira spp. This was probably due to the lack of a good representative sample of horses with different ages from each province.

Horses used in this study were divided into different categories based on the activity they performed. Six categories were identified: breeding, equestrian event, general pleasure, work horse, racing and“other.”When tested for association to serovar Bratislava using the Chisquare test, the difference between these categories was statistically significant. Variable "use” was also significantly associated with seropositivity of horses to Leptospira spp. This was likely to be caused by management factors associated with each breed. Horses involved in the equestrian events usually benefit from special care. They usually stay inside the stables where feed and clean water are provided. They don't spend too much time outside their stables, hence minimizing the risk of exposure. Lees and Gale (1994) found that track horses that were managed individually had lower odds ratios than rodeo horses that were managed in groups for all investigated serovars. However for both models in the multivariable regression analysis, this variable was not significant.

\subsubsection{Geographic and environmental factors}

Horses in this study were grouped into three categories based on the annual average temperature their properties received. This temperature ranged from $21.5^{\circ} \mathrm{C}$ to $26.7^{\circ} \mathrm{C}$ with a median of $26^{\circ} \mathrm{C}$. Three categories of horses were then identified. A low medium temperature group is the group of horses whose properties received an annual average temperature ranging from $21.5^{\circ} \mathrm{C}$ to $23.9^{\circ} \mathrm{C}$ whereas medium and high temperature groups are groups of horses whose properties received an annual average temperature ranging from 
$24-25.9^{\circ} \mathrm{C}$ and $\geq 26^{\circ} \mathrm{C}$ respectively. The present study has failed to show a significant association between temperature and seropositivity to both serovar Bratislava and Leptospira spp. This was probably due to the fact that the temperature data from different meteorological stations in each province showed little or no variation between them; making the range very small.

Horses were grouped into three categories based on the average annual precipitation their properties received. Average annual rainfall received by the properties in the three provinces ranged from $395.6 \mathrm{~mm}$ to $1050.6 \mathrm{~mm}$ with the median of $625.6 \mathrm{~mm}$. The three categories were classified as low average annual rainfall $(0-600 \mathrm{~mm})$, medium average annual rainfall $(600-1000 \mathrm{~mm})$ and high average annual rainfall $(>1000 \mathrm{~mm})$. The variable annual average rainfall was significantly associated with horses being seropositive to both serovar Bratislava and Leptospira spp. This is in agreement with Ward. (2002) who reported also a strong association between periods of high rainfall and the incidence of leptospirosis. In Australia, Wangdi et al. (2013) also found that the odds that horses on a horse-property with an average annual rainfall of $>2000 \mathrm{~mm}$ becoming seropositive to serovar Arborea was 6.1 times higher compared to horses residing in horse-properties with an average annual of $<1000 \mathrm{~mm}$. A longer rainy season and floods increase the exposure to leptospires by releasing the leptospires from the soil and bringing them to the surface in standing water. In this study contrarily, the highest prevalence of serovar Bratislava and Leptospira spp was found among the horses whose properties received a low average rainfall $(0-600 \mathrm{~mm})$. This is not surprising since a decreased rainfall was proven to eliminate food sources and forces carrier animals (including rodents) into human habitats or surroundings, to scavenge for food, thereby increasing their contact with accidental hosts (Gubler et al. 2001). However, in the multivariable logistic analysis, this variable was not significant for both models Bratislava and Leptospira spp.

Agricultural activity comprised forestry, fruit trees, sugarcane and other. When analysed using the Chi-square test, the difference in proportion of seropositive horses to both serovar Bratislava and Leptospira spp among the categories was significant. The seroprevalence of both Bratislava and Leptospira spp was the highest for horses residing on the properties surrounded by "forestry" as the main agricultural activity. In the multivariable logistic regression analysis, the two models (Bratislava and Leptospira spp) showed that horses surrounded by “forestry” were at greater risk of being seropositive to both serovar Bratislava $(\mathrm{OR}=9.3)$ and Leptospira spp $(\mathrm{OR}=5.21)$. Forests harbour different animal reservoirs of Leptospira spp including rodents and small mammals which play an important role in 
transmission of leptospirosis to other species including humans (Millan et al. 2009). This is also in agreement with a recent study in Europe where leptospirosis was found to be a major zoonotic occupational disease in forestry workers due to their close contact between them and wild animals (Richard and Oppliger. 2015). In addition, another recent study confirmed that serovars from serogroup Australis (including Bratislava) are maintained in wild animal species (Milas et al. 2013). In this study owners of horses whose properties were surrounded by "forestry" have confirmed the presence of wild animals like peridomestic rodents (porcupines), bushpigs, bushbucks, reedbucks, duikers, anteaters and warthogs (Personal communication, Crowe, Greytown, 2015). However, there is still no serological evidence of any serovar from serogroup Australis being reported in South African wildlife. In northern Kwazulu-Natal game parks, sera of free-living game including reedbuck and bushpig had positive titers to Leptospira interrogans serovar mini (serogroup Hebdomadis) (Hunter et al. 1988) but not for serovars from serogroup Australis. An isolation of serovar Bratislava (or any other serovar from this serogroup) and other leptospiral serovars in wildlife surrounding these horse-properties would give more insight into the possible transmission of leptospirosis from wildlife animal species to horses.

\subsubsection{Management factors}

Presence of other animals on the same pasture with horses or in the vicinity of horseproperties had a significant influence on the status of the horses being seropositive to serovar Bratislava and Leptospira spp. In the Chi-square test, presence of pigs and cattle on the same pasture with horses or in the vicinity of horse-properties had the highest prevalence among other categories of animals. Pigs are thought to be maintenance hosts of serovar Pomona (Faine. 1994, Adler and Faine. 2006). Serovar Pomona has been isolated from South African pigs in various studies (Delange et al. 1987, Hunter et al. 1987, Potts et al. 1995, Gummow et al. 1999). A previous survey conducted on horses in South Africa has detected and reported a prevalence of 27\% for serovar Pomona (Anon. 1986-1987). However, the details with regard to the study area, sample size and panel of antigens used in the survey are scant. In this current study, the apparent prevalence of this serovar in horses was 1.1\% in Gauteng Province; 2.56\% and 5.8\% in the Western Cape and Kwazulu Natal Provinces respectively. The small sample size related to this variable because of the low prevalence in this study, makes it difficult to establish the potential role of pigs in transmission of serovar Pomona to horses. A similar situation was also seen for cattle which are known to be the maintenance hosts of serovar Hardjo (Adler and Faine. 2006). This serovar was only detected in Gauteng 
Province and the apparent prevalence was $0.4 \%$. It appears that horses rarely come into contact with reservoirs of the serovar Hardjo.

Concerning the serovar Bratislava, it was found in pigs (Potts et al. 1995) and cattle in Kwazulu Natal (Hesterberg et al. 2009) and Gauteng Provinces (Personal communication, Madoroba, OVI, 2014). However, for the same reason mentioned above, the role of pigs and cattle in transmission of serovar Bratislava to horses or vice versa needs further investigation. It is probably due to the small sample size that the variable "other species in the vicinity of horse-properties" was not significant in the multivariable logistic regression models.

Different types of water sources did not have any influence on the status of horses being seropositive to both serovar Bratislava and Leptospira spp. Wangdi et al. (2013) also did not find any significant difference among different sources of drinking water in his study. Variable "rodents" did not have any significant association for seropositivity to serovar Bratislava using the Chi-square test, but was significantly associated with Leptospira spp. However in the multivariable logistic analysis, this variable did not come up significant on the Wald test. Some owners reported the presence of house mice (Mus musculus) on their properties. Rodents including house mice were reported to harbour serovar Bratislava. In Canada, the combined results from MAT and FAT suggested that natural infection with serovar Bratislava occur in house mice (Smith et al. 1992). Other studies also reported the isolation of serovar Bratislava from house mice (Galton. 1966) and Norway rat (Rattus norvegicus) (Hathaway et al. 1983). In South Africa, rodents were also reported to be the main risk factor of human leptospirosis. In a study published in 2012, it was found that communities in informal settlements in urban areas are at risk as infected rodent populations are a continuous source of transmission (Saif et al. 2012). The apparent incidence of leptospirosis in the South African human population was also found to be moderately high (Saif et al. 2012). The failure of this study to demonstrate the role of rodents in transmission of leptospiral serovars to South African horses was probably due to the lack of a good representative sample of horse-properties with rodents across each of the Provinces. In the previous paragraph, the author has explained the difficulty in explaining the role of the pigs in transmission of serovar Bratislava to horses due to the small sample size of horseproperties with pigs. Pigs have been found to attract house mice (or rodents) because house mice are frequently abundant where pigs are raised due to ready access to food and shelter (Smith et al. 1992). It appears that the number of rodents that could be attracted by pigs was small since the number of pigs on the properties or in the vicinity of horse-properties was 
also small. The role of the rodents in the epidemiology of leptospirosis in both humans and animals in South Africa needs to be investigated thoroughly. An attempt was made to isolate Leptospira serovars from rodents in South Africa but only a small number of rodents were trapped and neither the isolation nor serology could yield any positive result (Gummow et al. 1999). However, the isolation of serovar Bratislava is known to be difficult due to its fastidious nature (Smith et al. 1992).

\subsection{Disease history and its association with antibodies to both serovar Bratislava and Leptospira spp.}

Ocular disease (uveitis), kidney disease, high fever, liver failure, abortion and still births are the main clinical signs of equine leptospirosis. None of these clinical signs were associated with seropositive horses to serovar Bratislava, suggesting that serovar Bratislava may not cause any clinical disease in horses (Baverud et al. 2009). However in a recent study, it was demonstrated that seroreactivity against serovar Bratislava was more likely to be associated with reproductive problems than seroreactivity against serovar Copenhageni in horses (Pinna et al. 2014). None of these clinical signs above mentioned were associated with seropositivity of horses to Leptospira spp, indicating that most leptospiral infections in horses are asymptomatic (Hathaway et al. 1981).

\subsection{Limitations}

The collection, processing and shipment of samples from the practices was very slow due to various reasons that one could not control. For example, at the beginning of the sample collection, the Equine Clinic of Onderstepoort Veterinary Academic Hospital had to be closed for an extended period due to an outbreak of equine influenza. This delayed the collection of samples in Gauteng.

A random sampling of the horse population would have been the best approach in order to get a good representative sample per province. However in South Africa, it is difficult to get a database of registered properties with horses on them and the number of horses per property. Unfortunately, a lot of samples were collected by private veterinarians on a convenience basis instead of following the required protocol. This has resulted in many samples coming from one property instead of having a few samples from many different properties which is what was originally intended when the clinics were engaged. This is the reason why the apparent prevalences found in this study do not accurately reflect the reality of each of the provinces. 
Some inaccuracies were also noticed when recording information about the surveyed horses. Some owners could not remember some specific information regarding their horses due to the lack of keeping records. In addition to that, some owners were not residing on the properties where horses were kept. For such owners, confirming that their horses were not having access to dam water for example, which was inside the property or other details was not possible.

Despite these limitations, the results of this study could serve as a foundation on which different recommendations and future studies can be built. 


\section{CHAPTER 6}

\section{CONCLUSIONS AND RECOMMENDATIONS}

\subsection{Conclusions}

This study concludes that:

i. Leptospiral infection is wide spread among South African horses from three provinces. The $95 \%$ confidence interval for true prevalence of serum antibodies to one or more serovars of Leptospira spp at a serum dilution of 1:100 in Gauteng, KwaZulu-Natal and Western Cape Provinces was 24-74\%; 20-54\% and 26-39\% respectively.

ii. As expected, antibodies to a wide range of leptospiral serovars were detected in the three provinces.

iii. The predominant serovars circulating in the horse population of the three provinces were Bratislava, Arborea, Djasiman and Tarassovi

iv. The breed "Nooitgedacht" and the presence of "Forestry in the vicinity of horseproperties” were the main risk factors for seropositivity to serovar Bratislava and Leptospira spp.

\subsection{Recommendations}

Based on the findings from this study, the following recommendations have been formulated:

- An isolation of local strains of leptospiral serovar in horses, wildlife animal species and other domestic animals.

- A full scale survey of the horses of each province of South Africa with a good representative sample and using all the serovars detected so far, to be conducted to ascertain an accurate prevalence of leptospirosis in horses. To do so, a horse population census is required to obtain demographic statistics.

- Future vaccine development to include the four commonly identified serovars Bratislava, Arborea, Djasiman and Tarassovi.

- Future survey of leptospirosis in pigs and isolation of leptospiral serovars in humans, rodents and wildlife animal species in South Africa.

- Raising of awareness of health service practitioners and veterinarians about leptospirosis which is often underestimated. 


\section{REFERENCES}

Adler, B., and S. Faine, 2006: The genus Leptospira. In: Dworkin, M., S. Falkow, E.

Rosenberg, K. H. Schleifer, E. Stackebrandt (eds), The prokaryotes, pp. 294-317. Springer. New York.

Adler, B., and A. de la Pena Moctezuma 2010: Leprospira and leptospirosis. Vet Microbiol 140, 287-296.

Alonso-Andicoberry, C., F. J. Garcia-Pena, J. Pereira-Bueno, E. Costas, and L. M. OrtegaMora 2001: Herd-level risk factors associated with Leptospira spp. seroprevalence in dairy and beef cattle in Spain. Prev Vet Med 52, 109-117.

Anon., 1986-1987: Bacteriology \& Reproduction 1986-1987.

Arent, Z. J., and S. Kedzierska-Mieszkowska 2013: Seroprevalence study of leptospirosis in horses in northern Poland. Vet Rec 172.

Bandino, J. P., A. Hang, and S. A. Norton 2015: The Infectious and Noninfectious Dermatological Consequences of Flooding: A Field Manual for the Responding Provider. Am J Clin Dermatol 16, 399-424.

Barwick, R. S., H. O. Mohammed, E. R. Atwill, P. L. McDonough, and M. E. White 1998: The prevalence of equine leptospirosis in New York State. Journal of Equine Science 9, 119-124.

Barwick, R. S., H. O. Mohammed, P. L. McDonough, and M. E. White 1997: Risk factors associated with the likelihood of leptospiral seropositivity in horses in the state of New York. Am J Vet Res 58, 1097-1103.

Baverud, V., A. Gunnarsson, E. O. Engvall, P. Franzen, and A. Egenvall 2009: Leptospira seroprevalence and associations between seropositivity, clinical disease and host factors in horses. Acta Vet Scand 51, 15.

Bernard, W. V., C. Bolin, T. Riddle, M. Durando, B. J. Smith, and R. R. Tramontin 1993: Leptospiral Abortion and Leptospiruria in Horses from the Same Farm. J Am Vet Med Assoc 202, 1285-1286.

Bolin, C. A. 1996: Diagnosis of leptospirosis: A reemerging disease of companion animals. Seminars in Veterinary Medicine and Surgery-Small Animal 11, 166-171.

Braga, J., C. Hamond, G. Martins, R. N. Abreu, and W. Lilenbaum 2011: Ophthalmic alterations in horses with leptospirosis by serovar Icterohaemorrhagiae in Rio de Janeiro, Brazil. Pesquisa Veterinaria Brasileira 31, 147-150.

Bryans, J. T. 1955: Studies on equine leptospirosis. Cornell Vet 45, 16-50.

Cameron, A., 1999: Survey toolbox: A practical manual and software package for active surveillance of livestock diseases in developing countries. 
Carvajal-de la Fuente, V., C. Zapata-Campos, J. Loredo-Osti, R. Lopez-Zavala, J. Osiel Jasso-Obregon, and E. Martinez-Bautista 2012: Seroprevalence and Risk Factors associated with Leptospirosis (L. interrogans) in Bovine Cattle in Northeastern Mexico. Thai Journal of Veterinary Medicine 42, 7-12.

Christianson, W. T. 1992: Stillbirths, Mummies, Abortions, and Early Embryonic Death. Veterinary Clinics of North America-Food Animal Practice 8, 623-639.

Coiro, C. J., H. Langoni, and R. C. da Silva 2012: Epidemiological Aspects in the Leptospira spp. and Toxoplasma gondii Infection in Horses from Botucatu, Sao Paulo, Brazil. Journal of Equine Veterinary Science 32, 620-623.

Davidson, M. G., M. P. Nasisse, and S. M. Roberts 1987: Immunodiagnosis of Leptospiral Uveitis in 2 Horses. Equine Vet J 19, 155-157.

de Oliveira Filho, R. B., K. C. Malta, J. M. B. Oliveira, V. L. Assis Santana, M. H. V. Harrop, D. T. Stipp, and J. W. Pinheiro Júnior 2014: Epidemiological Analysis of Leptospira spp. Infection in Equids from the Brejo Paraibano Microregion of Brazil. Journal of Equine Veterinary Science 34, 407-414.

Delange, J. F., B. Gummow, G. V. Turner, and A. R. Redman 1987: The Isolation of Leptospira-Interrogans Serovar Pomona and Related Serological Findings Associated with a Mixed Farming Unit in the Transvaal. Onderstepoort J Vet Res 54, 119-121.

Department of Agriculture, Forestry \& Fisheries, 2004: Equine stock figures, Pretoria, South Africa.

Dickeson, D., and D. N. Love 1993: A Serological Survey of Dogs, Cats and Horses in South-Eastern Australia for Leptospiral Antibodies. Aust Vet J 70, 389-390.

Divers, T., and Y. -. Chang, 2009: Leptospirosis. In: Robinson, N. E., K. A. Sprayberry (eds), Current Therapy in Equine Medicine, 6th Edn, pp. 145-147. Saunders Elsevier. Missouri.

Donahue, J. M., B. J. Smith, K. B. Poonacha, J. K. Donahoe, and C. L. Rigsby 1995: Prevalence and Serovars of Leptospira Involved in Equine Abortions in Central Kentucky during the 1991-1993 Foaling Seasons. Journal of Veterinary Diagnostic Investigation 7, 87-91.

Donahue, J. M., B. J. Smith, K. J. Redmon, and J. K. Donahue 1991: Diagnosis and prevalence of leptospira infection in aborted and stillborn horses. Journal of Veterinary Diagnostic Investigation 3, 148-151.

Donahue, J. M., and N. M. Williams 2000: Emergent causes of placentitis and abortion. Veterinary Clinics of North America-Equine Practice 16, 443-+.

Dwyer, A. E., R. S. Crockett, and C. M. Kalsow 1995: Association of Leptospiral Seroreactivity and Breed with Uveitis and Blindness in Horses - 372 Cases (1986-1993). J Am Vet Med Assoc 207, 1327-\&.

Dyson, L. L. 2009: Heavy daily-rainfall characteristics over the Gauteng Province. Water SA 35, 627-638. 
Dyson, L. L., J. v. Heerden, and P. D. Sumner 2015: A baseline climatology of soundingderived parameters associated with heavy rainfall over Gauteng, South Africa. Int J Climatol 35, 114-127.

Ebani, V. V., F. Bertelloni, P. Pinzauti, and D. Cerri 2012: Seroprevalence of Leptospira spp. and Borrelia burgdorferi sensu lato in Italian horses. Annals of Agricultural and Environmental Medicine 19, 237-240.

Ellis, W. A. 1995: International Committee on Systematic Bacteriology. Subcommittee on the Taxonomy of Leptospira. Minutes of the Meetings, 1 and 2 July 1994, Prague, Czech Republic. International Journal of Systematic Bacteriology 45, 872-874.

Ellis, W. A., 1986: The diagnosis of leptospirosis in farm animals. In: Ellis, W. A., T. W. A. Little (eds), The present state of leptospirosis diagnosis and control, pp. 13-31. Martinus Nijhoff Publishers. Dordrecht.

Ellis, W. A., D. G. Bryson, J. J. Obrien, and S. D. Neill 1983b: Leptospiral Infection in Aborted Equine Fetuses. Equine Vet J 15, 321-324.

Ellis, W. A., P. J. Mcparland, D. G. Bryson, A. B. Thiermann, and J. Montgomery 1986: Isolation of Leptospires from the Genital-Tract and Kidneys of Aborted Sows. Vet Rec 118, 294-295.

Ellis, W. A., J. J. Obrien, J. A. Cassells, and J. Montgomery 1983a: Leptospiral Infection in Horses in Northern-Ireland - Serological and Microbiological Findings. Equine Vet J 15, 317-320.

Everard, J. D., 1996: Leptospirosis. In: Cox, F. E. G. (ed.), The Wellcome Trust illustrated history of tropical diseases, pp. 111-119, 416-418. The Wellcome Trust. London.

Faber, N. A., M. Crawford, R. B. LeFebvre, N. C. Buyukmihci, J. E. Madigan, and N. H. Willits 2000: Detection of Leptospira spp. in the aqueous humor of horses with naturally acquired recurrent uveitis. J Clin Microbiol 38, 2731-2733.

Faine, S. 1994: Leptospira and leptospirosis. CRC Press, Boca Raton, Florida.

Frazer, M. L. 1999: Acute renal failure from leptospirosis in a foal. Aust Vet J 77, 499500.

Frellstedt, L. 2009: Equine recurrent uveitis: A clinical manifestation of leptospirosis. Equine Veterinary Education 21, 546-552.

Galton, M. M., 1966: Leptospiral serotype distribution lists according to host and geographic area. Atlanta, Georgia.

Gerhards, H., B. Wollanke, and S. Brem 1999: Vitrectomy as a diagnostic and therapeutic approach for Equine Recurrent Uveitis (ERU). Proceedings of the 45th Annual Convention of the American Association of Equine Practitioners, Albuquerque, New Mexico, 5-8 December 1999 , 89-93.

Gerritsen, M. J., T. Olyhoek, M. A. Smits, and B. A. Bokhout 1991: Sample Preparation Method for Polymerase Chain Reaction-Based Semiquantitative Detection of Leptospira- 
Interrogans Serovar Hardjo Subtype Hardjobovis in Bovine Urine. J Clin Microbiol 29, 2805-2808.

Gilger, B. C., D. A. Wilkie, M. G. Davidson, and J. B. Allen 2001: Use of an intravitreal sustained-release cyclosporine delivery device for treatment of equine recurrent uveitis. Am J Vet Res 62, 1892-1896.

Gubler, D. J., P. Reiter, K. L. Ebi, W. Yap, R. Nasci, and J. A. Patz 2001: Climate variability and change in the United States: Potential impacts on vector- and rodent-borne diseases. Environ Health Perspect 109, 223-233.

Gummow, B., J. G. Myburgh, P. N. Thompson, J. J. van der Lugt, and B. T. Spencer 1999: Three case studies involving Leptospira interrogans serovar pomona infection in mixed farming units. Journal of the South African Veterinary Association-Tydskrif Van Die SuidAfrikaanse Veterinere Vereniging 70, 29-34.

Hajikolaei, M. R. H., M. Gorbanpour, M. Haidari, and G. Abdollapour 2005: Comparison of leptospiral infection in the horse and donkey. Bulletin of the Veterinary Institute in Pulawy 49, 175-178.

Hamond, C., G. Martins, R. Lawson-Ferreira, M. A. Medeiros, and W. Lilenbaum 2013: The role of horses in the transmission of leptospirosis in an urban tropical area. Epidemiol Infect 141, 33-35.

Hamond, C., G. Martins, and W. Lilenbaum 2012: Subclinical leptospirosis may impair athletic performance in racing horses. Trop Anim Health Prod 44, 1927-1930.

Hashimoto, V. Y., D. D. Goncalves, F. G. d. Silva, R. C. d. Oliveira, L. A. Alves, P. Reichmann, E. E. Muller, and J. C. d. Freitas 2007: Occurrence of antibodies against Leptospira spp. in horses of the urban area of Londrina, Parana, Brazil. Rev Inst Med Trop Sao Paulo 49, 327-30.

Hathaway, S. C., T. W. A. Little, S. M. Finch, and A. E. Stevens 1981: Leptospiral Infection in Horses in England - a Serological Study. Vet Rec 108, 396-398.

Hathaway, S. C., T. W. A. Little, A. E. Stevens, W. A. Ellis, and J. Morgan 1983: Serovar Identification of Leptospires of the Australis Serogroup Isolated from Free-Living and Domestic Species in the United-Kingdom. Res Vet Sci 35, 64-68.

Hery, G., J. Letheulle, E. Flecher, C. Quentin, C. Piau, Y. Le Tulzo, and P. Tattevin 2015: Massive Intra-Alveolar Hemorrhage Caused by Leptospira Serovar Djasiman in a Traveler Returning From Laos. Journal of Travel Medicine 22, 212-214.

Hesterberg, U. W., R. Bagnall, B. Bosch, K. Perrett, R. Horner, and B. Gummow 2009: A serological survey of leptospirosis in cattle of rural communities in the province of KwaZulu-Natal, South Africa. Journal of the South African Veterinary AssociationTydskrif Van Die Suid-Afrikaanse Veterinere Vereniging 80, 45-49.

Hickey, P. W., 2010: Pediatric leptospirosis workup. WebMD professional. Available at: http://emedicine.medscape.com/article/965698-workup (Accessed on 8 September 2014). 
Hines, M. T., 2014: Leptospirosis. In: Sellon, D. C., M. T. Long (eds), Equine Infectious Diseases, Second edition Edn , pp. 302-311.e5. Saunders/Elsevier. St.Louis, Missouri.

Hintze, J., 2013: NCSS 9. Kaysville, Utah, USA.

Hodgin, E. C., D. A. Miller, and F. Lozano 1989: Leptospira abortion in horses. Journal of veterinary diagnostic investigation: official publication of the American Association of Veterinary Laboratory Diagnosticians, Inc 1, 283-7.

Houwers, D. J., M. G. A. Goris, T. Abdoel, J. A. Kas, S. S. Knobbe, A. M. van Dongen, F. E. Westerduin, W. R. Klein, and R. A. Hartskeerl 2011: Agglutinating antibodies against pathogenic Leptospira in healthy dogs and horses indicate common exposure and regular occurrence of subclinical infections. Vet Microbiol 148, 449-451.

Hunter, P., 2004: Leptospirosis. In: Coetzer, J. A. W., R. C. Tustin (eds), Infectious Diseases of Livestock, 2nd Edn , pp. 1445-1456. Oxford University Press Southern Africa. Cape Town.

Hunter, P., J. R. Flamand, J. Myburgh, and S. M. Van der Merwe 1988: Serological reactions to Leptospira species in game animals of Northern Natal. Onderstepoort Journal of Veterinary Research 55, 191-192.

Hunter, P., F. H. Vandervyver, A. Selmerolsen, M. M. Henton, S. Herr, and J. F. Delange 1987: Leptospirosis as a Cause of White Spot Kidneys in South-African Pig Abattoirs. Onderstepoort J Vet Res 54, 59-62.

Jung, B. Y., K. W. Lee, and T. Y. Ha 2010: Seroprevalence of Leptospira spp. in Clinically Healthy Racing Horses in Korea. Journal of Veterinary Medical Science 72, 197-201.

Katz, M. H. 1999: Multivariable analysis: A pratical guide for clinicians. Cambridge University Press, The Pitt Building, TrumpingtonStreet, Cambridge, United Kingdom.

Kmety, E., and H. Dikken 1993: Classification of the Species Leptospira interrogans and History of its Serovars. University Press, Groningen.

Kruger, A. C., 2004: Climate of South Africa. Climate Regions. Pretoria, South Africa.

Lau, C. L., C. Skelly, M. Dohnt, and L. D. Smythe 2015: The emergence of Leptospira borgpetersenii serovar Arborea in Queensland, Australia, 2001 to 2013. Bmc Infectious Diseases 15, 230.

Lau, C. L., L. D. Smythe, S. B. Craig, and P. Weinstein 2010: Climate change, flooding, urbanisation and leptospirosis: fuelling the fire? Trans R Soc Trop Med Hyg 104, 631-638.

Lees, V. W., and S. P. Gale 1994: Titers to Leptospira Species in Horses in Alberta. Canadian Veterinary Journal-Revue Veterinaire Canadienne 35, 636-640.

Leon, A., S. Pronost, J. Tapprest, N. Foucher, B. Blanchard, G. Andre-Fontaine, C. Laugier, G. Fortier, and R. Leclercq 2006: Identification of pathogenic Leptospira strains in tissues of a premature foal by use of polymerase chain reaction analysis. Journal of Veterinary Diagnostic Investigation 18, 218-221. 
Levett, P. N. 2001: Leptospirosis. Clinical Microbiology Reviews 14, 296-326.

Matthews, A. G., S. A. Waitkins, and M. F. Palmer 1987: Serological Study of Leptospiral Infections and Endogenous Uveitis among Horses and Ponies in the United-Kingdom. Equine Vet J 19, 125-128.

Merien, F., P. Amouriaux, P. Perolat, G. Baranton, and I. Saintgirons 1992: Polymerase Chain-Reaction for Detection of Leptospira Spp in Clinical-Samples. J Clin Microbiol 30, 2219-2224.

Milas, Z., Z. S. Majetic, J. Habus, V. M. Perko, V. Staresina, L. Barbic, V. Stevanovic, M. Perharic, B. Ljubic, and N. Turk 2013: The occurrence and maintenance of Leptospira serovars Australis and Bratislava in domestic and wild animals in Croatia. Veterinarski Arhiv 83, 357-369.

Millan, J., M. G. Candela, J. Vicente Lopez-Bao, M. Pereira, M. Angeles Jimenez, and L. Leon-Vizcaino 2009: Leptospirosis in Wild and Domestic Carnivores in Natural Areas in Andalusia, Spain. Vector-Borne and Zoonotic Diseases 9, 549-554.

Miller, R. I., S. P. Ross, N. D. Sullivan, and N. R. Perkins 2007: Clinical and epidemiological features of canine leptospirosis in North Queensland. Aust Vet J 85, 1319.

Myburgh, J. G., S. J. Posnett, and J. V. Lawrence 1993: Serological Survey for Canine Leptospirosis in the Pretoria Area. Journal of the South African Veterinary AssociationTydskrif Van Die Suid-Afrikaanse Veterinere Vereniging 64, 37-38.

NICD. 2015: Leptospirosis. Available at: www.nicd.ac.za/assets/files/Leptosprirosis.pdf (Accessed on 11 November 2015).

Odontsetseg, N., D. Boldbaatar, A. S. Mweene, and H. Kida 2005: Serological prevalence of Leptospira interrogans serovar Bratislava in horses in Mongolia. Vet Rec 157, 518-519.

OIE, 2008: Manual of Diagnostic Tests and Vaccines for Terrestrial Animals, Paris.

Park, Y. G., J. C. Gordon, S. Bechnielsen, and R. D. Slemons 1992: Factors for Seropositivity to Leptospirosis in Horses. Prev Vet Med 13, 121-127.

Pearce, J. W., L. E. Galle, S. B. Kleiboeker, J. R. Turk, S. K. Schommer, R. R. Dubielizig, W. J. Mitchell, C. P. Moore, and E. A. Giuliano 2007: Detection of Leptospira interrogans DNA and antigen in fixed equine eyes affected with end-stage equine recurrent uveitis. Journal of Veterinary Diagnostic Investigation 19, 686-690.

Picardeau, M. 2013: Diagnosis and epidemiology of leptospirosis. Med Mal Infect 43, 1-9.

Pinna, A., G. Martins, C. Hamond, M. A. Medeiros, G. N. de Souza, and W. Lilenbaum 2014: Potential differences between Leptospira serovars, host-adapted (Bratislava) and incidental (Copenhageni), in determining reproductive disorders in embryo transfer recipient mares in Brazil. Vet Rec 174, 531-+.

Pinna, A., G. Martins, and W. Lilenbaum 2012: Leptospirosis and embryo recovering rate in mare. Veterinary Record 170, 60. 
Poonacha, K. B., J. M. Donahue, R. C. Giles, C. B. Hong, M. B. Petritesmurphy, B. J. Smith, T. W. Swerczek, R. R. Tramontin, and P. A. Tuttle 1993: Leptospirosis in Equine Fetuses, Stillborn Foals, and Placentas. Vet Pathol 30, 362-369.

Potts, A. D., C. Lotter, and J. T. R. Robinson 1995: Serological prevalence of leptospiral antibodies in pigs in South Africa. Onderstepoort J Vet Res 62, 281-284.

Prescott, J. 1991: Treatment of Leptospirosis. The Cornell veterinarian 81, 7-12.

Quinn, P. J., B. K. Markey, F. C. Leonard, E. S. FitzPatrick, S. Fanning, and P. J. Hartigan, 2011: Spirochaetes, Veterinary Microbiology and Microbial Disease, 2nd Edn, pp. 354366. Blackwell Publishing Ltd.

Richard, S., and A. Oppliger 2015: Zoonotic occupational diseases in forestry workers Lyme borreliosis, tularemia and leptospirosis in Europe. Annals of Agricultural and Environmental Medicine 22, 43-50.

Roach, J. M., M. van Vuuren, and J. A. Picard 2010: A serological survey of antibodies to Leptospira species in dogs in South Africa. Journal of the South African Veterinary Association-Tydskrif Van Die Suid-Afrikaanse Veterinere Vereniging 81, 156-159.

Rocha, T., W. A. Ellis, J. Montgomery, C. Gilmore, J. Regalla, and S. Brem 2004: Microbiological and serological study of leptospirosis in horses at slaughter: first isolations. Res Vet Sci 76, 199-202.

Rossetti, C. A., M. Liem, L. E. Samartino, and R. A. Hartskeerl 2005: Buenos Aires, a new Leptospira serovar of serogroup Djasiman, isolated from an aborted dog fetus in Argentina. Vet Microbiol 107, 241-248.

Saif, A., J. Frean, J. Rossouw, and A. N. Trataris 2012: Leptospirosis in South Africa. Onderstepoort J Vet Res 79, 133-133.

SAWS, 1998: Climate of South Africa. Climate statistics 1961-1990., Pretoria, South Africa.

Sehgal, S. C., A. P. Sugunan, M. V. Murhekar, S. Sharma, and P. Vijayachari 2000: Randomized controlled trial of doxycycline prophylaxis against leptospirosis in an endemic area. Int J Antimicrob Agents 13, 249-255.

Sillerud, C. L., R. F. Bey, M. Ball, and S. I. Bistner 1987: Serologic Correlation of Suspected Leptospira-Interrogans Serovar Pomona-Induced Uveitis in a Group of Horses. J Am Vet Med Assoc 191, 1576-1578.

Slack, A. T., M. L. Symonds, M. F. Dohnt, and L. D. Smythe 2006: The epidemiology of leptospirosis and the emergence of Leptospira borgpetersenii serovar Arborea in Queensland, Australia, 1998-2004. Epidemiol Infect 134, 1217-1225.

Slack, A. T., M. L. Symonds, M. F. Dohnt, S. B. Craig, and L. D. Smythe 2010: Short Report: Molecular Epidemiology of Leptospira borgpetersenii Serovar Arborea, Queensland, Australia, 1998-2005. Am J Trop Med Hyg 83, 820-821. 
Smith, K. E., J. J. Zimmerman, C. A. Bolin, G. W. Beran, and H. T. Hill 1992: A Survey of House Mice from Iowa Swine Farms for Infection with Leptospira-Interrogans Serovar Bratislava. Canadian Veterinary Journal-Revue Veterinaire Canadienne 33, 742-744.

Smythe, L. D., V. Wuthiekanun, W. Chierakul, Y. Suputtamongkol, S. Tiengrim, M. F. Dohnt, M. L. Symonds, A. T. Slack, A. Apiwattanaporn, S. Chueasuwanchai, N. P. Day, and S. J. Peacock 2009: The microscopic agglutination test (MAT) is an unreliable predictor of infecting Leptospira serovar in Thailand. Am J Trop Med Hyg 81, 695-697.

Subharat, S., P. R. Wilson, C. Heuer, J. M. Collins-Emerson, L. D. Smythe, M. F. Dohnt, S. B. Craig, and M. A. Burns 2011: Serosurvey of leptospirosis and investigation of a possible novel serovar Arborea in farmed deer in New Zealand. N Z Vet J 59, 139-142.

Suepaul, S. M., C. V. Carrington, M. Campbell, G. Borde, and A. A. Adesiyun 2011: Seroepidemiology of leptospirosis in livestock in Trinidad. Trop Anim Health Prod 43, 367-375.

Swart, K. S., K. Calvert, and C. Meney 1982: The Prevalence of Antibodies to Serovars of Leptospira-Interrogans in Horses. Aust Vet J 59, 25-27.

Swart, S., 2007: Riding High-Horses, Power and Settler Society in Southern Africa, c. 1654-1840. In: Bankoff, G., S. Swart (eds), Breeds of Empire: The 'Invention of the Horse' in Southeast Asia and Southern Africa 1500-1950, pp. 123-140. NIAS Press. Copenhagen.

Szeredi, L., and D. A. Haake 2006: Immunohistochemical identification and pathologic findings in natural cases of equine abortion caused by leptospiral infection. Vet Pathol 43, 755-761.

Terpstra, W. J., 2003: Human leptospirosis: guidance for diagnosis, surveillance and control. Geneva.

Thiermann, A. B. 1984: Leptospirosis - Current Developments and Trends. J Am Vet Med Assoc 184, 722-725.

Thrusfield, M. 2005: Veterinary Epidemiology. Blackwell publishing.

Timoney, J. F., N. Kalimuthusamy, S. Velineni, J. M. Donahue, S. C. Artiushin, and M. Fettinger 2011: A unique genotype of Leptospira interrogans serovar Pomona type kennewicki is associated with equine abortion. Vet Microbiol 150, 349-353.

Turk, N., Z. Milas, J. Habus, Z. S. Majetic, V. M. Perko, L. Barbic, V. Stevanovic, M. Perharic, and V. Staresina 2013: Equine leptospirosis in Croatia - occurrence of subclinical infections and abortions. Veterinarski Arhiv 83, 253-262.

Tyson, P. D., and R. A. Preston-Whyte 2000: The weather and climate of Southern Africa. Oxford University Press, Cape Town.

Vanasco, N. B., C. Rossetti, G. Sequeira, M. D. Sequeira, G. Calderon, and H. D. Tarabla 2000: First isolations of leptospires serogroup Ballum serovar arborea in Argentina. Vet Rec 147, 246-247. 
Vaneys, G. J. J. M., C. Gravekamp, M. J. Gerritsen, W. Quint, M. T. E. Cornelissen, J. Terschegget, and W. J. Terpstra 1989: Detection of Leptospires in Urine by Polymerase Chain-Reaction. J Clin Microbiol 27, 2258-2262.

Vemulapalli, R., I. M. Langohr, A. Sanchez, M. Kiupel, C. A. Bolin, C. C. Wu, and T. L. Lin 2005: Molecular detection of Leptospira kirschneri in tissues of a prematurely born foal. Journal of Veterinary Diagnostic Investigation 17, 67-71.

Verma, A., and B. Stevenson 2012: Leptospiral Uveitis - There Is More to It Than Meets the Eye! Zoonoses and Public Health 59, 132-141.

Verma, A., B. Stevenson, and B. Adler 2013: Leptospirosis in horses. Vet Microbiol 167, 61-66.

Waitkins, S. A., 1986: Review of the zoonotic aspects of leptospirosis. In: Ellis, W. A., T. W. A. Little (eds), The present state of leptospirosis diagnosis and control, pp. 235-241. Martinus Nijhoff Publishers. Dordrecht.

Wangdi, C., J. Picard, R. Tan, F. Condon, B. Dowling, and B. Gummow 2013: Equine leptospirosis in tropical Northern Queensland. Aust Vet J 91, 190-197.

Ward, M. P. 2002: Seasonality of canine leptospirosis in the United States and Canada and its association with rainfall. Prev Vet Med 56, 203-213.

Weil, A. 1886: Ueber eine eigentumliche mit Milztumor, Icterus und Nephritis einhergehende acute Infektionskrankheit. Dtsche Arch. Klin. Med. 39, 209-232.

WHO/FAO/OIE Collaborating Center for Reference and Research on Leptospirosis. 2011: Leptospira serovar data sheet. Serovar Djasiman. Available at: http://www.health.qld.gov.au/qhcss/qhss/lepto/documents/djasiman.pdf (Accessed on 4 November 2015).

Williams, D. M., B. J. Smith, J. M. Donahue, and K. B. Poonacha 1994: Serological and Microbiological Findings on 3 Farms with Equine Leptospiral Abortions. Equine Vet J 26, 105-108.

Wollanke, B., B. W. Rohrbach, and H. Gerhards 2001: Serum and vitreous humor antibody titers in and isolation of Leptospira interrogans from horses with recurrent uveitis. J Am Vet Med Assoc 219, 795-800.

Yan, W., S. M. Faisal, T. Divers, S. P. McDonough, B. Akey, and Y. -. Chang 2010: Experimental Leptospira interrogans Serovar Kennewicki Infection of Horses. Journal of Veterinary Internal Medicine 24, 912-917.

Zoetis. 2015: Lepto EQ Innovator. Available at: https://www.zoetisus.com/products/horses/lepto-eq-innovator/index.aspx (Accessed on 12 February 2016). 
APPENDIXES

Appendix i: Survey Form

\section{RISK FACTOR QUESTIONNAIRE}

\section{CONSENT:}

I, [insert owner name] hereby give permission for blood collection from my horse, [insert horse name] and thereby to take part in the research project entitled: "Seroprevalence of leptospirosis in horses admitted to three large equine hospitals in South Africa”

Signature of the owner:

I, [insert veterinarian name] have sought permission from owner for participation in this study [signature]

\section{QUESTIONNAIRE AND SAMPLE IDENTIFICATION:}

Equine Hospital:

Study reference: (Please use for tubes and cryotubes identification)

Your reference:

Date $: \ldots \ldots \ldots \ldots \ldots$ Name of owner : Address:

Province : .......... Postal Code : ......Tel:

District/Municipality where the horse is from: 
1. Name of the horse:

2. How many adult horses did you have on the property at the time it was bled?:

3. How long has the horse been on the farm for?

4. Gender: $\square$ Mare

$\square$ Gelding

$\square$ Stallion

5. Breed: $\square$ Thoroughbred

$\square$ Arabian

$\square$ Pony

$\square$ Warmblood $\square$ Other

6. Age:

7. Usage:

$\square$ Trotting

$\square$ Competition riding

$\square$ Polo/polocrosse

$\square$ Racing

$\square$ Riding school

$\square$ Not used for anything

$\square$ Breeding

$\square$ General pleasure/Pony club $\square$ Other

8. How is your horse housed and fed?

$\square$ Complete pasture access with little or no stable feeding

$\square$ Complete stable feeding with little or no pasture access

$\square$ Combination of pasture and stable feeding

a. What per cent of time does it spend on pasture?

Pasture ..$\%$

Stable $\%$

9. Do you have a concrete floor in the stable?

$\square$ Yes

$\square$ No

10. Where do your horses most commonly drink from?

$\square$ River $\square$ Dam water $\square$ Bore hole water $\square$ Municipal water $\square$ Other.

11. Do your horses mix together with other animals on the farm?

$\square$ Yes

$\square$ No

12. If yes, which ones?

$\square$ Pigs $\square$ Cattle $\square$ Small ruminants $\square$ Wild animals $\square$ Dogs $\quad \square$ Other.......

13. Do you see rodents on your property?

$\square$ Yes $\quad \square$ No $\quad \square$ Occasionally seen in the property, but not a major problem

14. If yes, do they get into feed storage areas?

$\square$ Yes $\quad \square$ No 
15. Did your horse recently travel around the time it was bled?

$\square$ Yes $\quad \square$ No

15a. If yes, where did it travel to or from?

16. Did you have other horses that were recently introduced onto your farm at the time it was bled?

$\square$ Yes $\quad \square$ No

16a.When?

16b. From where?

17. Do you have a good drainage system in your farm?

$\square$ Yes $\quad \square$ No

18. Do you have any dams or lacs or standing water on the property?

$\square$ Yes $\quad \square$ No

18a. Do the horses have access to it?

$\square$ Yes $\quad \square$ No

19. Do you irrigate your pasture?

$\square$ Yes $\quad \square$ No

20. If yes, where does the water for irrigation come from?
$\square$ River
$\square$ Farm
$\square$ Storage tank
$\square$ Other.

21. Are there other farms with animals on them in the vicinity of your farm?

$\square$ Yes

$\square$ No

22. If yes which ones?

$\square$ Piggery $\square$ Cattle $\square$ Small ruminant $\square$ Wild animals $\square$ Other

23. Do they come into contact with them?
$\square$ Yes
$\square$ No

24. Do you see water-borne waste or run-off water from that farm in the vicinity of yours?

$\square$ Yes $\quad \square$ No

24a. Do horses come into contact with this?

$\square$ Yes $\quad \square$ No

25. What are the main agricultural activities in the locality?

$\square$ Sugarcane $\square$ Banana $\quad \square$ Fodder plantation $\quad \square$ Other. 
26. Has your horse ever had ocular disease (swollen eyes, watering eyes, red eyes ulcer)?
$\square$ Yes
$\square$ No
$\square$ Not known

27. If yes, when?

28. Has your horse ever been diagnosed by your veterinarian as suffering from kidney disease?
$\square$ Yes
$\square$ No
$\square$ Not known

29. If yes, what was the diagnosis?

30. When did it happen?.

31. Has your horse suffered from high fever in the past one year?
$\square$ Yes
$\square$ No
$\square$ Not known

32. Has your horse ever had yellow eye mucous membranes or yellow gums in the last one year?
$\square$ Yes
$\square$ No
$\square$ Not known

33. Do you have any other properties with horses on them?
$\square$ Yes
$\square$ No

33a. If yes how many?

34. Do horses from the different properties come into contact with each other?
$\square$ Yes
$\square$ No

35. For breeding mares:

a. Has your horse ever aborted?
$\square$ Yes
$\square$ No
$\square$ Not sure

b. Has your horse ever had stillbirths?
$\square$ Yes
$\square$ No
$\square$ Not sure

c. Has your horse ever been found empty after being confirmed as pregnant?
$\square$ Yes
$\square$ No
$\square$ Not sure

d. What proportion of the mares on the premises are found to be barren after they are mated with stallion?

END

Thank you for your cooperation and time spent with me. Enjoy your day! 


\title{
Appendix ii: Research Committee Approval
}

Ref: V040/12

10 July 2012

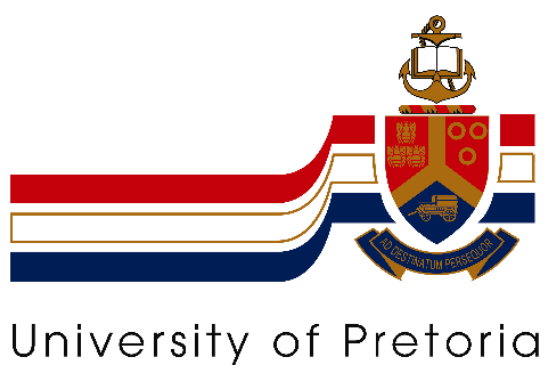

\author{
Faculty of Veterinary Science \\ Private Bag X04 \\ Onderstepoort \\ 0110
}

Tel: +27125298000

Fax: +27 125298300

Prof MN Saulez

Department Companion Animal Clinical Studies

(montague.saulez@up.ac.za)

Dear Prof Saulez

PROTOCOL V040/12: SEROPREVALENCE OF LEPTOSPIROSIS IN HORSES ADMITTED TO THREE EQUINE HOSPITALS IN SOUTH AFRICA - $V$ Simbizi

I am pleased to inform you that the abovementioned protocol was approved by the Research Committee.

Kindly note that, if there are animal ethical issues involved in the project, the protocol needs to be approved by the Animal Use and Care Committee as well before you may commence with the project.

Please take note of the attached document.

Kind regards

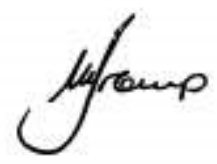

NIESJE TROMP

SECRETARY: RESEARCH COMMITTEE

Copy: Prof JAW Coetzer, Deputy Dean: Research (koos.coetzer@up.ac.za)

V Simbizi, Researcher (vsimbizi@yahoo.fr)

Prof JP Schoeman, HOD (johan.schoeman@up.ac.za)

Ms M Human. Student Administration (magda.human@up.ac.za)

Ms Elmarie Mostert, Animal Use and Care Committee (elmarie.mostert@up.ac.za) 
Appendix iii: Calculation of true seroprevalence 95\% CI of Leptospira spp in Gauteng Province

Seroprevalence of equine leptospirosis in Gauteng Province using cluster sampling formula

\begin{tabular}{|c|c|c|c|c|c|c|c|c|}
\hline No & Cluster & $\begin{array}{c}\text { No of } \\
\text { horses } \\
\text { sampled }\end{array}$ & $\begin{array}{c}\text { No of } \\
\text { positive } \\
\text { horse }\end{array}$ & $\begin{array}{c}\text { Apparent } \\
\text { prevalence }\end{array}$ & $\begin{array}{c}\text { True } \\
\text { prevalence }\end{array}$ & $n^{\wedge} 2$ & $\mathrm{~m}^{\wedge} 2$ & $\mathbf{n}^{*} \mathbf{m}$ \\
\hline 1 & Cluster 1 & 22 & 17 & 77.27 & 77.09 & 484 & 289 & 374 \\
\hline 2 & Cluster 2 & 54 & 48 & 88.89 & 88.70 & 2916 & 2304 & 2592 \\
\hline 3 & Cluster 3 & 2 & 0 & 0.00 & -0.19 & 4 & 0 & 0 \\
\hline 4 & Cluster 4 & 38 & 27 & 71.05 & 70.87 & 1444 & 729 & 1026 \\
\hline 5 & Cluster 5 & 59 & 17 & 28.81 & 28.63 & 3481 & 289 & 1003 \\
\hline 6 & Cluster 6 & 100 & 24 & 24.00 & 23.81 & 10000 & 576 & 2400 \\
\hline 7 & Cluster 7 & 1 & 1 & 100.00 & 99.81 & 1 & 1 & 1 \\
\hline 8 & Cluster 8 & 1 & 1 & 100.00 & 99.81 & 1 & 1 & 1 \\
\hline 9 & Cluster 9 & 1 & 1 & 100.00 & 99.81 & 1 & 1 & 1 \\
\hline 10 & Cluster 10 & 1 & 1 & 100.00 & 99.81 & 1 & 1 & 1 \\
\hline 11 & Cluster 11 & 1 & 1 & 100.00 & 99.81 & 1 & 1 & 1 \\
\hline 12 & Cluster 12 & 1 & 1 & 100.00 & 99.81 & 1 & 1 & 1 \\
\hline 13 & Cluster 13 & 1 & 1 & 100.00 & 99.81 & 1 & 1 & 1 \\
\hline 14 & Cluster 14 & 1 & 0 & 0.00 & -0.19 & 1 & 0 & 0 \\
\hline 15 & Cluster 15 & 1 & 0 & 0.00 & -0.19 & 1 & 0 & 0 \\
\hline 16 & Cluster 16 & 1 & 0 & 0.00 & -0.19 & 1 & 0 & 0 \\
\hline 17 & Cluster 17 & 1 & 1 & 100.00 & 99.81 & 1 & 1 & 1 \\
\hline 18 & Cluster 18 & 1 & 1 & 100.00 & 99.81 & 1 & 1 & 1 \\
\hline 19 & Cluster 19 & 1 & 1 & 100.00 & 99.81 & 1 & 1 & 1 \\
\hline 20 & Cluster 20 & 9 & 2 & 22.22 & 22.04 & 81 & 4 & 18 \\
\hline & TOTAL & 297 & 145 & 48.82 & 48.63 & 88209 & 21025 & 43065 \\
\hline & & \multicolumn{2}{|c|}{ Seroprevalence: 0.49} & $\begin{array}{r}95 \% \mathrm{CI}: \mathrm{c} \\
\mathrm{C} / \mathrm{T}=\mathbf{0} \\
\mathrm{V} \\
\mathrm{C}(\mathrm{C}-1)=380\end{array}$ & $\begin{array}{l}24-0.74 \\
\Gamma=297 \\
C=20 \\
0673400673 \\
1344.16 \\
\text { Se=0.92; } \mathrm{Sp}=\end{array}$ & & & \\
\hline
\end{tabular}

$\operatorname{Var}(\mathrm{AP})=\frac{\mathrm{AP}(1-\mathrm{AP})}{\mathrm{n}(\mathrm{Se}+\mathrm{Sp})^{2}} \quad($ Equation 1$)$

$\mathrm{AP}-\left(\mathrm{Z}_{\alpha / 2} \mathrm{X} \sqrt{\operatorname{Var}(\mathrm{AP})}\right) ; \mathrm{AP}+\left(\mathrm{Z}_{\alpha / 2} \mathrm{x} \sqrt{\operatorname{Var}(\mathrm{AP})}\right) \quad$ (Equation 2)

$\hat{P}-1.96\left\{\frac{C}{T} \sqrt{\frac{V}{C(C-1)}}\right\}, \hat{P}+1.96\left\{\frac{C}{T} \sqrt{\frac{V}{C(C-1)}}\right\}, \quad$ (Equation 3)

$\mathrm{V}=\hat{P}^{2}\left(\sum n^{2}\right)-2 \hat{P}\left(\sum n m\right)+\left(\sum m^{2}\right), \quad($ Equation 4$)$ 
Appendix iv: Calculation of true prevalence 95\% CI of Leptospira spp in the Western Cape Province

Seroprevalence of equine leptospirosis in the Western Cape Province using cluster sampling formula

\begin{tabular}{|c|c|c|c|c|c|c|c|c|}
\hline No & Cluster & $\begin{array}{c}\text { No of } \\
\text { horses } \\
\text { sampled }\end{array}$ & $\begin{array}{c}\text { No of } \\
\text { positive } \\
\text { horse }\end{array}$ & AP & $\begin{array}{c}\text { True } \\
\text { prevalence }\end{array}$ & $n^{\wedge} 2$ & $\mathbf{m}^{\wedge} 2$ & $\mathbf{n}^{*} \mathbf{m}$ \\
\hline 1 & Cluster 1 & 41 & 13 & 31.71 & 31.52 & 1681 & 169 & 533 \\
\hline 2 & Cluster 2 & 2 & 1 & 50.00 & 49.81 & 4 & 1 & 2 \\
\hline 3 & Cluster 3 & 35 & 13 & 37.14 & 36.96 & 1225 & 169 & 455 \\
\hline 4 & Cluster 4 & 16 & 6 & 37.50 & 37.31 & 256 & 36 & 96 \\
\hline 5 & Cluster 5 & 11 & 2 & 18.18 & 17.99 & 121 & 4 & 22 \\
\hline 6 & Cluster 6 & 35 & 7 & 20.00 & 19.81 & 1225 & 49 & 245 \\
\hline 7 & Cluster 7 & 14 & 4 & 28.57 & 28.38 & 196 & 16 & 56 \\
\hline 8 & Cluster 8 & 40 & 17 & 42.50 & 42.31 & 1600 & 289 & 680 \\
\hline & TOTAL & 194 & 63 & 32.47 & 32.29 & 37636 & 3969 & 12222 \\
\hline & & & Seroprev & $\begin{array}{l}\text { lence: } \\
\text { C/T }=\end{array}$ & $\begin{array}{l}32 \quad 95 \% C \\
T=194 \\
C=8 \\
.041237113 \\
V=41.45 \\
(C-1)=56 \\
\text { Se }=0.92 \\
\text { Sp }=0.95\end{array}$ & [: $0.26-$ & 0.39 & \\
\hline
\end{tabular}

$\operatorname{Var}(\mathrm{AP})=\frac{\mathrm{AP}(1-\mathrm{AP})}{\mathrm{n}(\mathrm{Se}+\mathrm{Sp})^{2}} \quad($ Equation 1$)$

$\mathrm{AP}-\left(\mathrm{Z}_{\alpha / 2} \mathrm{x} \sqrt{\operatorname{Var}(\mathrm{AP})}\right) ; \mathrm{AP}+\left(\mathrm{Z}_{\alpha / 2} \mathrm{x} \sqrt{\operatorname{Var}(\mathrm{AP})}\right) \quad$ (Equation 2)

$\hat{P}-1.96\left\{\frac{C}{T} \sqrt{\frac{V}{C(C-1)}}\right\}, \hat{P}+1.96\left\{\frac{C}{T} \sqrt{\frac{V}{C(C-1)}}\right\}, \quad$ (Equation 3)

$\mathrm{V}=\hat{P}^{2}\left(\sum n^{2}\right)-2 \hat{P}\left(\sum n m\right)+\left(\sum m^{2}\right), \quad($ Equation 4$)$ 
Appendix v: Calculation of true prevalence 95\% CI of Leptospira spp in KwaZuluNatal Province

Seroprevalence of equine leptospirosis in KwaZulu-Natal using cluster sampling formula

\begin{tabular}{|c|c|c|c|c|c|c|c|c|}
\hline No & Cluster & $\begin{array}{c}\text { No of } \\
\text { horses } \\
\text { sampled }\end{array}$ & $\begin{array}{c}\text { No of } \\
\text { positive } \\
\text { horse }\end{array}$ & $\begin{array}{c}\text { Apparent } \\
\text { prevalence }\end{array}$ & $\begin{array}{c}\text { True } \\
\text { prevalence }\end{array}$ & $n^{\wedge} 2$ & $m^{\wedge} 2$ & $\mathbf{n} * \mathbf{m}$ \\
\hline 1 & Cluster 1 & 78 & 21 & 26.92 & 26.74 & 6084 & 441 & 1638 \\
\hline 2 & Cluster 2 & 6 & 4 & 66.67 & 66.48 & 36 & 16 & 24 \\
\hline 3 & Cluster 3 & 9 & 5 & 55.56 & 55.37 & 81 & 25 & 45 \\
\hline 4 & Cluster 4 & 25 & 20 & 80.00 & 79.81 & 625 & 400 & 500 \\
\hline 5 & Cluster 5 & 20 & 4 & 20.00 & 19.81 & 400 & 16 & 80 \\
\hline 6 & Cluster 6 & 8 & 2 & 25.00 & 24.81 & 64 & 4 & 16 \\
\hline 7 & Cluster 7 & 11 & 2 & 18.18 & 17.99 & 121 & 4 & 22 \\
\hline 8 & Cluster 8 & 15 & 5 & 33.33 & 33.15 & 225 & 25 & 75 \\
\hline & TOTAL & 172 & 63 & 37 & 36.44 & 29584 & 3969 & 10836 \\
\hline & & & Seropı & $\begin{array}{r}\text { evalence: } 0 . \\
\mathrm{C} / \mathrm{T}=\mathbf{0} . \\
\mathrm{V} \\
\mathrm{C}( \\
\mathrm{S} \\
\mathrm{S}\end{array}$ & $\begin{array}{l}7 \quad 95 \% \text { CI: } \\
=172 \\
=8 \\
465116279 \\
197.31 \\
-1)=56 \\
=0.92 \\
=0.95\end{array}$ & $0.2-0.5$ & & \\
\hline
\end{tabular}

$\operatorname{Var}(\mathrm{AP})=\frac{\mathrm{AP}(1-\mathrm{AP})}{\mathrm{n}(\mathrm{Se}+\mathrm{Sp})^{2}} \quad($ Equation 1$)$

$\mathrm{AP}-\left(\mathrm{Z}_{\alpha / 2} \mathrm{X} \sqrt{\operatorname{Var}(\mathrm{AP})}\right) ; \mathrm{AP}+\left(\mathrm{Z}_{\alpha / 2} \mathrm{x} \sqrt{\operatorname{Var}(\mathrm{AP})}\right) \quad$ (Equation 2)

$\hat{P}-1.96\left\{\frac{C}{T} \sqrt{\frac{V}{C(C-1)}}\right\}, \hat{P}+1.96\left\{\frac{C}{T} \sqrt{\frac{V}{C(C-1)}}\right\}, \quad$ (Equation 3)

$\mathrm{V}=\hat{P}^{2}\left(\sum n^{2}\right)-2 \hat{P}\left(\sum n m\right)+\left(\sum m^{2}\right), \quad($ Equation 4$)$ 
Appendix vi: Multivariable analysis for Bratislava model

Logistic Regression Report

Dataset

Response ....Lepto_working 22102015.NCSS brati_pos

\section{Run Summary}

Item

Dependent Variable

Reference Group

Number of Groups

Frequency Variable

Numeric Ind. Variables

Categorical Ind. Variables

Final Log Likelihood

Model R ${ }^{2}$

Actual Convergence

Target Convergence

Model D.F.

Response Analysis

brati_pos

Categories

0

1

Total

Count
293
125
418

Unique
Value

brati_pos

0

2

None

0

8

$-204.60515$

0.41154

$1.644468 \mathrm{E}-10$

1E-06

22
Item

Rows Processed

Rows Used

Rows for Validation

Rows X's Missing

Rows Freq Miss. or 0

Rows Prediction Only

Unique Row Patterns

Sum of Frequencies

Likelihood Iterations

Maximum Iterations

Completion Status
Value

663

418

0

243

0

2

120

418

6

20

Normal Completion

\section{Coefficient Significance Tests}

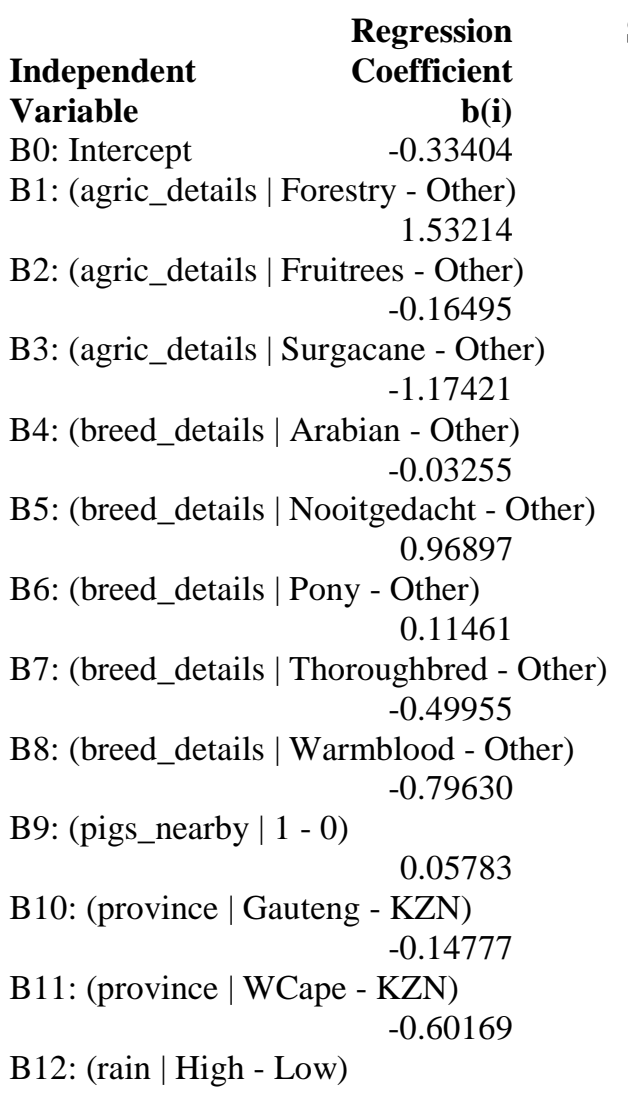

Standard

Error

Sb(i)

0.79592

0.60503

0.65281

0.51635

0.66057

0.62757

0.58104

0.34119

0.62277

0.18774

0.38593

0.58937

\section{Act vs Pred \\ $\mathbf{R}^{2}$ \\ 0.21805 \\ 0.22665}

\begin{tabular}{|c|c|c|}
\hline $\begin{array}{r}\text { Wald } \\
\text { Z-Value }\end{array}$ & $\begin{array}{l}\text { Wald } \\
\text { Prob }\end{array}$ & $\begin{array}{l}\text { Odds } \\
\text { Ratio }\end{array}$ \\
\hline H0: $\beta=0$ & Level & $\operatorname{Exp}(\mathbf{b}(\mathbf{i}))$ \\
\hline-0.420 & 0.67471 & 0.71602 \\
\hline 2.532 & 0.01133 & 4.62805 \\
\hline-0.253 & 0.80052 & 0.84794 \\
\hline-2.274 & 0.02296 & 0.30906 \\
\hline-0.049 & 0.96070 & 0.96797 \\
\hline 1.544 & 0.12259 & 2.63522 \\
\hline 0.197 & 0.84363 & 1.12144 \\
\hline-1.464 & 0.14316 & 0.60680 \\
\hline-1.279 & 0.20102 & 0.45099 \\
\hline 0.308 & 0.75803 & 1.05954 \\
\hline-0.383 & 0.70181 & 0.86263 \\
\hline-1.021 & 0.30730 & 0.547 \\
\hline
\end{tabular}


B13: (rain | Medium - Low)

$$
-0.93422 \quad 0.75074
$$

$-1.244$

0.21335

0.39289

$$
0.50530
$$

0.40684

1.242

0.21423

1.65749

B14: (sex_details | Mare - Gelding)

0.39009

$-1.173$

0.24092

0.63289

B15: (sex_details | Stallion - Gelding)

0.72358

0.926

0.35431

1.95468

B16: (smallrum_nearby | 1 - 0)

$$
-0.47773 \quad 0.45544
$$

$-1.049$

0.29420

0.62019

B17: (use_details | Breeding - General pleasure)

$$
0.49042 \quad 0.51308
$$

0.956

0.33916

1.63300

B18: (use_details | Equestrian event - General pleasure)

0.583

0.55963

1.21646

B19: (use_details | Other - General pleasure)

$0.77467 \quad 0.60698$

1.276

0.20186

2.16987

B20: (use_details | Racing - General pleasure)

$-0.69239 \quad 0.70621$

$-0.980$

0.32687

0.50038

B21: (use_details | Work horse - General pleasure)

$$
-0.26194 \quad 0.51366
$$

0.76956 
Dataset

Logistic Regression Report

Response ...Lepto_working 22102015.NCSS brati_pos

\section{Coefficient Confidence Intervals}

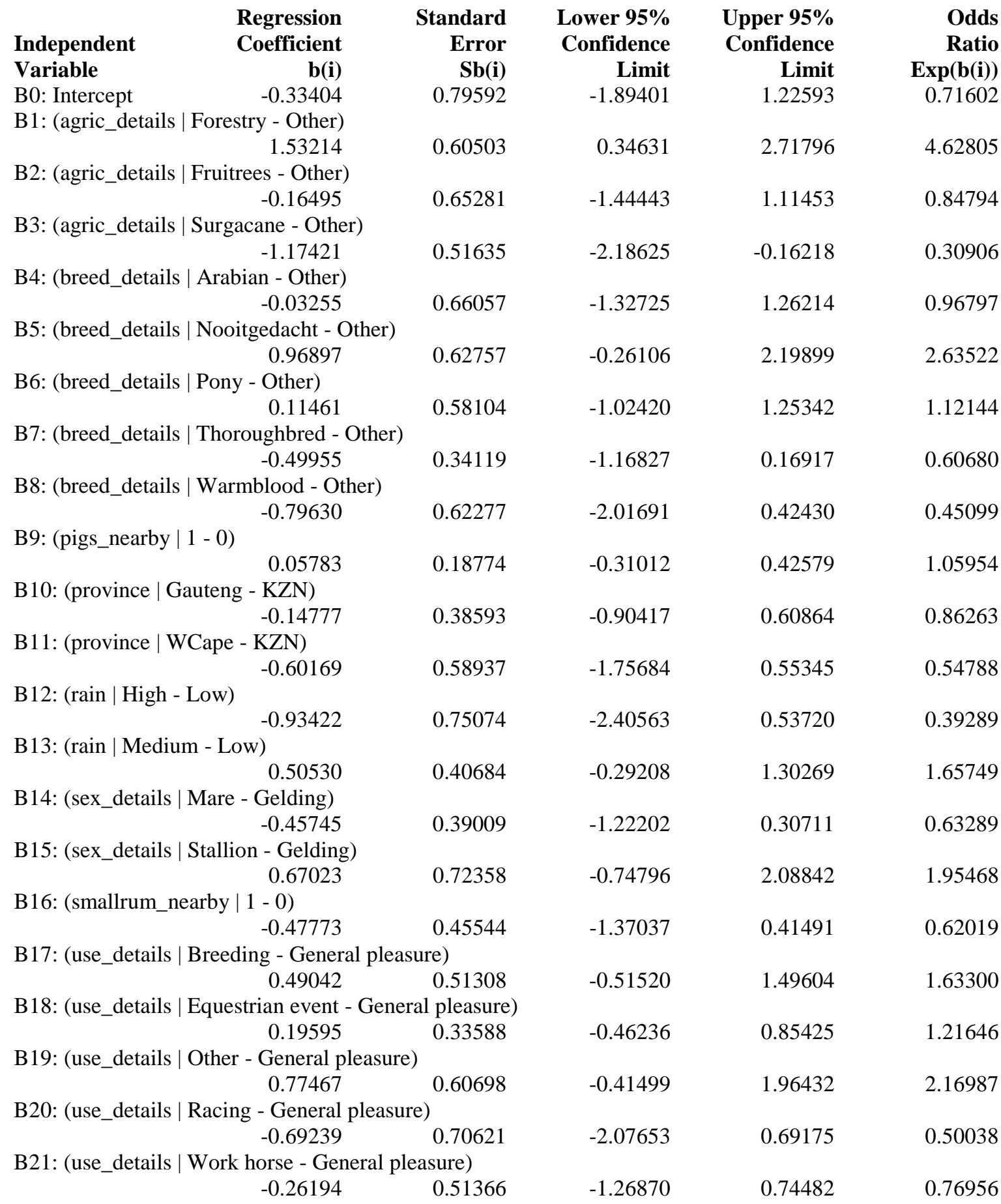


Dataset

Logistic Regression Report

Response ...Lepto_working 22102015.NCSS brati_pos

\section{Odds Ratios Report}

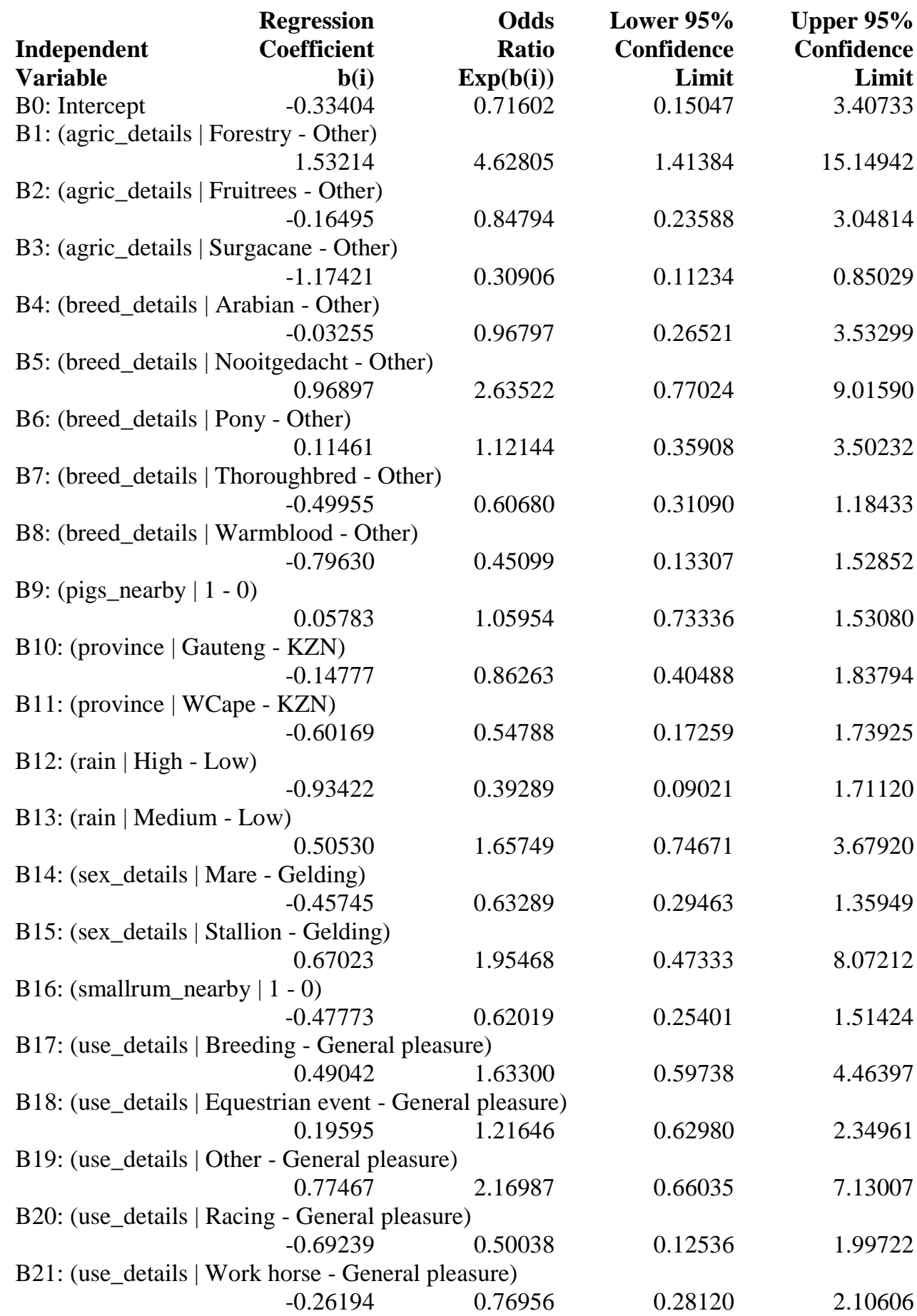


Dataset

\section{Logistic Regression Report}

Response ...LLepto_working 22102015.NCSS

brati_pos

\section{Estimated Logistic Regression Model(s)}

Model For brati_pos $=1$

-.334040776626963 + 1.53213508140304*(agric_details | Forestry - Other) -

$.164948895173337 *$ (agric_details | Fruitrees - Other) $-1.17421231735382 *$ (agric_details | Surgacane Other) -.0325531221216203*(breed_details | Arabian - Other) + .968966213692454*(breed_details | Nooitgedacht - Other) + .114614220875678*(breed_details | Pony - Other) .499549010380693*(breed_details | Thoroughbred - Other) -.796303701813184*(breed_details | Warmblood - Other) + .0578349886676127*(pigs_nearby | 1 - 0) -.147765414199731*(province | Gauteng - KZN) $.601693170987765 *$ (province | WCape - KZN) -.934217869816454*(rain | High - Low) + $.50530487579373 *$ (rain | Medium - Low) -.457454181487092*(sex_details | Mare - Gelding) + .67022626976026*(sex_details | Stallion - Gelding) -.477729801156663*(smallrum_nearby | 1 - 0) + $.490417739173629 *$ (use_details | Breeding - General pleasure) + .195946346832871*(use_details | Equestrian event - General pleasure) + .77466791262825*(use_details | Other - General pleasure) .692386640370711*(use_details | Racing - General pleasure) -.261941217962593*(use_details | Work horse - General pleasure)

Note that each model estimates $\mathrm{B}$ for a specific group, where $\operatorname{Logit}(\mathrm{Y})=\mathrm{XB}$. To calculate the group probabilities when there are only 2 response groups, transform the logit using $\operatorname{Prob}(\mathrm{Y}=$ group $)=1 /(1+\operatorname{Exp}(-\mathrm{XB}))$ or $\operatorname{Prob}(\mathrm{Y} \neq \operatorname{group})=\operatorname{Exp}(-\mathrm{XB}) /(1+\operatorname{Exp}(-\mathrm{XB}))$. For the calculation formula to use when there are more than 2 response groups, see the help documentation.

\section{Analysis of Deviance}

\section{Term}

Omitted

All

agric_details

breed_details

pigs_nearby

province

rain

sex_details

smallrum_nearby

use details

None(Model)
Deviance

510.00289

431.95411

415.61778

409.30489

410.81645

411.06643

410.73524

410.35656

414.04738

409.21030

\section{Increase}

From Model

Deviance

(Chi')

100.79259

22.74381

6.40748

0.09459

1.60615

1.85613

1.52494

1.14626

4.83708
Prob

Level

0.00000

0.00005

0.26856

0.75842

0.44795

0.39532

0.46651

0.28433

0.43608

The Prob Level is for testing the significance of that term after considering all other terms.

\section{Log Likelihood \& $\mathbf{R}^{2}$}

$\begin{array}{lrr}\text { Term(s) } & \text { DF } & \begin{array}{r}\text { Log } \\ \text { Omitted }\end{array} \\ \text { All } & 1 & \begin{array}{r}\text { Likelihood } \\ -255.00145\end{array} \\ \text { agric_details } & 3 & -215.97706 \\ \text { breed_details } & 5 & -207.80889 \\ \text { pigs_nearby } & 1 & -204.65245 \\ \text { province } & 2 & -205.40823 \\ \text { rain } & 2 & -205.53322 \\ \text { sex_details } & 2 & -205.36762 \\ \text { smallrum_nearby } & 1 & -205.17828 \\ \text { use_details } & 5 & -207.02369 \\ \text { None(Model) } & 21 & -204.60515\end{array}$

$\mathbf{R}^{2}$ of
Remaining
Term(s)
0.00000
0.31868
0.38538
0.41115
0.40498
0.40396
0.40531
0.40686
0.39179
0.41154

$\begin{array}{r}\text { Reduction } \\ \text { From } \\ \text { Model R }\end{array}$

0.09286
0.02616
0.00039
0.00656
0.00758
0.00623
0.00468
0.01975
0.00000

Reduction

From

Saturated $\mathbf{R}^{2}$

0.68132

0.61462

0.58885

0.59502

0.59604

0.59469

0.59314

0.60821

0.58846 
Appendix vii: Multivariable analysis for Leptospira spp model

Logistic Regression Report Dataset ...Lepto_working 22102015.NCSS

Response lepto_pos

Run Summary

Item

Dependent Variable

Reference Group

Number of Groups

Frequency Variable

Numeric Ind. Variables

Categorical Ind. Variables

Final Log Likelihood

Model R ${ }^{2}$

Actual Convergence

Target Convergence

Model D.F.

\section{Response Analysis}

lepto_pos
Categories
0
1
Total

Count
220
199
419

$\begin{array}{lll}\text { Value } & \text { Item } & \text { Value } \\ \text { lepto_pos } & \text { Rows Processed } & 663 \\ 0 & \text { Rows Used } & 419 \\ 2 & \text { Rows for Validation } & 0 \\ \text { None } & \text { Rows X's Missing } & 243 \\ 0 & \text { Rows Freq Miss. or 0 } & 0 \\ 10 & \text { Rows Prediction Only } & 1 \\ -230.87047 & \text { Unique Row Patterns } & 130 \\ 0.49182 & \text { Sum of Frequencies } & 419 \\ 3.089827 \mathrm{E}-07 & \text { Likelihood Iterations } & 5 \\ 1 \mathrm{E}-06 & \text { Maximum Iterations } & 20 \\ 24 & \text { Completion Status } & \text { Normal Completion }\end{array}$

\section{1}

$$
\text { lepto_pOS }
$$


Dataset

Logistic Regression Report

Response ...Lepto_working 22102015.NCSS lepto_pos

\section{Coefficient Significance Tests}

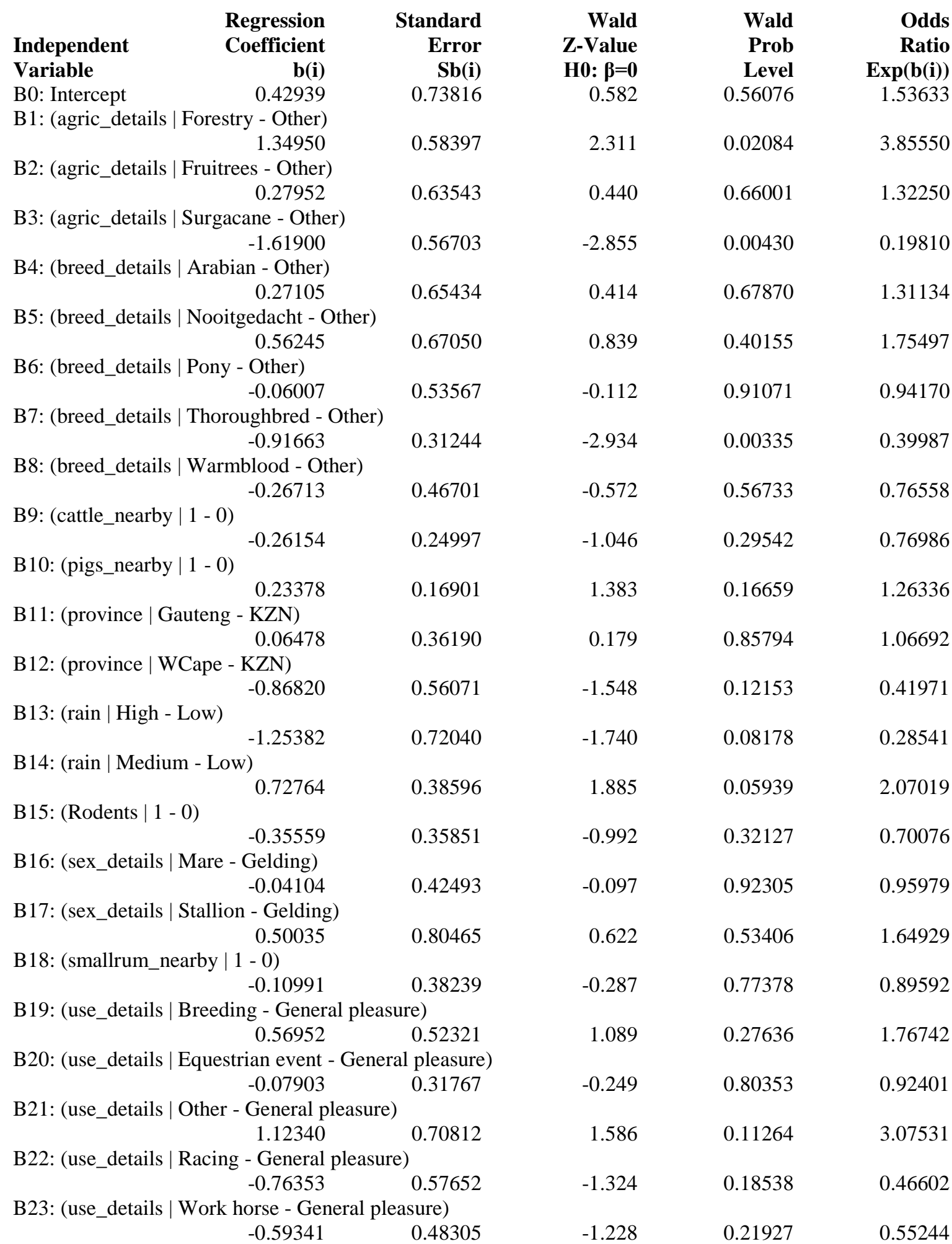


Dataset

Logistic Regression Report

Response ...Lepto_working 22102015.NCSS lepto_pos

\section{Coefficient Confidence Intervals}

\begin{tabular}{|c|c|c|c|c|c|}
\hline Independent & $\begin{array}{l}\text { Regression } \\
\text { Coefficient }\end{array}$ & $\begin{array}{r}\text { Standard } \\
\text { Error }\end{array}$ & $\begin{array}{l}\text { Lower 95\% } \\
\text { Confidence }\end{array}$ & $\begin{array}{l}\text { Upper 95\% } \\
\text { Confidence }\end{array}$ & $\begin{array}{l}\text { Odds } \\
\text { Ratio }\end{array}$ \\
\hline Variable & b(i) & $\mathrm{Sb}(\mathbf{i})$ & Limit & Limit & $\operatorname{Exp}(\mathbf{b}(\mathbf{i}))$ \\
\hline B0: Intercept & 0.42939 & 0.73816 & -1.01738 & 1.87616 & 1.53633 \\
\hline \multicolumn{6}{|c|}{ B1: (agric_details | Forestry - Other) } \\
\hline & 1.34950 & 0.58397 & 0.20495 & 2.49406 & 3.85550 \\
\hline \multicolumn{6}{|c|}{ B2: (agric_details | Fruitrees - Other) } \\
\hline & 0.27952 & 0.63543 & -0.96590 & 1.52495 & 1.32250 \\
\hline \multicolumn{6}{|c|}{ B3: (agric_details | Surgacane - Other) } \\
\hline \multicolumn{6}{|c|}{ B4: (breed_details | Arabian - Other) } \\
\hline \multicolumn{6}{|c|}{ B5: (breed_details | Nooitgedacht - Other) } \\
\hline \multicolumn{6}{|c|}{ B6: (breed_details | Pony - Other) } \\
\hline B7: (breed_de & \multicolumn{5}{|c|}{ B7: (breed_details | Thoroughbred - Other) } \\
\hline B8: (breed_de & \multicolumn{4}{|c|}{ B8: (breed_details | Warmblood - Other) } & 0.39987 \\
\hline \multicolumn{6}{|c|}{ B9: (cattle_nearby | 1 - 0) } \\
\hline \multicolumn{6}{|c|}{ B10: (pigs_nearby | 1 - 0) } \\
\hline B11: (province & \multicolumn{4}{|c|}{ B11: (province | Gauteng - KZN) } & 1.26336 \\
\hline B12: (province & $\begin{array}{l}0.06478 \\
\text { - KZN) }\end{array}$ & 0.36190 & -0.64454 & 0.77409 & 1.06692 \\
\hline \multicolumn{6}{|c|}{ B13: (rain | High - Low) } \\
\hline \multicolumn{6}{|c|}{ B14: (rain | Medium - Low) } \\
\hline \multicolumn{6}{|c|}{ B15: (Rodents | 1 - 0) } \\
\hline & -0.35559 & 0.35851 & -1.05827 & 0.34708 & 0.70076 \\
\hline \multicolumn{6}{|c|}{ B16: (sex_details | Mare - Gelding) } \\
\hline \multicolumn{6}{|c|}{ B17: (sex_details | Stallion - Gelding) } \\
\hline \multicolumn{6}{|c|}{ B18: (smallrum_nearby | 1 - 0) } \\
\hline & -0.10991 & 0.38239 & -0.85937 & 0.63955 & 0.89592 \\
\hline \multicolumn{6}{|c|}{ B19: (use_details | Breeding - General pleasure) } \\
\hline & 0.56952 & 0.52321 & -0.45594 & 1.59499 & 1.76742 \\
\hline \multicolumn{6}{|c|}{ B20: (use_details | Equestrian event - General pleasure) } \\
\hline & -0.07903 & 0.31767 & -0.70165 & 0.54359 & 0.92401 \\
\hline \multicolumn{6}{|c|}{ B21: (use_details | Other - General pleasure) } \\
\hline & 1.12340 & 0.70812 & -0.26449 & 2.51130 & 3.07531 \\
\hline \multicolumn{6}{|c|}{ B22: (use_details | Racing - General pleasure) } \\
\hline & -0.76353 & 0.57652 & -1.89349 & 0.36643 & 0.46602 \\
\hline B23: (use_de & $\begin{array}{c}\text { horse - Gene } \\
-0.59341\end{array}$ & $\begin{array}{l}\text { asure) } \\
0.48305\end{array}$ & -1.54017 & 0.35335 & 0.55244 \\
\hline
\end{tabular}


Dataset

Logistic Regression Report

Response ...Lepto_working 22102015.NCSS lepto_pos

\section{Odds Ratios Report}

\begin{tabular}{|c|c|c|c|c|}
\hline Independent & $\begin{array}{l}\text { Regression } \\
\text { Coefficient }\end{array}$ & $\begin{array}{l}\text { Odds } \\
\text { Ratio }\end{array}$ & $\begin{array}{r}\text { Lower } 95 \% \\
\text { Confidence }\end{array}$ & $\begin{array}{l}\text { Upper } 95 \% \\
\text { Confidence }\end{array}$ \\
\hline Variable & b(i) & $\operatorname{Exp}(\mathbf{b}(\mathbf{i}))$ & Limit & Limit \\
\hline B0: Intercept & 0.42939 & 1.53633 & 0.36154 & 6.52842 \\
\hline \multicolumn{5}{|c|}{ B1: (agric_details | Forestry - Other) } \\
\hline & 1.34950 & 3.85550 & 1.22746 & 12.11030 \\
\hline \multicolumn{5}{|c|}{ B2: (agric_details | Fruitrees - Other) } \\
\hline & 0.27952 & 1.32250 & 0.38064 & 4.59490 \\
\hline \multicolumn{5}{|c|}{ B3: (agric_details | Surgacane - Other) } \\
\hline \multicolumn{5}{|c|}{ B4: (breed_details | Arabian - Other) } \\
\hline & \multicolumn{4}{|c|}{ B5: (breed_details | Nooitgedacht - Other) } \\
\hline & 0.56245 & 1.75497 & 0.47156 & 6.53137 \\
\hline B6: (breed_de & $\begin{array}{l}y-\text { Other) } \\
-0.06007\end{array}$ & 0.94170 & 0.32957 & 2.69078 \\
\hline \multicolumn{5}{|c|}{ B7: (breed_details | Thoroughbred - Other) } \\
\hline \multicolumn{5}{|c|}{ B8: (breed_details | Warmblood - Other) } \\
\hline \multicolumn{5}{|c|}{ B9: (cattle_nearby | 1 - 0) } \\
\hline \multicolumn{5}{|c|}{ B10: (pigs_nearby | 1 - 0) } \\
\hline B11: (province & $\begin{array}{c}0.23378 \\
\mathrm{~g}-\mathrm{KZN})\end{array}$ & 1.26336 & 0.90713 & 1.75949 \\
\hline \multicolumn{5}{|c|}{ B12: (province | WCape - KZN) } \\
\hline \multicolumn{5}{|c|}{ B13: (rain | High - Low) } \\
\hline & \multicolumn{3}{|c|}{ B14: (rain | Medium - Low) } & 1.17133 \\
\hline & 0.72764 & 2.07019 & 0.97158 & 4.41105 \\
\hline \multicolumn{5}{|c|}{ B15: (Rodents | 1 - 0) } \\
\hline \multicolumn{5}{|c|}{ B16: (sex_details | Mare - Gelding) } \\
\hline & -0.04104 & 0.95979 & 0.41733 & 2.20736 \\
\hline \multicolumn{5}{|c|}{ B17: (sex_details | Stallion - Gelding) } \\
\hline \multicolumn{5}{|c|}{ B18: (smallrum_nearby | 1 - 0) } \\
\hline \multicolumn{5}{|c|}{ B19: (use_details | Breeding - General pleasure) } \\
\hline & 0.56952 & 1.76742 & 0.63385 & 4.92826 \\
\hline \multicolumn{5}{|c|}{ B20: (use_details | Equestrian event - General pleasure) } \\
\hline & -0.07903 & 0.92401 & 0.49577 & 1.72218 \\
\hline \multicolumn{5}{|c|}{ B21: (use_details | Other - General pleasure) } \\
\hline & 1.12340 & 3.07531 & 0.76759 & 12.32096 \\
\hline \multicolumn{5}{|c|}{ B22: (use_details | Racing - General pleasure) } \\
\hline & -0.76353 & 0.46602 & 0.15055 & 1.44257 \\
\hline \multicolumn{5}{|c|}{ B23: (use_details | Work horse - General pleasure) } \\
\hline & -0.59341 & 0.55244 & 0.21434 & 1.42383 \\
\hline
\end{tabular}


Dataset

Response

Logistic Regression Report

lepto_pos

Estimated Logistic Regression Model(s)

Model For lepto_pos $=1$

$.429393585820883+1.34950186383701 *($ agric_details | Forestry - Other) +

.279522788753936*(agric_details | Fruitrees - Other) -1.61899852459134*(agric_details | Surgacane -

Other $)+.271053027356912 *$ (breed_details | Arabian - Other) + .562454229619736*(breed_details |

Nooitgedacht - Other) -.0600704405852375*(breed_details | Pony - Other) -

.916625937756351*(breed_details | Thoroughbred - Other) -.267125918459787*(breed_details | Warmblood

- Other) -.261541169808766*(cattle_nearby | 1 - 0) +.233777729524703*(pigs_nearby | 1 - 0) +

.0647783792883688*(province | Gauteng - KZN) -.868202267519113*(province | WCape - KZN) -

$1.25382012252069 *($ rain | High - Low $)+.727642394769676 *($ rain | Medium - Low) -

.355594992458091*(Rodents | 1 - 0) -.041044396982277*(sex_details | Mare - Gelding) +

$.500346603946102 *$ (sex_details | Stallion - Gelding) -.109909583682205*(smallrum_nearby | 1 - 0) +

$.56952138912411 *$ (use_details | Breeding - General pleasure) -.0790296149641518*(use_details | Equestrian event - General pleasure) + 1.12340444291549*(use_details | Other - General pleasure) -

.763530312505578*(use_details | Racing - General pleasure) -.593410595444253*(use_details | Work horse

- General pleasure)

Note that each model estimates B for a specific group, where $\operatorname{Logit}(\mathrm{Y})=\mathrm{XB}$. To calculate the group probabilities when there are only 2 response groups, transform the logit using

$\operatorname{Prob}(\mathrm{Y}=$ group $)=1 /(1+\operatorname{Exp}(-\mathrm{XB}))$ or $\operatorname{Prob}(\mathrm{Y} \neq \operatorname{group})=\operatorname{Exp}(-\mathrm{XB}) /(1+\operatorname{Exp}(-\mathrm{XB}))$. For the calculation formula to use when there are more than 2 response groups, see the help documentation.

Analysis of Deviance

Term

Omitted

All

agric_details

breed_details

cattle_nearby

pigs_nearby

province

rain

Rodents

sex_details

smallrum_nearby

use_details

None(Model)

DF
23
3
5
1
1
2
2
1
2
1
5
23

DF

3

5

1

1

2

2

1

2

1

5

23

\section{Increase \\ From Model}

Deviance

(Chi')

118.06344

20.69594

11.11525

1.08660

1.90071

2.62701

4.08038

1.01318

2.14965

0.08253

5.35263

\section{Prob}

Level

0.00000

0.00012

0.04914

0.29723

0.16800

0.26888

0.13000

0.31414

0.34136

0.77390

0.37438

The Prob Level is for testing the significance of that term after considering all other terms.

\section{Log Likelihood \& $\mathbf{R}^{2}$}

$\begin{array}{lrr}\text { Term(s) } & \text { DF } & \begin{array}{r}\text { Log } \\ \text { Omitted }\end{array} \\ \text { All } & 1 & \begin{array}{c}\text { Likelihood } \\ -289.90220\end{array} \\ \text { agric_details } & 3 & -241.21844 \\ \text { breed_details } & 5 & -236.42810 \\ \text { cattle_nearby } & 1 & -231.41377 \\ \text { pigs_nearby } & 1 & -231.82083 \\ \text { province } & 2 & -232.18398 \\ \text { rain } & 2 & -232.91066 \\ \text { Rodents } & 1 & -231.37706 \\ \text { sex_details } & 2 & -231.94530 \\ \text { smallrum_nearby } & 1 & -230.91174 \\ \text { use_details } & 5 & -233.54679 \\ \text { None(Model) } & 23 & -230.87047 \\ \text { None(Saturated) } & 130 & -169.87473\end{array}$

$\mathbf{R}^{2}$ of
Remaining
Term(s)
0.00000
0.40561
0.44552
0.48729
0.48390
0.48088
0.47482
0.48760
0.48286
0.49147
0.46952
0.49182
1.00000

\section{Reduction \\ From \\ Model R}

0.08621

0.04630

0.00453

0.00792

0.01094

0.01700

0.00422

0.00895

0.00034

0.02230

0.00000
Reduction

From

Saturated $\mathbf{R}^{2}$

0.59439

0.55448

0.51271

0.51610

0.51912

0.52518

0.51240

0.51714

0.50853

0.53048

0.50818

0.00000 